\title{
Instruments, Methods, Rationale, and Derived Data Used to Quantify and Compare the Trapping Efficiencies of Four Types of Pressure-Difference Bedload Samplers
}

Open-File Report 2021-1064 



\section{Instruments, Methods, Rationale, and Derived Data Used to Quantify and Compare the Trapping Efficiencies of Four Types of Pressure-Difference Bedload Samplers}

By John R. Gray, Gregory E. Schwarz, David J. Dean, Jonathan A. Czuba, and Joel T. Groten

Open-File Report 2021-1064 


\section{U.S. Geological Survey, Reston, Virginia: 2021}

For more information on the USGS - the Federal source for science about the Earth, its natural and living resources, natural hazards, and the environment—visit https://www.usgs.gov or call 1-888-ASK-USGS.

For an overview of USGS information products, including maps, imagery, and publications, visit https://store.usgs.gov/.

Any use of trade, firm, or product names is for descriptive purposes only and does not imply endorsement by the U.S. Government.

Although this information product, for the most part, is in the public domain, it also may contain copyrighted materials as noted in the text. Permission to reproduce copyrighted items must be secured from the copyright owner.

Suggested citation:

Gray, J.R., Schwarz, G.E., Dean, D.J., Czuba, J.A., and Groten, J.T., 2021, Instruments, methods, rationale, and derived data used to quantify and compare the trapping efficiencies of four types of pressure-difference bedload samplers: U.S. Geological Survey Open-File Report 2021-1064, 61 p., https://doi.org/10.3133/ofr20211064.

Associated data for this publication:

Groten, J.T., and Gray, J.R., 2021, Data describing the trapping efficiency of four types of pressure-difference bedload samplers, St. Anthony Falls Laboratory, Minneapolis, Minnesota, 2006: U.S. Geological Survey data release, https://doi.org/10.5066/P9VBB2YF.

ISSN 2331-1258 (online) 


\section{Acknowledgments}

The StreamLab06 experiments described in this report were supported, in part, by the Science and Technology Centers of the National Science Foundation through the National Center for Earth-Surface Dynamics (NCED) at the University of Minnesota under the agreement number EAR-0120914. The bedload-sampler calibration research activities described herein also received staff support and funding through many direct and indirect sources. The authors recognize and appreciate the following with respect to the bedload-sampler calibration experiments:

- The generous investment in the rehabilitation of the main flume by the NCED and the University of Minnesota's St. Anthony Falls Laboratory, without which the StreamLab06 experiments would not have been possible.

- The St. Anthony Falls Laboratory and the Federal Interagency Sedimentation Project for their indispensable support during both phases of the experiments. Jeffrey D.G. Marr, Chris Ellison, and Sarah Johnson deserve special credit for their support for these experiments.

- The Bureau of Reclamation, U.S. Forest Service, U.S. Geological Survey, University of Colorado, Colorado State University, and Graham Matthews and Associates for the participation of their employees in the experiments, as well as independent contractor Kurt Swingle, Ft. Collins, Colorado.

- Robert Thomas and Jack Lewis, retired, U.S. Forest Service; William Emmett, retired, U.S. Geological Survey; William Carey, retired, Bureau of Land Management; Roger Kuhnle, Agricultural Research Service; Basil Gomez, retired, Indiana State University; Peter Wilcock, Utah State University; and Panayiotis Diplas, Lehigh University; for their suggestions, reviews, and insights related to the instruments and protocols used in the experiments.

- The efforts of Emily Osborne, Kristen Skowronski, and Michael McDonnell to develop several of the figures and tables appearing herein were instrumental in production of this report. Last but hardly least, Annette Goode's astute manipulation of many of the report figures that appear herein are appreciated. 



\section{Contents}

Acknowledgments ……...................................................................................................................

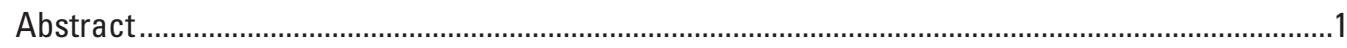

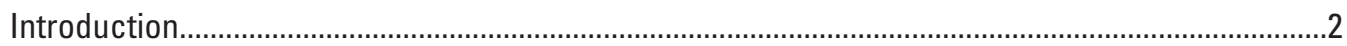

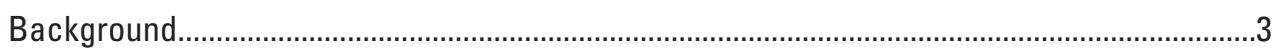

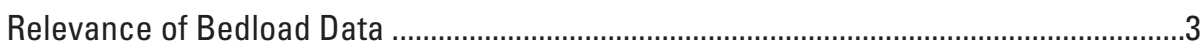

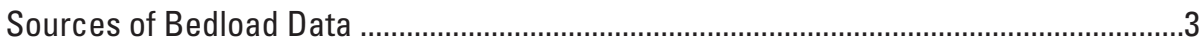

Overview of Types of Bedload Samplers .......................................................................

Historical Pressure-Difference Bedload-Sampler Trapping Efficiency Comparisons

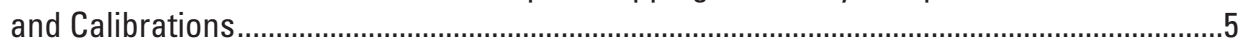

Physical Characteristics of Pressure-Difference Bedload Samplers ........................................5

Factors and Challenges .................................................................................................. 6

Previous Research..........................................................................................................

Comparisons of Sampler Trapping Efficiencies...............................................................

Calibration of Sampler Trapping Efficiencies.............................................................10

East Fork River, Wyoming, Slot Sampler (Leopold and Emmett, 1976, 1997; Emmett,1980, 1981) ................................................................................11

St. Anthony Falls Laboratory Main Flume Slot Sampler ..........................................13

Rationale for the StreamLab06 Bedload-Sampler Calibration Experiments .....................................14

The StreamLab06 Bedload-Sampler Trapping-Efficiency Tests ....................................................20

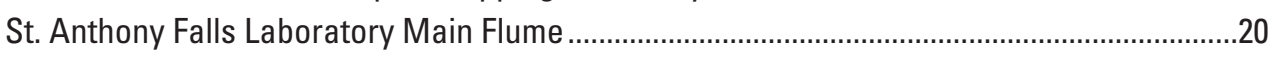

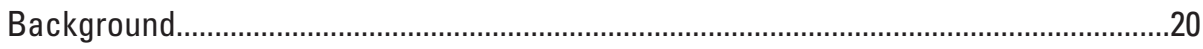

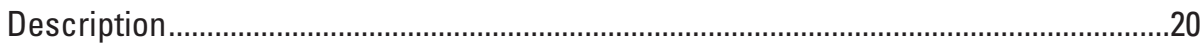

Sediment Monitoring and Recirculation System......................................................21

Sediment-Flux Monitoring Component .....................................................................22

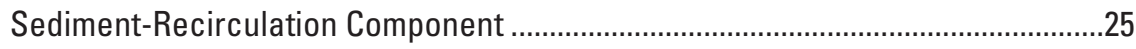

Supporting and Ancillary Instruments ................................................................27

Pressure-Difference Bedload-Sampler Trapping Efficiency Tests ...........................................27

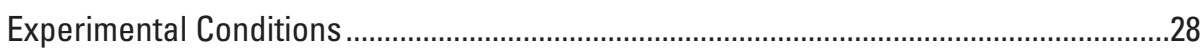

Pressure-Difference Bedload Samplers Used in the Tests ..................................................28

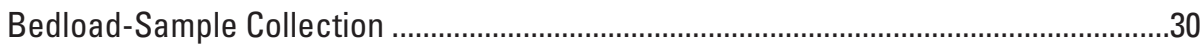

Suspended-Sediment Sample Collection ....................................................................32

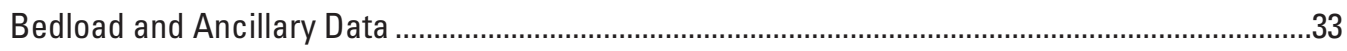

Bedload Accumulation, Flux, and Ancillary Data Measured by the

Sediment-Monitoring and Recirculation System.......................................................33

Bedload Flux and Ancillary Data Measured by Pressure-Difference Bedload Samplers .....33

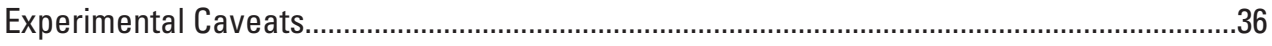

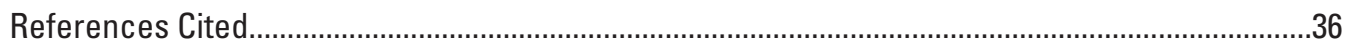

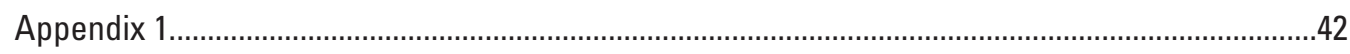

Appendix 2 


\section{Figures}

1. Diagram illustrating the components of total sediment load considered by origin, transport, and sampling method

2. Schematic cross-section of an automatic-weighing box sampler

3. Sketch of bedload measuring station using a vortex-tube bedload trap on Virginio Creek in Italy

4. Schematic diagrams of the original Helley-Smith cable-suspended, pressure-difference bedload sampler

5. Graph showing differences in bedload-transport rates concurrently measured with a Helley-Smith sampler and a BL-84 sampler compared to those measured by just the Helley-Smith sampler during October 1989, at Colorado River near Supai, Arizona

6. Graphs showing variability in sand bedload-transport rates that were measured two meters apart with a Helley-Smith sampler and a BL-84 sampler during October 1989, at Colorado River near Supai, Arizona....

7. Box and whisker plots showing the cross-sectional distribution of bedload transport during steady flow of 165 cubic meters per second, using results from all 390 bedload samples collected in October 1989, assuming sampler trapping efficiencies of unity, Colorado River above National Canyon near Supai, Arizona..........10

8. Photographs of bedload traps ......................................................................................11

9. Photographs of the bedload trap on the East Fork River near Pinedale, Wyoming ........12

10. Photograph of four types of hand-deployed pressure-difference bedload samplers tested in the St. Anthony Falls Laboratory main flume, January to March 2006

11. Photographs of cable-suspended versions of the four pressure-difference bedload samplers tested in the St. Anthony Falls Laboratory main flume, January to March 2006

12. Photograph of a bedload clast lodged in the entrance of the 76-mm-square BLH-84 intake nozzle used on March 11, 2006, during the StreamLab06 gravel-bed experiments

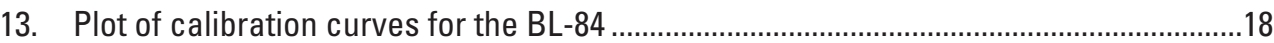

14. Plot of calibration curves for the standard Helley-Smith ............................................19

15. Side-view schematic of the St. Anthony Falls Laboratory main flume showing the entire facility from the water intake to the tailwater of the sharp-crested weir.......21

16. Plan-view schematic of the St. Anthony Falls Laboratory main flume showing the section in which bedload is captured by the weigh drums and recirculated to the upstream approach section to the knee wall

17. Schematic of the Sediment Monitoring and Recirculation System, showing the right-most of the five weigh drums in the cross-channel slot over the auger in the bottom of the slot.

18. Photographs of the main flume sediment-flux monitoring component of the Sediment Monitoring and Recirculation System..

19. Photograph of the operations controller seated at the main flume sediment-flux monitoring component's central data-acquisition system console...

20. Graph of weigh-drum accumulation data and the removal of spurious data caused by vagaries in weights measured during drum-tipping events

21. Cross-section schematic of the Sediment Monitoring and Recirculation System's sediment-removal apparatus. 
22. Right-side view schematic of the Sediment Monitoring and Recirculation System.......26

23. Graph showing the results of the sieved grain-size distributions of the original sand- and gravel-bed materials used in StreamLab06 Phase I and II tests, respectively

24. Photographs of three downstream views of the St. Anthony Falls Laboratory main flume.

25. A plan-view schematic of the section of the main flume showing the cross section in which the pressure-difference bedload samplers were manually deployed to the weigh drums within the cross-channel slot..

26. Mean lateral distribution of mean transport rate in the seven main flume weigh drums shown in the original English units

27. Photographs showing the sequence of deploying a bedload sampler in the gravel-bedded main flume, St. Anthony Falls Laboratory, March 6, 2006

\section{Tables}

1. Location of submersible sonar probes in the main flume

2. Summary of main flume experimental conditions as part of StreamLab06 bedload-sampler trapping-efficiency tests.

3. Selected characteristics of bedload samplers used in the StreamLab06 Phase I and II tests, and the median bed-material grain size in which each bedload sampler was deployed

4. Summary statistics for bedload-sampler trapping-efficiency trials in flows over a sand bed $\left(d_{50}=1.0\right.$ millimeter) during Phase I of the StreamLab06 experiments, January 31, 2006, through February 9, 2006

5. Summary of bedload-sampler trials during runs over a gravel bed ( $d 50=11.2$ millimeters) during Phase II of the StreamLab06 experiments, March 11, 2006, through March 28, 2006 



\title{
Instruments, Methods, Rationale, and Derived Data Used to Quantify and Compare the Trapping Efficiencies of Four Types of Pressure-Difference Bedload Samplers
}

\author{
By John R. Gray, ${ }^{1}$ Gregory E. Schwarz, ${ }^{2}$ David J. Dean, ${ }^{2}$ Jonathan A. Czuba, ${ }^{3}$ and Joel T. Groten ${ }^{2}$
}

\section{Abstract}

Bedload and ancillary data were collected to calculate and compare the bedload trapping efficiencies of four types of pressure-difference bedload samplers as part of episodic, sediment-recirculating flume experiments at the St. Anthony Falls Laboratory, University of Minnesota, Minneapolis, in January-March 2006. The bedload-sampler experiments, which were conceived, organized, and led by the U.S. Geological Survey's Office of Surface Water, were part of a broader suite of experiments performed in the rectangular, concrete-lined, sediment-recirculating Main Channel Facility ("main channel flume"). Collectively referred to as "StreamLab06," the experiments were conducted under the auspices of the National Center for Earth-Surface Dynamics, University of Minnesota.

Four pressure-difference-type bedload samplers - a standard Helley-Smith, US BLH-84, Elwha, and Toutle River-2 - were deployed by using hand-held rods in the main flume in a series of trials during steady flows as part of the first two of seven phases of the StreamLab06 experiments. The Phase I flows were released over a sand bed. Gravel composed the bed during the Phase II flows. Bedload samples were collected during flows ranging from 2.0 cubic meters per second (near the incipient motion of bed material) to 5.5 cubic meters per second. A total of 2,030 bedload samples were collected-1,000 as part of 19 sand-bed trials, and 1,030 as part of 27 gravel-bed trials.

Bedload was captured in five contiguous weigh drums inside a slot spanning the full width of the main flume channel 8.5 meters downstream from the cross-section in which the bedload samplers were deployed. The contents of each drum were automatically weighed and recorded as a time

${ }^{1}$ U.S. Geological Survey, Scientist Emeritus.

${ }^{2}$ U.S. Geological Survey.

${ }^{3}$ Department of Biological Systems Engineering, Virginia Tech. series about every 1.1 seconds. Each drum automatically, independently, and episodically dumped its contents into the bottom of the slot upon the accumulation of a pre-determined mass of entrapped sediment, after which the drum continued to capture and weigh bedload. An auger at the bottom of the slot evacuated the accumulating sediment to a side-channel pump that piped the captured sediments upstream and discharged them back to the flume.

Bedload-transport rates were calculated from measurements of the masses of material trapped by the bedload samplers and from the data produced by the automated bedload capture-and-weigh system of the main channel flume. These data were used to compute at-a-point and mean bedload-transport rates for subsequent use in developing bedload-trapping efficiency (calibration) coefficients for each bedload sampler and for comparing the relative trapping efficiencies of the manually deployed bedload samplers. The data were collected to enable the use of several computational methods for deriving bedload-trapping coefficients.

Continuous ancillary data including stage, water discharge, and water temperature were automatically collected and stored. Flow depths were manually measured and recorded concurrent with each at-a-point bedload-sampler deployment. Other information obtained during parts of the experiments included longitudinal water-surface slope, bedload particle-size distributions, and suspended-sediment concentrations and percent sand analyzed from samples collected by depth integration with a US DH-48 isokinetic suspended-sediment sampler.

This report describes the types and availability of the bedload and ancillary data derived through the StreamLab06 experiments. The data are available from the St. Anthony Falls Laboratory and the U.S. Geological Survey through a data release (Groten and Gray, 2021). Also included are selected descriptive and historical information as well as the background, experimental design, experimental caveats, and other factors relevant to the production of the bedload-transport and ancillary data produced through Phases I and II of the StreamLab06 experiments. 


\section{Introduction}

Bedload and ancillary data were collected to calculate and compare the bedload-trapping efficiencies (otherwise referred to as "calibration coefficients") of four types of pressure-difference bedload samplers in a newly refurbished sediment-recirculating flume at the University of Minnesota's St. Anthony Falls Laboratory (SAFL). The bedload-sampler experiments, which were conceived, organized, and led by the U.S. Geological Survey's (USGS) Office of Surface Water, took place during the first two of seven experimental phases performed in the rectangular, concrete-lined, sediment-recirculating main channel flume at the SAFL in January-March 2006. Collectively referred to as "StreamLab06,"(Marr and others, 2010a, 2010b; Singh and others, 2013), the experiments were conducted under the auspices of the National Center for Earth-Surface Dynamics (NCED) at the University of Minnesota (University of Minnesota, 2021). An overview of all seven StreamLab06 experiments is available from Singh and others (2013).

Nine steady flows ("runs") ranging from 2.0 to 5.5 cubic meters per second $\left(\mathrm{m}^{3} / \mathrm{s}\right)$ were released for the bedload-sampler trapping-efficiency experiments. The bed material in the Phase I tests was composed of a well-sorted siliceous sand of 1.0 millimeter $[\mathrm{mm}]$ median diameter ${ }^{4}$ and a range of $0.6-1.8 \mathrm{~mm}$. The bed material in Phase II was made up of a gravel mixture median diameter of $11.2 \mathrm{~mm}$ and a range of $1-32 \mathrm{~mm}$.

Four types of pressure-difference bedload samplers were tested under steady flow conditions. Each sampler was manually deployed by a hand-held rod anchored in a single cross-section by a tether line. Most deployments involved repeated at-a-point sampling, and several involved sampling laterally in the cross-section. Each combination of a deployed sampler, bed type, and flow rate are referred to as a "trial."

Nineteen such bedload-sampler trapping efficiency trials took place over a sand bed, and 28 over a gravel bed. At-a-point and mean bedload-transport rates for each trial were derived from the duration a sampler rested on the bed, the width of the sampler intake nozzle, and the measurements of the equivalent dry mass of each bedload sample.

A cross-channel slot in the main channel flume 8.5 meter (m) downstream from the sampler-deployment section was designed to temporarily retain and weigh the bedload material falling into the slot. The captured bedload was automatically and continuously weighed in five drums that contiguously spanned the flume's 2.74-m width within the slot. Sediments

\footnotetext{
${ }^{4}$ Hereafter, all references to sediment sizes are for the median diameter of a particle unless otherwise indicated or required for clarity.
}

episodically dumped by the weigh drums into the bottom of the slot were automatically transferred to the right side of the flume via a horizontally imposed auger. A trash pump recessed in the right flume wall evacuated the augered sediments and recirculated them to an upstream section of the flume.

Data derived from the bedload samplers and the weigh drums were used with ancillary data to enable subsequent evaluations of the bedload-trapping efficiencies of the samplers tested in sand- and gravel-bedded conditions during nine steady flows. These data also enabled comparisons of the samplers' bedload-trapping characteristics. The bedload-sampler calibrations and comparisons enabled by these tests may be used by the Federal Interagency Sedimentation Project (FISP) to endorse one or more of the tested bedload samplers for use by its member organizations and others.

This report summarizes the trapping-efficiency (calibration) test results of four types of pressure-difference bedload samplers conducted during Phases I and II of the StreamLab06 experiments. The report includes:

- A summary of the relevance of bedload data and an overview of available means for quantifying bedload-transport rates.

- Factors that led to the bedload-sampler experiments and concomitant challenges and caveats.

- Summaries of selected relevant historical research on bedload-sampler calibrations and comparisons.

- Relevant attributes and function of the St. Anthony Falls Laboratory main flume.

- Attributes of pressure-difference bedload samplers, including the four types used in these experiments.

- Experimental procedures and the derived data that enable subsequent calibration and comparison of the bedload-trapping efficiencies of the bedload samplers.

- Selected historical descriptions considered potentially relevant to those interested in the collection of physical bedload samples.

Bedload-transport data automatically collected from the main flume and selected ancillary data are available through the St. Anthony Falls Laboratory NCED Data Repository (https://repository.nced.umn.edu/) under the heading "St. Anthony Falls Lab/Streamlab 2006" and in a U.S. Geological Survey data release (Groten and Gray, 2021). Manually collected bedload-transport and ancillary data are also available in the USGS data release (Groten and Gray, 2021). 


\section{Background}

\section{Relevance of Bedload Data}

Bedload - that part of the total sediment load that is transported by rolling, skipping, or sliding along the streambed (ASTM International, 1998) - provides the major process link between the hydraulic and material conditions that govern river-channel morphology. An understanding of bedload-transport mechanisms and what constitutes technically supportable, reliable data describing bedload-transport rates is important to engineers, scientists, managers, and others interested in the causes and consequences of changes in channel form and to make informed management decisions that affect a river's function (Gomez, 2006). Additionally,

- Bedload is part of the river's total sediment load (fig. 1) that represents net erosion by runoff from a watershed.

- When accelerated, bedload transport can result in bed and bank scour that, in turn, can have catastrophic consequences, including the failure of bridge piers or other hydraulic structures through bed denudation or collapses of structures abutting the river caused by riverbank instability.

- When deposited as bed material, bedload can have deleterious effects, including reducing the capacity of reservoirs, estuaries, harbors, and other receiving waters; impeding river navigation; impairing aquatic habitat; reducing hydropower capacity; compromising public water supplies; increasing the frequency and severity of floods; or, in extreme cases, contributing to channel avulsion.
- Technically supportable efforts to manage and restore watercourses and assess channel stability require reliable bedload data.

- The most credible and useful equations for estimating bedload and total load are empirically based and, thus, require demonstrably reliable bedload data for their development or calibration.

As part of the 2003 Federal Interagency Sediment Monitoring Instrument and Analysis Research Workshop (Gray, 2005), a workgroup led by Ryan and others (2005) recognized an "overarching need for more thorough testing of the accuracy of existing [bedload samplers]," along with, "...better documentation of existing samplers, including information on limitations and uncertainty of the data obtained."

A study of sediment transport logically begins with theories of bedload movement, because the discharge of bedload provides a basis for the computation of bed-material discharge and is also closely related to processes of erosion and deposition (Colby, 1963)

\section{Sources of Bedload Data}

Information on bedload-transport rates can be derived indirectly from empirical equations, inferred directly from bedload-surrogate monitoring technologies, and (or) measured by physical samplers. The quality of the data, which can be difficult or impossible to quantify or to reliably infer from these various sources, can have an inordinate influence on the reliability and usefulness of these data.

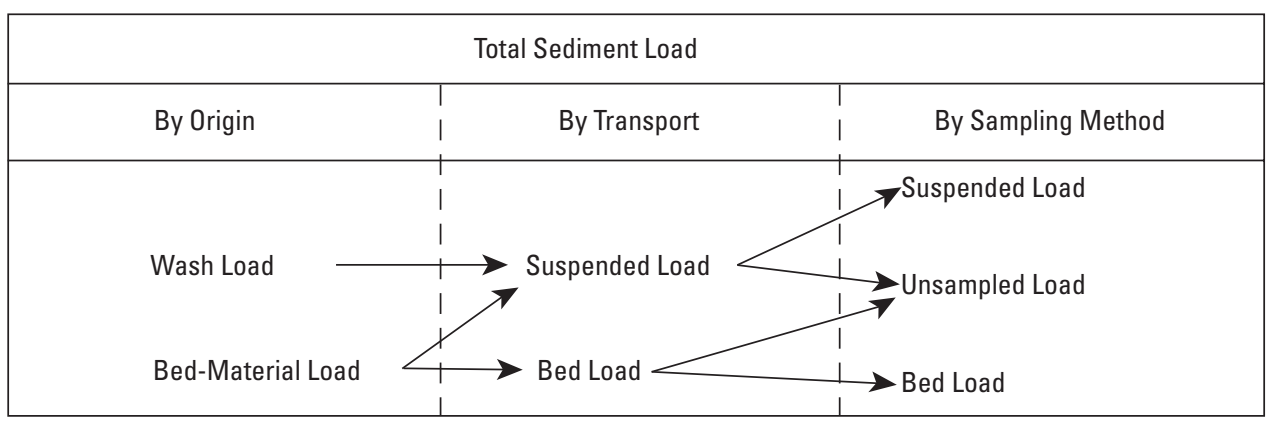

Figure 1. Diagram illustrating the components of total sediment load considered by origin, transport, and sampling method. The unsampled load is the part that is not collected by the depth-integrating suspended-sediment and pressure-difference bedload samplers used, depending on the type and size of the samplers(s). Unsampled-load sediment can occur in one or more of the following categories: (1) sediment that passes under the nozzle of the suspended-sediment sampler when the sample is touching the streambed and no bedload sampler is used; (2) sediment small enough to pass through the bedload sampler's mesh bag; (3) sediment in transport above the bedload sampler that is too large to be sampled reliably by the suspended-sediment sampler; and (4) material too large to enter the bedload-sampler nozzle. From Diplas and others (2008, p. 306). 
Empirical equations are predicated on the presence of specific relations among hydraulic variables, sedimentological parameters, and bedload-transport rates. They also are predicated on the availability of relevant, reliable bedload-transport rates from measurements and related sedimentological and ancillary information. Gray and Simões (2008, p. 1083) observed the following problems,

"which range from [bedload and ancillary]

data-collection procedures, interpretation, and manipulation to the principles (or absence thereof) behind the [bedload-transport] equations employedburden these methods with uncertainty, inconsistency, and inaccuracies of unknown magnitudes. They also contribute to considerable difficulty in the error analysis of the methods' results, therefore severely compromising their reliability."

Numerous surrogate technologies for quantifying bedload-transport rates exist (for example, Ryan and Porth, 1999; Rubin and others, 2001; Abraham and Kuhnle, 2006; Barton and Pittman, 2010; Gaskin and Rennie, 2010; Gray, 2005; Gray and others, 2010; Holmes, 2010; Ramooz and Rennie, 2010; Wood, 2014; Marineau and others, 2015, 2016; Wyss and others, 2016; Geay and others, 2017; and Redolfi and others, 2017). Although some of these technologies are compelling, as of 2006 none had been proven to be sufficiently reliable and robust for deployment in large-scale operational programs (Laronne and others, 2007; Gray and others, 2010).

The reliability and accuracy of riverine bedload data derived from empirical equations or surrogate technologies cannot be quantified, let alone verified, in the absence of applicable and reliable ground-truth data. Thus, all technically supportable bedload-transport data are predicated on - that is, directly or indirectly derived from - physical bedload-transport measurements using data from properly designed and deployed bedload samplers. Hence, absent comparative, reliable physical bedload measurements, few if any derived bedload-transport data from empirical equations or from surrogate technologies, can be certified to be valid.

\section{Overview of Types of Bedload Samplers}

Bedload samplers can be classified according to one or a combination of the following types (Hubbell, 1964; Tacconi and Billi, 1987; Kuhnle, 1991, 2008; International Standards Organization, 1992; Carey, 2005; Gray and others, 2010):

- box or basket,

- pan or tray,

- vortex tube,

- trough or pit, or

- pressure-difference.
Box or basket samplers operate by retaining sediment that is deposited in the sampler that results from a reduction in the flow velocity and (or) that is captured by a sampler screen (Hubbell, 1964; Carey, 2005). Early box samplers required manual excavation and measurement. A schematic of an automated box sampler is shown in figure 2 (Kuhnle, 1991).

An example of a technologically advanced box-type (basket) sampler is described by Rickenmann and Fritschi (2010). The electric-powered basket sampler collects bedload by automatically traversing through the outfall of a check dam on the Erlenbach streams, a steep pre-alpine channel, in Switzerland.

Pan or tray samplers operate by retaining the sediment that drops into one or more slots after rolling, skipping, or sliding over an entrance ramp (Hubbell, 1964; Carey, 2005).

Vortex-tube samplers have been used to sample bedload successfully at several locations (Kuhnle, 2008). Their design is based on a vortex-tube sand trap that originally was developed to exclude unwanted bedload from irrigation and other canals. The vortex-tube sampler consists of a 45-degree diagonal slot in a concrete broad-crested weir constructed across the channel. As a mixture of water and sediment enters the tube, a circular or vortex flow pattern is established. With one end of the tube open, this mixture is discharged into a sampling area adjacent to the channel where flows can be bypassed back into the stream between sampling periods or deposited into a sampling box. Bedload particles are deposited in the sampling box, and the overflow water is returned to the stream (Beschta and others, 1981). Figure 3 shows a sketch of a vortex-tube bedload trap on the Virginio Creek in Italy. "Left bank" and "right bank" are referenced to the downstream direction.

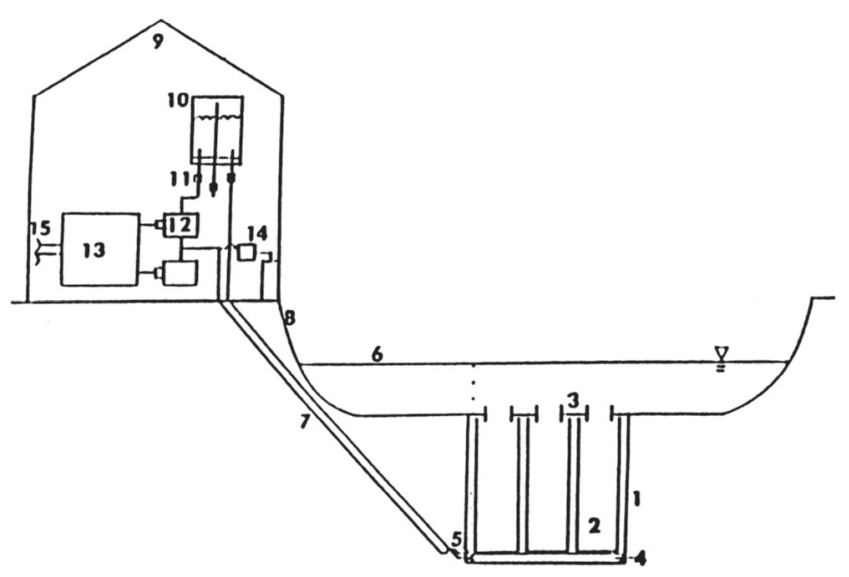

Figure 2. Schematic cross-section of an automatic-weighing box sampler: (1) outer box, (2) inner box, (3) slotted cover, (4) pressure pillow, (5) bubble tube outlet, (6) water surface, (7) tubes from bubbler and pillow, (8) stream bank, (9) instrument house, (10) air trap, (11) valves, (12) pressure transducer, (13) power supply, (14) bubble gage, and (15) wires to remote telemetry system. From Kuhnle (1991, p. 4-141). 

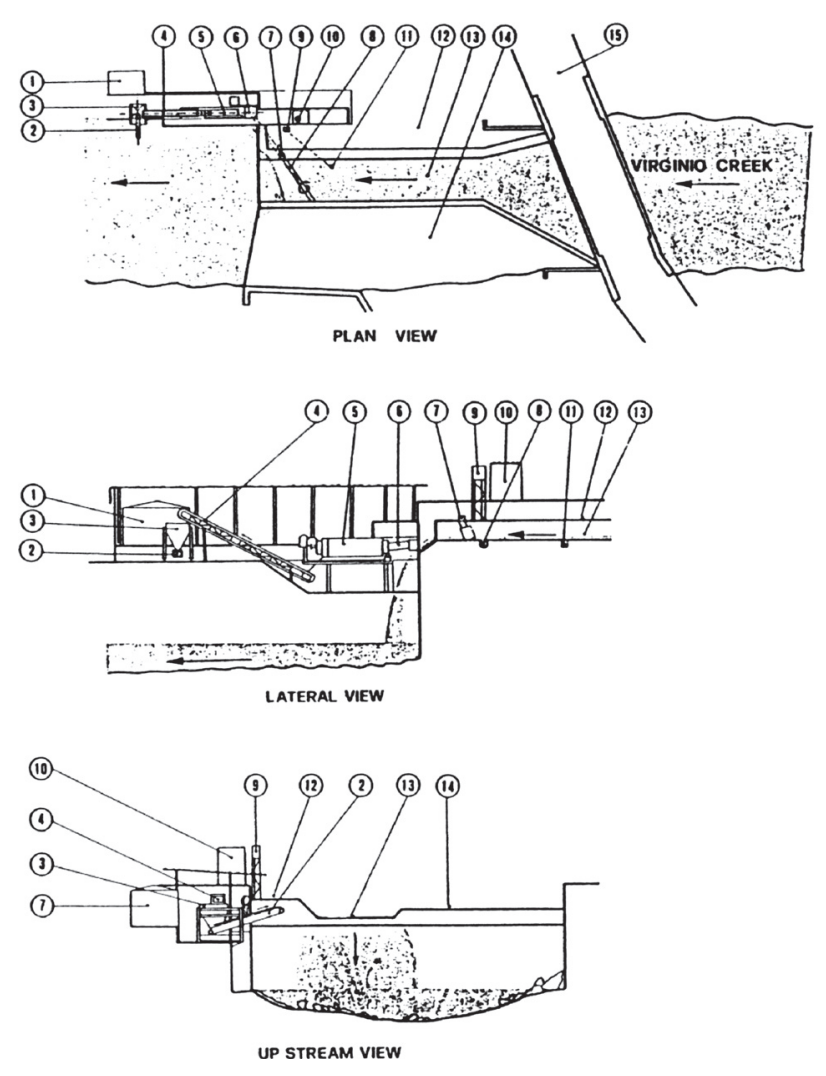

Figure 3. Sketch of bedload measuring station using a vortex-tube bedload trap on Virginio Creek in Italy:

(1) data-recording station, (2) unloading conveyor belt,

(3) weighing machine, (4) loading conveyer belt, (5) rotating

sieve, (6) manifold, (7) sluice gate, (8) vortex trap, (9) flow gage, (10) automatic suspended-sediment sampler, (11) flow gage intake, (12) right bank, (13) concrete flume, (14) left bank, and (15) road bridge. From Kuhnle (2008), originally published by Tacconi and Billi (1987).

Troughs or pits are rectangular holes, each constructed with a floor and walls in the streambed into which bedload material drops and is retained. Troughs (or "slots") typically are continuous across the channel width, as described by Emmett (1980) and Leopold and Emmett (1976, 1997), whereas pits span only part of the channel width. Various approaches have been used to empty the trough or pit prior to over-filling, including conveyor systems (Emmett, 1980; Leopold and Emmett, 1976, 1997), auger-pump assemblies (Hubbell and others, 1987; Marr and others, 2010a; Singh and others, 2013), and pumping or excavating the pit's contents after the cessation of runoff (Hubbell, 1964).

The magnitude and temporal variability in bedload-transport rates using a real-time sediment removal and measurement technique can be inferred with relative confidence. Post-runoff pit excavation and mass measurement of material from an unfilled trough or pit after cessation of bedload movement can provide a discrete value for the mass of material transported over the measurement period. The mass of material excavated from a filled trough or pit can only be inferred as being equal to or less than the total bedload mass transported during the period monitored.

Challenges in collecting reliable bedload data with trough or pit samplers compared to other types of bedload samplers can be substantial. Trough or pit samplers are the easiest to calibrate in rivers, but the most difficult to deploy. Calibration only requires that the opening be sufficiently large to ensure that all particles, regardless of the size, moving as bedload are captured. Deployment typically requires excavation so that the sampler can be emplaced into the streambed. In addition, a reliable system for emptying the sampler prior to overfilling is required.

Pressure-difference bedload samplers are one of numerous types of bedload samplers designed so the velocity of the flow entering a sampler's nozzle is equal to or greater than that which would have occurred in the same section of the bed in the absence of the sampler (Federal Interagency Sedimentation Project, 1940; Hubbell, 1964; Helley and Smith, 1971; Carey, 2005; Gray and Gartner, 2010; Gray and others, 2010). This attribute is important because, in general, reductions in flow velocities entering a nozzle typically result in spurious decreases in time-averaged bedload-transport rates.

No universally agreed-upon method exists for calibrating portable bedload samplers. Given appropriate deployment gear, however, portable samplers can be deployed by hand-held rod or by suspension cable from bridges, cableways, or boats without the need for pre-existing on-site support equipment.

\section{Historical Pressure-Difference Bedload-Sampler Trapping Efficiency Comparisons and Calibrations}

\section{Physical Characteristics of Pressure-Difference Bedload Samplers}

A pressure-difference bedload-sampler is composed of a nozzle, mesh collection bag, and a means for supporting the trailing end of the bag. Cable-deployed versions include a supporting frame terminating in a stabilizing tail fin and a bag fastener. Rod-deployed versions typically are equipped with a horizontal rod extending rearward from the top of the sampler with a bag fastener attached to its tail end. The sampler's key component - the nozzle - is a single feature composed of an upstream-oriented intake and a downstream-oriented outlet to which the mesh collection bag is affixed (fig. 4). 


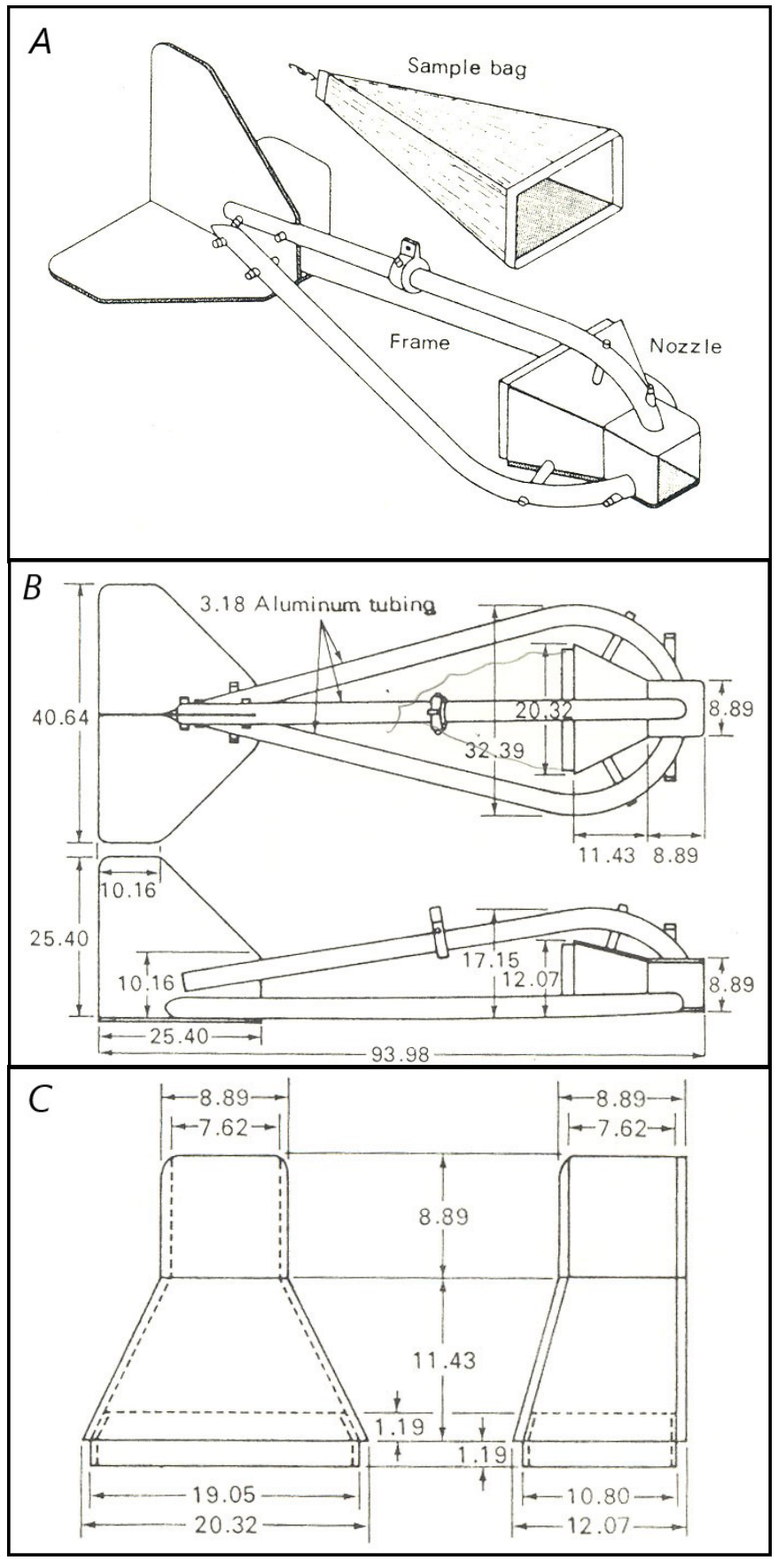

Figure 4. Schematic diagrams of the original Helley-Smith cable-suspended, pressure-difference bedload sampler. (A) Sampler and detached mesh sample bag. (B) Plan and side sampler views. (C) Upward-U-facing nozzle, overhead view (left) and side view (right). Dimensions are in centimeters. From Druffel and others (1976, p. 4-5).
Bedload-sampler nozzles with equal intake and outlet dimensions cause an increase in flow resistance, which in turn results in the flow velocity through the sample being less than the ambient flow velocity. Reductions in shear stress concomitant with lower flow velocities can result in spurious reductions in the mass of bedload captured by the sampler. This is due to the accumulation of particles in the nozzle entrance and others being diverted away from the intake (Kuhnle, 2008, p. 340-341).

Equalization of the flow velocity at the intake with respect to the ambient flow velocity is approximated through the creation of a pressure drop at the nozzle outlet by constructing walls that diverge toward the rear of the sampler nozzle (Hubbell, 1964). The cross-sectional area of the outlet divided by that of the smaller inlet is referred to interchangeably as the "nozzle-flare ratio" or "nozzle-expansion ratio." Although the nozzle-flare ratio is a fixed quantity for a given bedload sampler, pressure-difference samplers have been constructed with nozzle-flare ratios of 1.0, 1.11, 1.13, 1.4, 1.66, 1.96, 2.62, and 3.22 (Druffel and others, 1976); 1.10 and 3.07 (Hubbell and others, 1987); and possibly others. Additionally, samplers with varying dimensions have been constructed to measure particles as small as fine sand (0.125-0.25 $\mathrm{mm}$ in diameter) or as large as cobbles (less than $200 \mathrm{~mm}$ in diameter) (Hubbell, 1964). There is evidence that even slight design modifications can impinge on sampler performance (Ryan and Porth, 1999). Although the accuracy of data produced by a pressure-difference bedload sampler can be influenced by numerous factors even discounting vagaries associated with improper deployment techniques (Hubbell and Stevens, 1986), a key determinant in bedload-trapping efficiency is the nozzle-flare ratio.

\section{Factors and Challenges}

The capacity to sample any medium representativelythat is, to obtain a sample that proportionally reflects the presence of an attribute of interest - is a fundamental prerequisite of any credible sampling scheme. Assuming selection of an appropriate bedload sampler and its proper deployment based on approved guidelines (U.S. Geological Survey, 1990; Edwards and Glysson, 1999) for the ambient flow, bed, and sediment-transport conditions, the capacity to obtain a representative bedload sample is determined by the bedload sampler's sediment-trapping efficiency: the ratio resulting from the mass of captured bedload divided by that which otherwise would have passed the intake-nozzle section in the absence of the sampler (U.S. Geological Survey, 1990). For example, a trapping efficiency of 1.5 indicates that the bedload mass captured by the sampler is 50 percent larger than the mass that would have passed the width of the streambed occupied by the intake nozzle for the same duration but in the absence of the deployed bedload sampler. 
Quantifying a bedload sampler's sediment-trapping efficiency - usually referred to as, "calibrating the bedload sampler"-is of fundamental importance in the collection of quality-assured bedload-transport data. The use of a bedload sampler with an unknown trapping efficiency inevitably introduces uncertainty as to the reliability and usefulness of the derived data. This contrasts with the use of a FISP depth-integrating suspended-sediment sampler (Davis, 2005; Gray and others, 2008; Gray and Landers, 2014, 2015), which are designed to achieve a hydraulic efficiency within \pm 10 percent of unity over most or all of its operational range. This fundamentally important characteristic of FISP depth-integrating samplers is referred to as being "isokinetic." Properly deployed isokinetic suspended-sediment samplers, at least in theory, exhibit negligible bias, at most, in suspended-sediment sampling (Edwards and Glysson, 1999; Gray and others, 2008, p. 326; Gray and Landers, 2014).

Ascertaining reliable bedload-sampler trapping efficiencies is complicated by an inherent inability to quantify the bedload-transport rate that would have occurred in the absence of a bedload sampler deployed at the same time and location on the streambed, unless the efficiency of the deployed bedload sampler is known. Recognition of this "which comes first, the chicken or the egg?" conundrum led to the StreamLab06 bedload-sampler trapping-efficiency tests (Marr and others, 2010b), which took advantage of the relative utility and accuracy of a state-of-the-art automated system that produced a dense time series of captured masses of bedload by continuously collecting and weighing bedload falling into a slot across a sediment-recirculating flume. These measurements were made to enable production of ground-truth bedload-transport data that, in turn, could be used to calculate absolute bedload-trapping efficiencies for each of four types of portable pressure-difference bedload samplers, and to quantitatively compare the relative performances of the samplers.

\section{Previous Research}

The efficiency with which a sampler traps bedload can be described in relative (comparative) or absolute terms.

Relative efficiencies are derived from bedload measurements in adjacent or otherwise proximate parts of the riverbed with two or more bedload samplers, or from alternating bedload samplers deployed as part of an at-a-point sequential sampling scheme. Such comparisons yield potentially useful information on any differences in trapping efficiencies among co-deployed samplers, particularly to give data users a sense of the variance and potential bias associated with the performance of one type of sampler compared to another.
Although sampler comparisons can be informative and, in some cases, provide data useful for inferring reliable bedload-transport rates, actual transport rates can be derived only if the sampler's trapping efficiency, otherwise referred to as its calibration coefficient, is known. Thus, bedload-sampler comparisons - although inferentially indicative of differences in trapping efficiencies among bedload samplers and potentially useful from a general, relative perspective-fail to address the aforementioned "chicken-or-the-egg" conundrum.

Absolute trapping efficiencies are calculated using bedload-sampler data in conjunction with known bedload-transport rates such as from a river or flume equipped with an adequate bedload-metering system. Such tests are performed to identify the ratio, or range of ratios, that quantifies the presence or absence of bedload-sampling bias and, in turn, may enable subsequent mathematical bias corrections to raw-sampled bedload-transport rates.

Thus, data produced by a bedload sampler, the trapping efficiency for which has been calibrated against ground-truth data, meet the requisite requirement for computing technically supportable bedload-transport rates. Trapping efficiencies inferred from sampler comparisons may yield useful information but cannot be used to compute certifiably reliable bedload-transport data.

\section{Comparisons of Sampler Trapping Efficiencies}

Numerous studies have been conducted, mostly in field settings, to compare the trapping efficiencies of pressure-difference bedload samplers. For example, Childers (1999) compared the relative sampling characteristics of six pressure-difference bedload samplers in high-energy flows of the Toutle River at the Coal Bank Bridge near Silver Lake, Washington. The ratio of bedload-transport rates derived from each pair of samplers tested was computed from the mean bedload-transport rate determined for one sampler divided by that for a comparative sampler. Ratios of paired bedload-transport rates calculated for each sample set ranged from 0.40 - to 5.73-variations exceeding an order of magnitude in relative trapping efficiencies.

Gray and others (1991) compared the trapping efficiencies of two pressure-difference bedload samplers with different nozzle-flare ratios that were concurrently deployed 2 meters ( $\mathrm{m}$ ) apart from a cableway over the active bedload zone within the middle third of the 76-m-wide, sand-bedded Colorado River above National Canyon near Supai, in the Grand Canyon, Arizona, under steady low-flow conditions. The samplers exhibited divergent sampling efficiencies with increasing bedload-transport rates (fig. 5). 


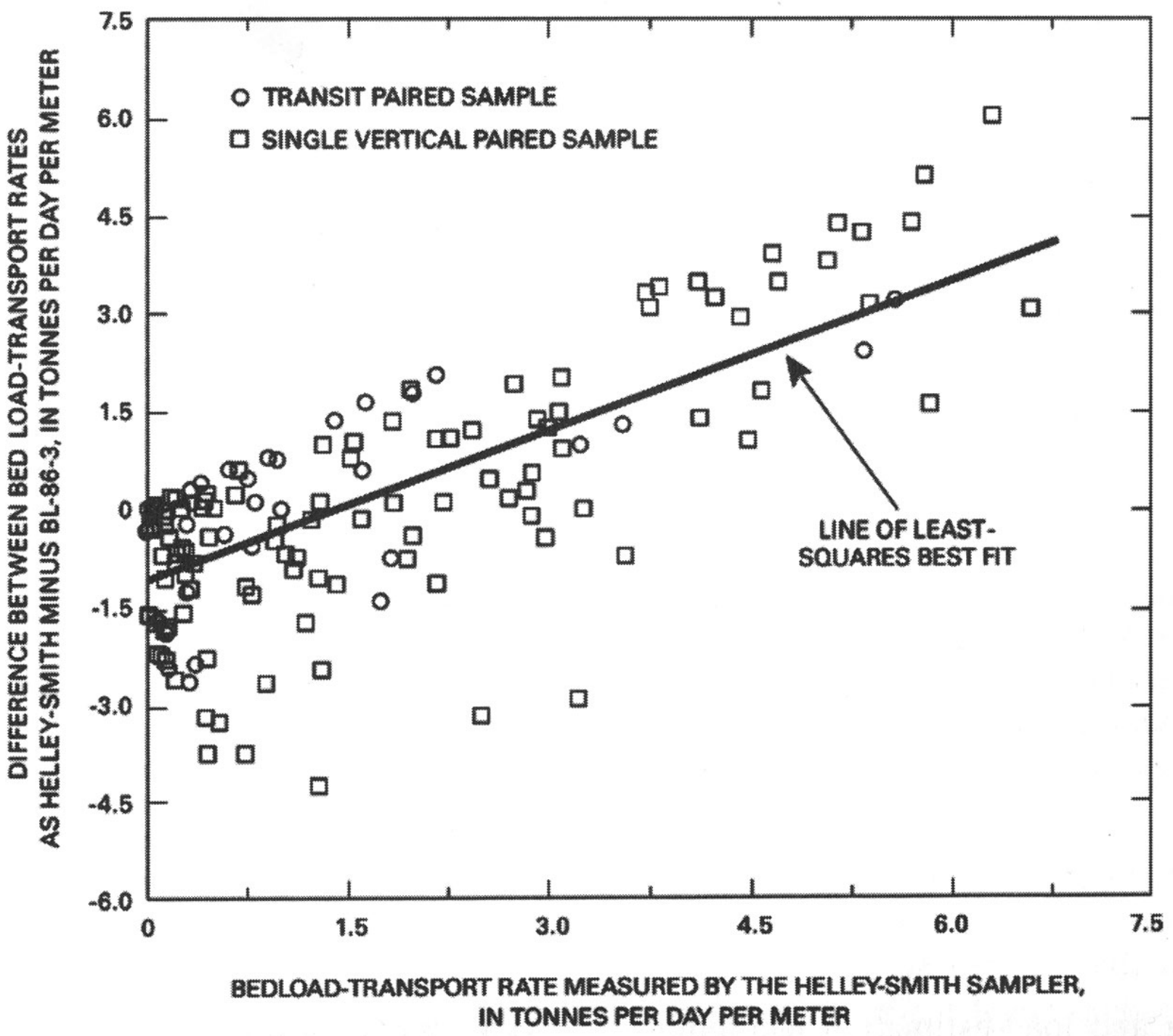

Figure 5. Graph showing differences in bedload-transport rates concurrently measured with a Helley-Smith sampler (3.22 nozzle-flare ratio) and a BL-84 sampler (formerly BL-86-3; 1.4 nozzle-flare ratio) compared to those measured by just the Helley-Smith sampler during October 1989, at Colorado River (above National Canyon) near Supai, Arizona (USGS streamgaging station 09404120). From Gray and others (1991).

Figure 6 shows differences in transport rates measured by two concurrently deployed bedload samplers, each with a 76-mm-square intake: a standard Helley-Smith sampler (3.22 nozzle-flare ratio; hereafter, all references to the Helley-Smith sampler are for this original design) and a BL-86-3 sampler, which in 1989 was experimental, with a 1.4 nozzle-flare ratio. Note that in 1989, the BL-86-3 bedload sampler was redesignated as the cable-suspended US BL-84 and the rod-deployed US BLH- $84^{5}$ and was formally endorsed by the FISP for use by its member agencies.

${ }^{5}$ Federal Interagency Sedimentation Project (FISP) isokinetic sampler designations are prefixed "US" (Beverage, 1988), followed by a 2-3 letter acronym denoting the type of sampler, and concluding with a 2-digit number corresponding to the year that the sampler was either produced or certified by the FISP. Hereafter, this report dispenses with the "US" prefix for FISP-developed samplers. Additionally, the words, "bedload sampler" are hereafter dropped when reference is made to any of the four types of bedload samplers tested. 


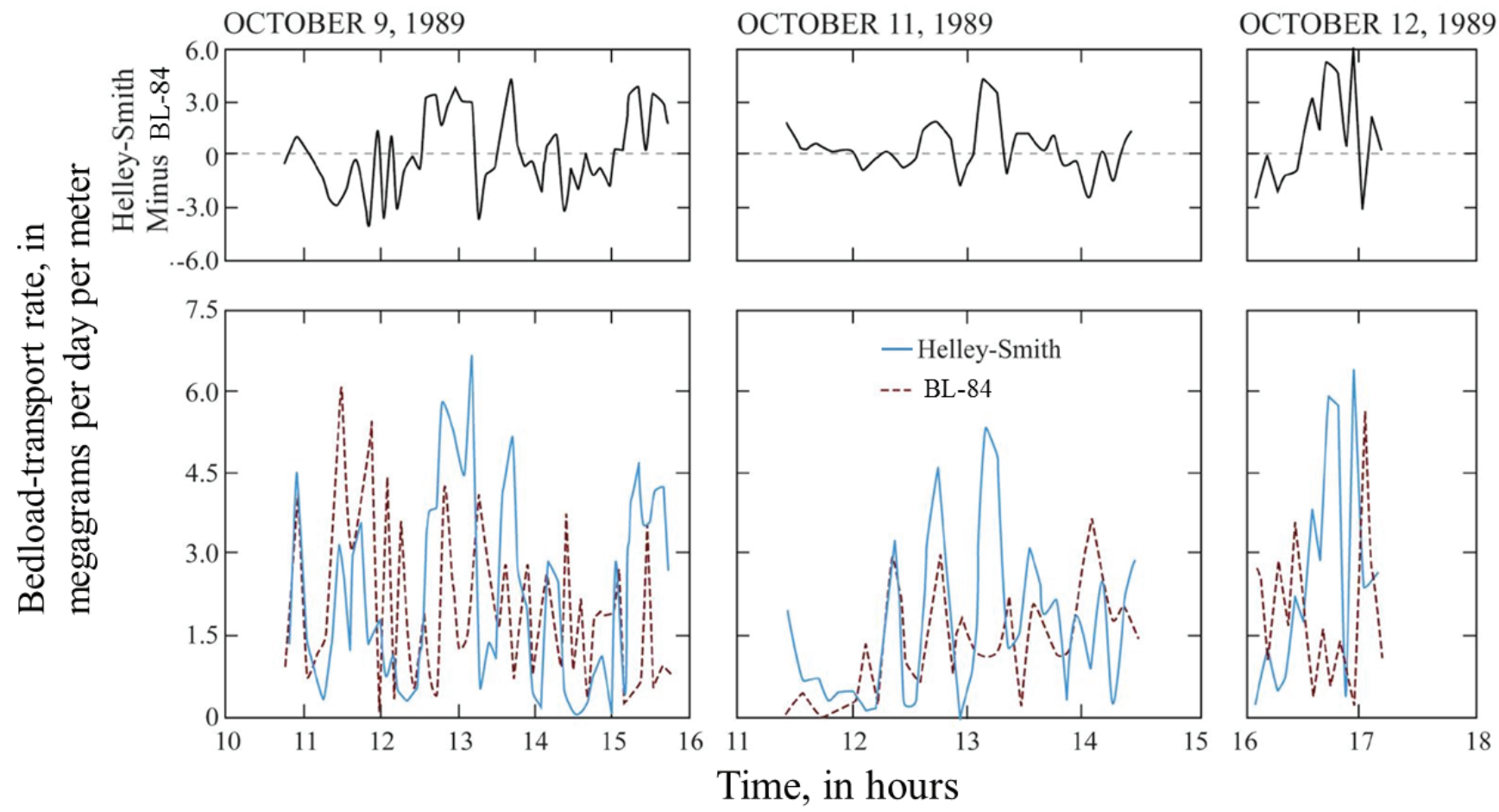

Figure 6. Graphs showing variability in sand bedload-transport rates that were measured two meters apart with a Helley-Smith sampler (3.22-nozzle-flare ratio) and a BL-84 sampler (1.40-nozzle-flare ratio) during October 1989, at Colorado River (above National Canyon) near Supai, Arizona (USGS streamgaging station 09404120). Modified from Gray and others (1991).

Although short-term transport rates-minutes to hours - measured by both samplers varied considerably (fig. 6), the cross-sectional distribution of bedload based on results from all 390 bedload samples collected over a 5-day period, assuming bedload-trapping efficiencies of unity for both samplers, indicated that bedload was transported at a mean rate of 2.8 megagrams per day $(\mathrm{Mg} / \mathrm{d})$ per meter of width. Most bedload moved in an approximately $16-\mathrm{m}$ interval near the middle of the 76-m-wide river (fig. 7). The study demonstrated potential inconsistencies in sampler collection efficiencies and the need for a relatively large bedload-transport rate dataset to adequately describe spatial and temporal characteristics of bed-load transport even under steady-flow conditions.

Ryan and Porth (1999) compared the trapping efficiencies of three bedload samplers in field settings: the BLH-84 and two Helley-Smiths - one of standard steel composition and the other fabricated from sheet metal. The authors determined that the relative trapping efficiencies from a gravel-and-cobble-bedded stream for the standard Helley-Smith and a sheet-metal version of this sampler were 1.6 and 2.4 times, respectively, those of the BLH-84. Their conclusion was limited to observing that the measured transport rates varied depending on the type of sampler used.

Vericat and others (2006) evaluated bias in bedload-trapping efficiencies collected by two Helley-Smiths with 76- and 152-mm square-intake nozzles in Spain's lower Ebro River. Bedload-transport rates computed from samples collected by the sampler with the larger nozzle tended to be greater than those for the smaller sampler. Under the conditions sampled, the authors inferred that 43 percent of the samples collected by the larger sampler were biased, compared to 65 percent of those for the smaller sampler. The authors surmised that larger grains on the bed (presumably either as bed material or as bedload) tended to block the nozzle of the smaller sampler at a relatively greater frequency or that the samplers may have perched atop clasts, thus permitting smaller-size bedload to pass beneath the samplers. The authors concluded that the use of bedload samplers with intake widths about 5 times that of the diameter of the largest bedload clasts in the water body of interest will result in an increase in the accuracy of bedload grain-size distributions and, consequently, in the precision of annual load estimates in gravel-bed rivers. 


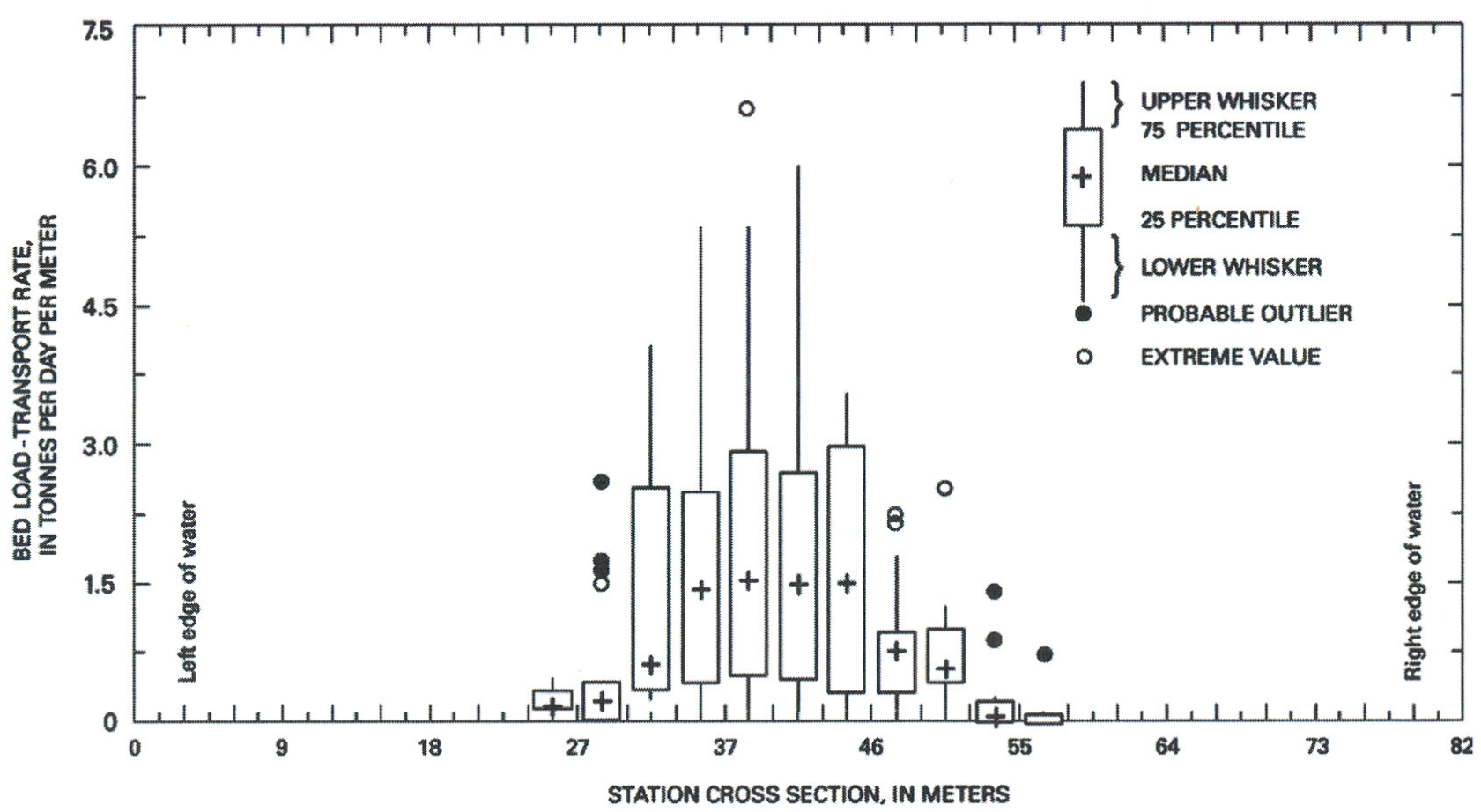

Figure 7. Box and whisker plots showing the cross-sectional distribution of bedload transport during steady flow of 165 cubic meters per second, using results from all 390 bedload samples collected in October 1989, assuming sampler trapping efficiencies of unity, Colorado River above National Canyon near Supai, Arizona (U.S. Geological Survey streamgaging station 09404120). Modified from Gray and others (1991).

Bunte and others $(2005,2010)$, Bunte and Swingle (2007), and Bunte and Abt (2009) compared bedload-transport rates of particles larger than $4 \mathrm{~mm}$ collected with bedload traps (fig. 8) to those collected with a thin-walled Helley-Smith in numerous mountain streams. Transport rates measured by the thin-walled Helley-Smith were substantially greater than those measured by the bedload traps at flows constituting 50 -percent bankfull stage, whereas similar transport rates were measured for the two types of bedload samplers deployed at flows above bankfull stage. Bedload traps were endorsed by the FISP (2009) for use in wadable, coarse-bedded streams.

\section{Calibration of Sampler Trapping Efficiencies}

Due to a fundamental need for reliable ground-truth data, most bedload-sampler trapping-efficiency tests have taken place in settings where bedload-transport rates can be controlled, or at least measured, with a quantifiably acceptable degree of accuracy. Although sediment-recirculating flumes are designed in part for this purpose, at least two problems impinge on flume bedload-sampler calibrations: the often-substantial temporal and spatial variabilities in bedload-transport rates that are consistent with those observed in natural settings. Even with a comparatively temporally stable mean transport rate, the instantaneous bedload-transport rate at a given "point" in a stream or flume channel ${ }^{6}$ can vary widely about the mean at that point (Hamamori, 1962; Hubbell and others, 1985; Gomez and others, 1990; Carey, 2005; Gray and Simões, 2008). Additionally, Fienberg and others (2010) deduced that mean bedload-transport rates measured in a flume at moderate flows decreased with increasing sampling time, indicating dependence. A general explanation for the occurrence of this phenomenon at low flow is that instantaneous bedload-transport rates exhibit rare but relatively large fluctuations (due to the irregular and stochastic nature of particle movement on the bed) (Singh and others, 2012). Thus, integrating intervals of varying durations over time alters the probability of sampling these high fluctuations.

\footnotetext{
${ }^{6}$ References to sampling bedload "at a point" in the literature is a common misnomer; more specifically and correctly, at-a-point bedload sampling involves deploying the bedload sampler in a discrete segment of a channel cross-section where the "point" is actually an area formed by the geometry of the intake nozzle when resting on the bed.
} 

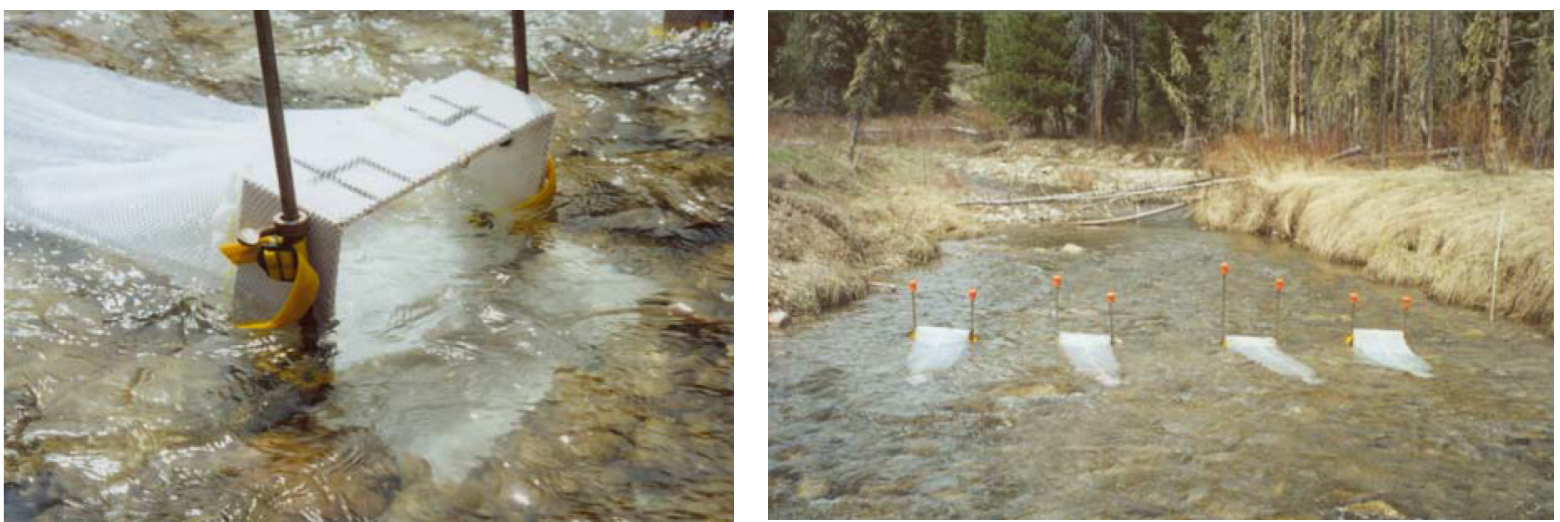

Figure 8. Photographs of bedload traps. Left, with a ground-plate apron, which prevents inadvertent particle entrainment and thus oversampling. Right, in Little Granite Creek, Colorado, at low flow.

Sampler calibrations also are hampered by the often considerable spatial variability in bedload movement. Transport rates in the section of the flume in which the bedload sampler is deployed (with respect to the distances from the sidewall, slot, and individual slot weigh drum) may differ from those at the flume ground-truth measuring location, such as a slot or a section of the slot. Spatial variability can be a factor,

- laterally and longitudinally, depending on how the bedload sampler is deployed,

- with increasing distance between the bedload-sample measuring section and the ground-truth measuring location (which, in turn, leads to uncertainties in the temporal bedload-transport characteristics, particularly when bedforms are present), and

- with the presence or absence of bedforms and other factors related to the bedload-transport process.

\section{East Fork River, Wyoming, Slot Sampler (Leopold and Emmett, 1976, 1997; Emmett,1980, 1981)}

One solution to the previously mentioned challenges imposed by the spatial and temporal variability in bedload movement was to construct a concrete trough across the bed of the East Fork River near Pinedale, Wyoming. The 14.6-m-long trough was oriented orthogonal to the mean flow direction to trap any sediment moving near or on the streambed. A walkway over the slot provided the platform from which a Helley-Smith sampler (Helley and Smith, 1971) was deployed by a hand-held rod (fig. 9).

Trapped sediment that collected on a continuously moving conveyer belt in the slot was transferred to a streamside hopper for real-time weighing and subsequent automated return to the river some $12 \mathrm{~m}$ downstream from the slot. The Helley-Smith was set on the upstream side of the slot atop the concrete apron adjacent to the slot at about 24 points across the channel. Manual samples were collected as part of two traverses, using the multiple-equal-width-increment method (Edwards and Glysson, 1999), for a total of about 48 samples per measurement. The sampler was then deployed at selected points on the concrete apron downstream and adjacent to the slot to ascertain if any bedload bypassed the slot.

Emmett (1980) concluded, for bedload particle sizes between $0.5-16 \mathrm{~mm}$ (medium-sand to pebble-size material), that the Helley-Smith's trapping efficiency was "near-perfect." The Helley-Smith trapped material finer than $0.5 \mathrm{~mm}$ with an efficiency somewhat greater than unity; however, this departure from calibration was partly attributed to the entry of suspended sand into the sampler. Bedload larger than $16 \mathrm{~mm}$ was determined to be trapped with sub-unity efficiency.

This system was used to collect bedload data from 1973 to 1979 and to field-calibrate the Helley-Smith. This work is notable for its considerable success in quantifying the bedload characteristics of the East Fork River and quantifying the Helley-Smith's range in trapping efficiencies under the measurement conditions as well as highlighting the difficulties and considerable time and expense ${ }^{7}$ of obtaining reliable bedload-transport data.

${ }^{7}$ William Emmett (U.S. Geological Survey retired, written commun., 2018) estimated that the capital costs of constructing the East Fork River near Pinedale bedload-monitoring facility totaled about $\$ 100,000$ in $1972-73$. The facility was operated from May 1973 to 1979 when data collection ceased and the site was decommissioned. By agreement with the landowner, the bridge was left in place in exchange for a release from future Federal Government obligations at the site, although the concrete trough remained after the site was abandoned. 

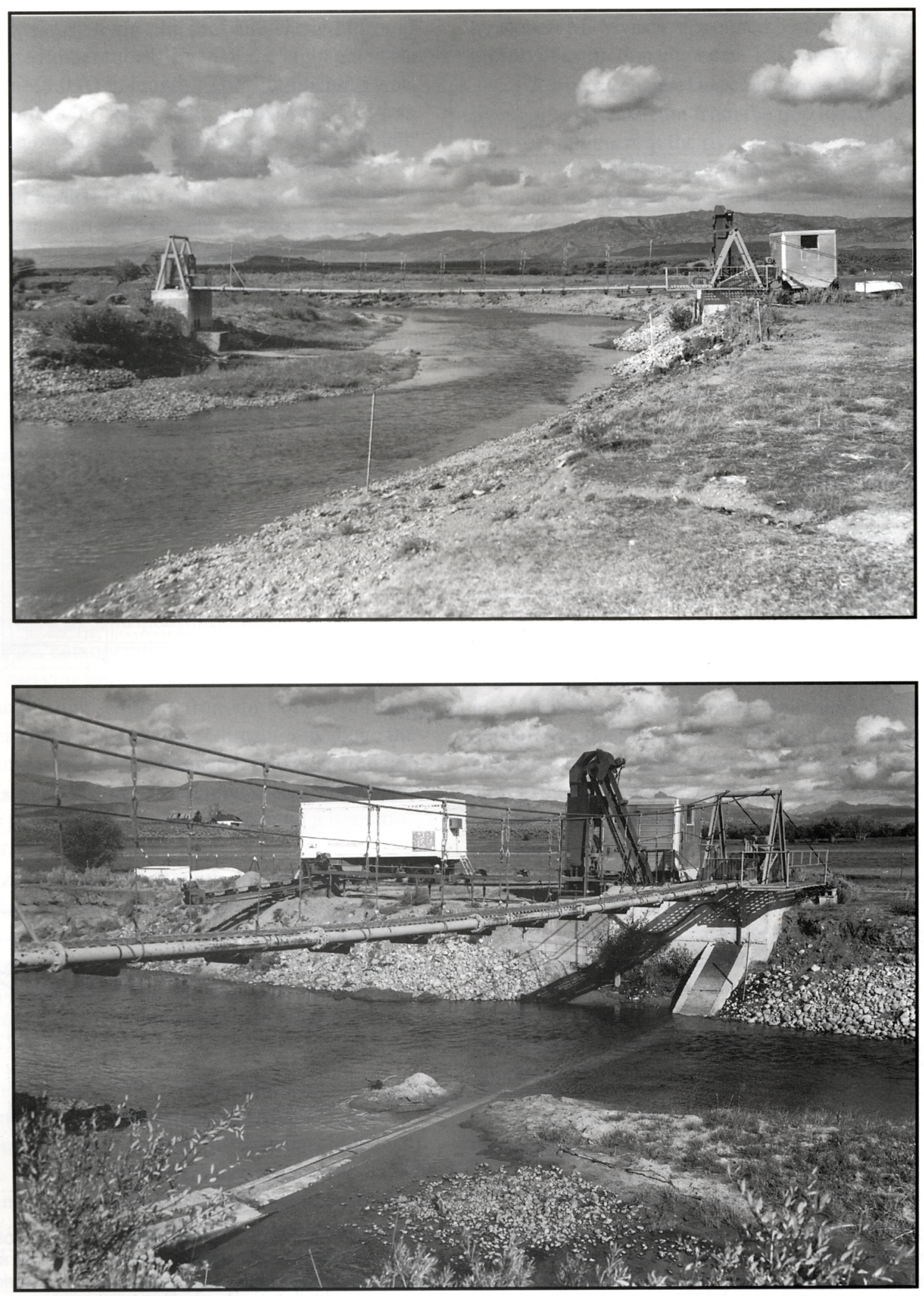

Figure 9. Photographs of the bedload trap on the East Fork River near Pinedale, Wyoming. Top, view downstream showing the suspension bridge, concrete wells on each bank, and the control trailer on the right bank. Bottom, view from the left bank at low flow. The concrete trough in the streambed is partly emergent in the foreground; the slot into which bedload falls is closed by metal gates in this photograph. From Leopold and Emmett (1997, p. 28). 


\section{St. Anthony Falls Laboratory Main Flume Slot Sampler}

Recognizing that the previously described trapping-efficiency characteristics of the Helley-Smith warranted further research and that a bedload sampler capable of collecting larger clasts was sought by the FISP member agencies, Hubbell and others $(1985,1987)$ deployed six pressure-difference-type bedload samplers in the St. Anthony Falls Hydraulic Laboratory (subsequently renamed the St. Anthony Falls Laboratory) main flume in 1977 to derive calibration curves (as opposed to single-value trapping-efficiency coefficients) for each sampler.

The main flume was operated at various combinations of flow rates and bed-material size compositions for 60-80 hours before the bedload samplers were deployed. Masses of sediment collected on 6-second intervals were automatically measured at each of the seven contiguous weigh drums imbedded in the flume slot. The bedload samplers were suspended by chain hoist from points 3-8 $\mathrm{m}$ upstream from the slot. A tether line (Childers, 1999, p. 12) connected the sampler to the ceiling over the flume several meters upstream from the deployment section. The tether line stabilized the sampler and prevented it from being swept downstream by the force of the flow.

The samplers were deployed at three lateral stations in the first four series of tests and at the center station only during the last two series of tests. The tests were performed sequentially with three mono-size distributions of 2.1-, 6.5-, and 23.5-mm material composing the bed and lastly with a logarithmic mixture of these size fractions. Dunes were present during all tests.

Because such calibrations are hampered by the previously mentioned inability of making matched individual sampler and trap measurements of sediment transport at the same time and place, two methods for developing calibration curves for the six bedload samplers were used:

1. Comparing sampled rates with corresponding estimated ground-truth rates computed from relations between bed elevations at the sampling point and rates at the bedload trap, and

2. Matching probability distribution functions for sampled transport rates and for those at the bedload trap, which entailed comparing sampler and trap averages under a range of steady-flow conditions.

Hubbell and others (1985), using the

probability-matching method, concluded that the close agreement between the curves obtained by the two methods demonstrated that accurate calibration curves can be defined by the probability-matching method. Calibration curves, defined in this way with data from different experimental runs, can be characterized by a single composite curve for a given bed-material size composition.

The primary objective of Hubbell and others $(1985,1987)$ was to develop composite curves to adjust bedload-transport rates inferred from bedload-sampler deployments to obtain true coefficient-corrected bedload-sampler rates. Their work, however, had a more lasting legacy in that it served as the basis for acceptance of the 1.4-flare-ratio version of the Helley-Smith (the BL-84 and BLH-84) as the only portable bedload samplers endorsed for use by the Technical Committee that oversees the FISP. The USGS, a member of the FISP Technical Committee, formally supports this position but continues to accept standard Helley-Smith bedload data "until additional calibration work is performed" (Edwards and Glysson, 1988, 1999).

Thomas and Lewis (1993) considered the probability-matching method of Hubbell and others (1985) to be invalid because it:

1. Implicitly assumes that neither trap nor sampler bedload-transport rates have associated measurement or sampling error, observing that errors are present in all physical measurements.

2. Gives biased and highly variable results.

3. Does not contain information for determining which independent variables to include and exclude from a regression equation.

Thomas and Lewis (1993) developed a new model for bedload-sampler calibrations that matches unobservable trap rates to normally distributed populations of cube-root transformed trap transport rates with individual rates measured by bedload samplers. The model requires at-a-point bedload-sampler data that correspond to trap data at a given weigh drum. The model "regresses transformed individual sampler measurements on daily means of transformed trap data and incorporates within-day variation in trap rates to explain part of the sampler variation" (Thomas and Lewis, 1993). The parameters are estimated by maximum likelihood using a nonstandard regression model to account for the physical inability of matching individual trap versus Helley-Smith sampler-type bedload measurements in time and over the cross-section.

The Thomas-Lewis (1993) model was used to develop calibration curves using data from Hubbell and others (1987), even though one of the requirements for the model's calibration - collecting a large number of bedload samples from at a single point - was not always met (many of the sample runs were made using three point measurements made laterally across the flume). The curves for the coarsest material tested $-23.5 \mathrm{~mm}$ in diameter-were near unity for all samplers. The curves for the finest (smallest) size material-2.1 $\mathrm{mm}$ in diameter - showed the most calibration-curve divergence with increasing bedload-transport rates. The results for the 6.5 -mm-diameter size class approximately ranged between the results for the coarsest and finest material. The results for the mixture of the three size classes were scattered around the line of equal value at lower transport rates but were not tested at high enough transport rates to provide a valid comparison. 


\section{Rationale for the StreamLab06 Bedload-Sampler Calibration Experiments}

Deficiencies associated with traditional instruments and techniques used to quantify bedload-transport rates, and potential solutions to address those deficiencies, were identified as part of two workshops sponsored by the Advisory Committee on Water Information's Subcommittee on Sedimentation (Advisory Committee on Water Information, 2017): The Federal Interagency Sediment Monitoring Instrument and Analysis Research Workshop (Gray, 2005; Ryan and others, 2005) and the International Bedload-Surrogate Monitoring Workshop (Gray and others, 2007, 2010). Both workshops described a fundamental need for ground-truth data to:

1. Quantify the accuracy of manual bedload measurements, and
2. Enable verification of bedload-transport-rate estimates derived from surrogate technologies that may provide a continuous time series of bedload-transport data.

The four types of hand-held pressure-difference bedload samplers that were deployed as part of the StreamLab06 (Marr and others, 2010b) experiments are shown in figure 10, and cable-suspended versions of these samplers are shown in figure 11. Collectively, the relevance of the tests was strengthened by inclusion of all four sampler types; the most recently developed - the Elwha-has been in use at least since the 1990s (Childers, 1999).

In addition to the goal of identifying absolute trapping efficiencies for each of the four types of bedload samplers, the experiments were designed to provide the comparative trapping-efficiency data that could enable inferences of the potential for bias in data produced by a given type of bedload sampler with respect to that of another. Such information would be of particular relevance when considering switching the type of bedload sampler used in a given monitoring program or selecting a different sampler than one used for historical measurements.

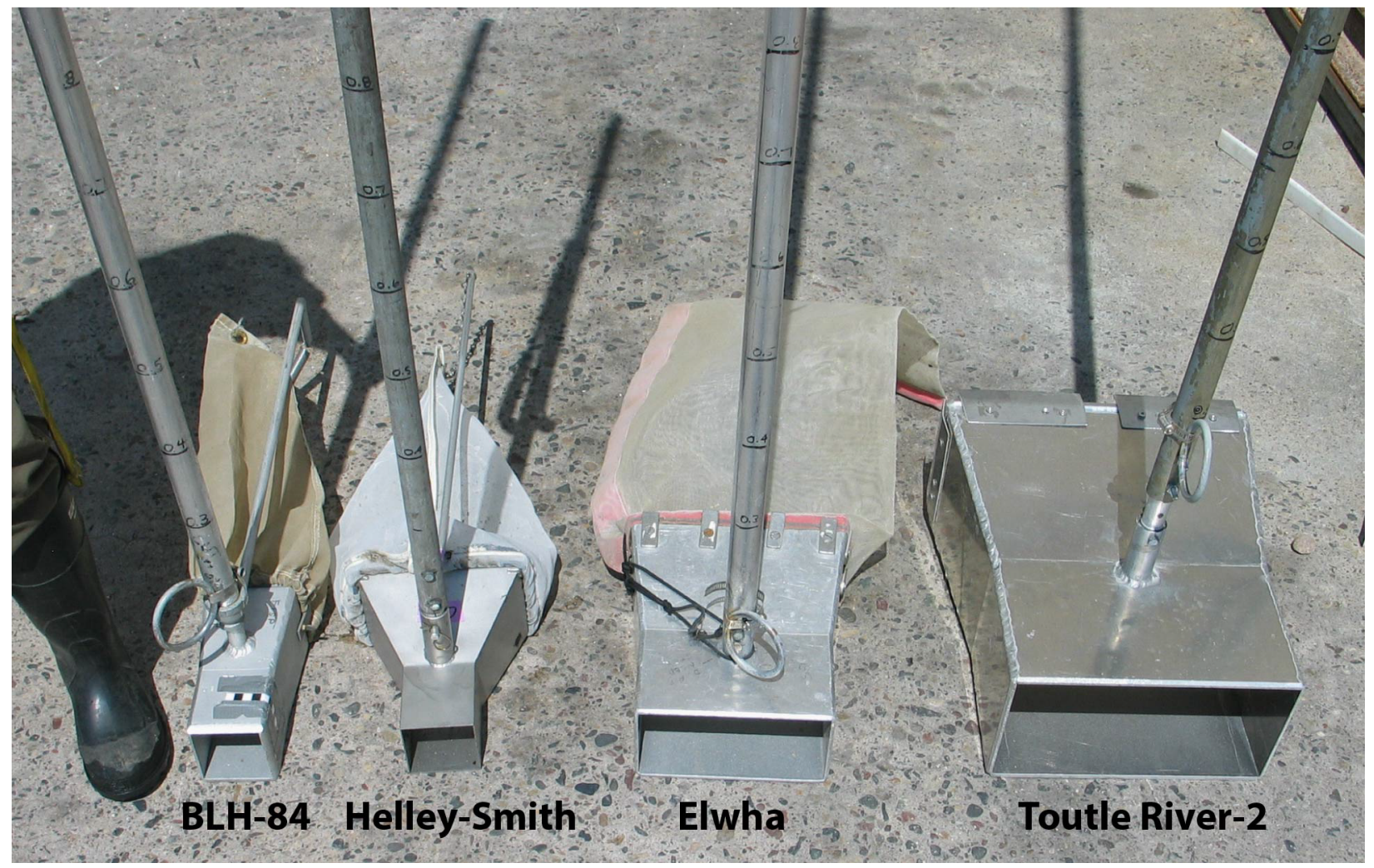

Figure 10. Photograph of four types of hand-deployed pressure-difference bedload samplers tested in the St. Anthony Falls Laboratory main flume, January to March 2006. From left to right: BLH-84, Helley-Smith, Elwha, and Toutle River-2 (TR-2, without collection bag). All the samplers shown, except for a standard thick-walled version of the Helley-Smith (a thin walled version appears here) were the actual samplers used in the tests. The dimensions of the deployed sampler's intake nozzles are as follows: BLH-84, 76.2 mm x 76.2 mm; Helley-Smith, 76.2 mm x 76.2 mm; Elwha, 102 mm x 203 mm; Toutle River-2, $152 \mathrm{~mm}$ x $305 \mathrm{~mm}$. All but the Helley-Smith sampler (flare ratio=3.22) have flare ratios of 1.4. Photograph courtesy of Kurt Swingle, Ft. Collins, Colorado, May 2006. 

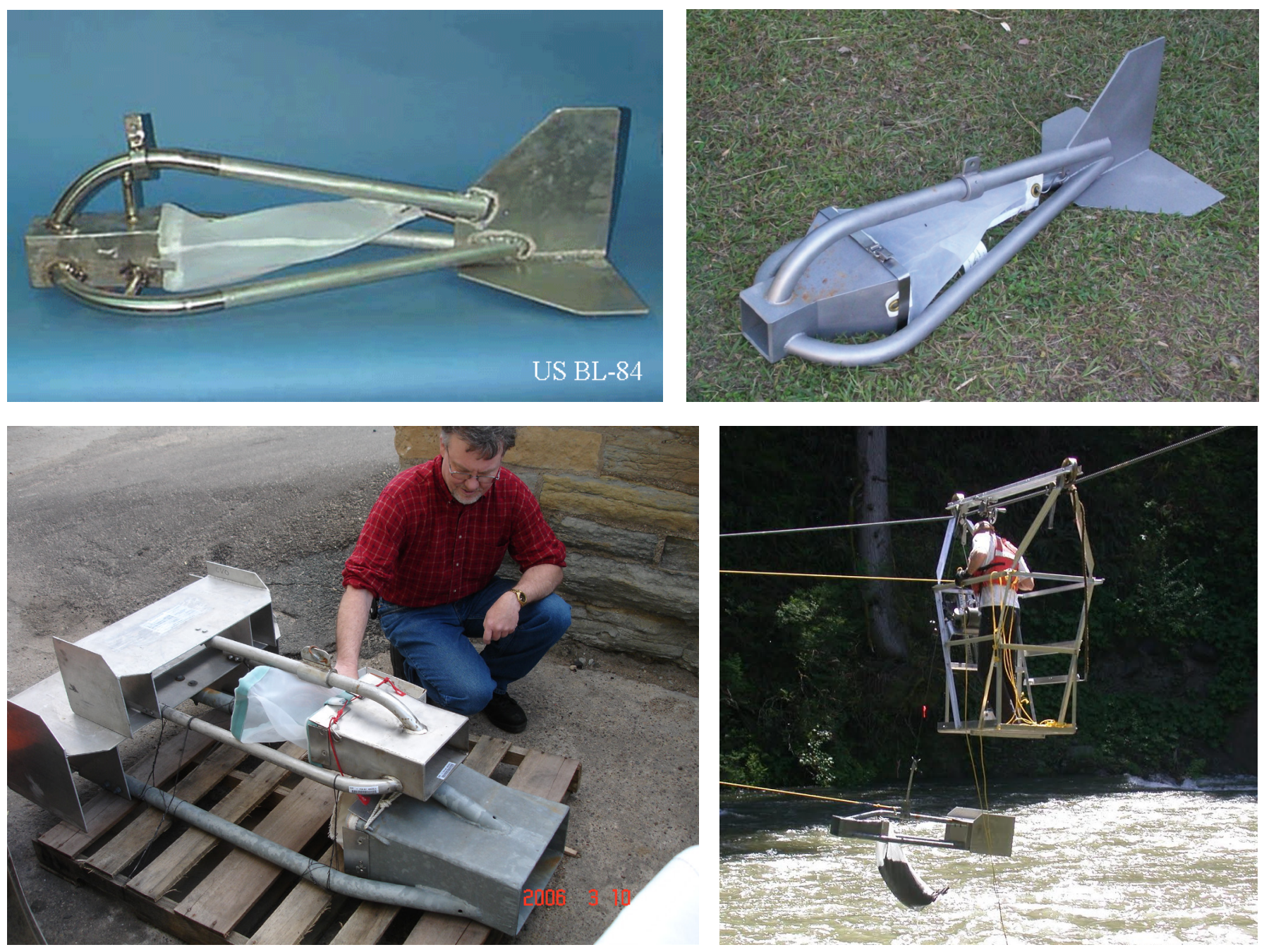

Figure 11. Photographs of cable-suspended versions of the four pressure-difference bedload samplers tested in the St. Anthony Falls Laboratory main flume, January to March 2006 (hand-deployed versions are shown in fig. 10). Clockwise from top left: BL-84; Helley-Smith; Toutle River-2 (TR-2) being retrieved from a cable car over the Sandy River at Marmot, Oregon; and an Elwha atop a TR-2 (the latter lacking a mesh bag).

The rationale for testing these four types of pressure-difference samplers follows:

Elwha sampler-The Elwha was calibrated in the sandand gravel-bedded flume based on a perceived need for a suite of calibrated bedload samplers for use on bed types ranging from sand- to gravel-size material. The Elwha (Childers, 1999) had been subject to comparisons but not to calibrations prior to the StreamLab06 experiments. It was developed by Dallas Childers of the USGS and originally deployed in the Elwha River, Washington, as a lighter, two-thirds dimensional scale version of the Toutle River-2 (TR-2) sampler (Subcommittee on Sedimentation, written commun., 1995) to:
- Retain the 1.4-flare expansion ratio of the BL-84, BLH-84, and TR-2.

- Be safely deployed using standard USGS streamgaging cable-suspension equipment from a boat, cableway, or bridge (the larger and heavier cable-suspended TR-2 sampler requires special, heavy-duty suspension equipment than that required for the other three cable-suspended samplers).

- Enable collection of all clasts in motion. According to U.S. Geological Survey (1990) guidelines, the sampler nozzle dimensions (width and height) should be at least double the size of the largest particles in motion. 
The aforementioned nozzle-size guidance

(U.S. Geological Survey, 1990) bears scrutiny. For a bedload sampler with a 76-mm-square intake nozzle, this requirement corresponds to a maximum clast diameter of $38 \mathrm{~mm}$. If taken literally, however, this guidance theoretically would apply solely to spherical clasts entering a square intake nozzle. Per conventional sedimentological nomenclature, a clast's "size" refers to its median diameter. Clasts rolling on the riverbed tend to do so with the long axis orthogonal to the ambient (downstream) flow direction, based on the orientation of rocks rolling downstream in rivers and in a beach swash zone as observed by the lead author.

An example of this phenomenon is illustrated in figure 12, which shows the BLH-84 after deployment in the gravel-bedded main flume on March 11, 2006. The approximately 80 -mm-long diameter of the clast lodged in the sampler's intake nozzle was substantially larger than its median diameter.

If the intent of this USGS guideline is to ensure that more than one natural (that is, nonspheroidal) clast can enter the bedload sampler at one time, specifying that "the nozzle intake be at least double the long diameter of the largest particles in motion" would be more appropriate for a sampler with a rectangular intake nozzle. This specification would infer that the dimensions of an intake nozzle should be somewhatslightly to considerably-larger than double the median diameter of the previously mentioned particles. Because of the variable relation between the long, median, and short axes of natural sediments, developing precise guidelines for the dimensions of a bedload-sampler intake on the basis of the dimensions of clasts in transport is challenging at best and beyond the scope of this report.

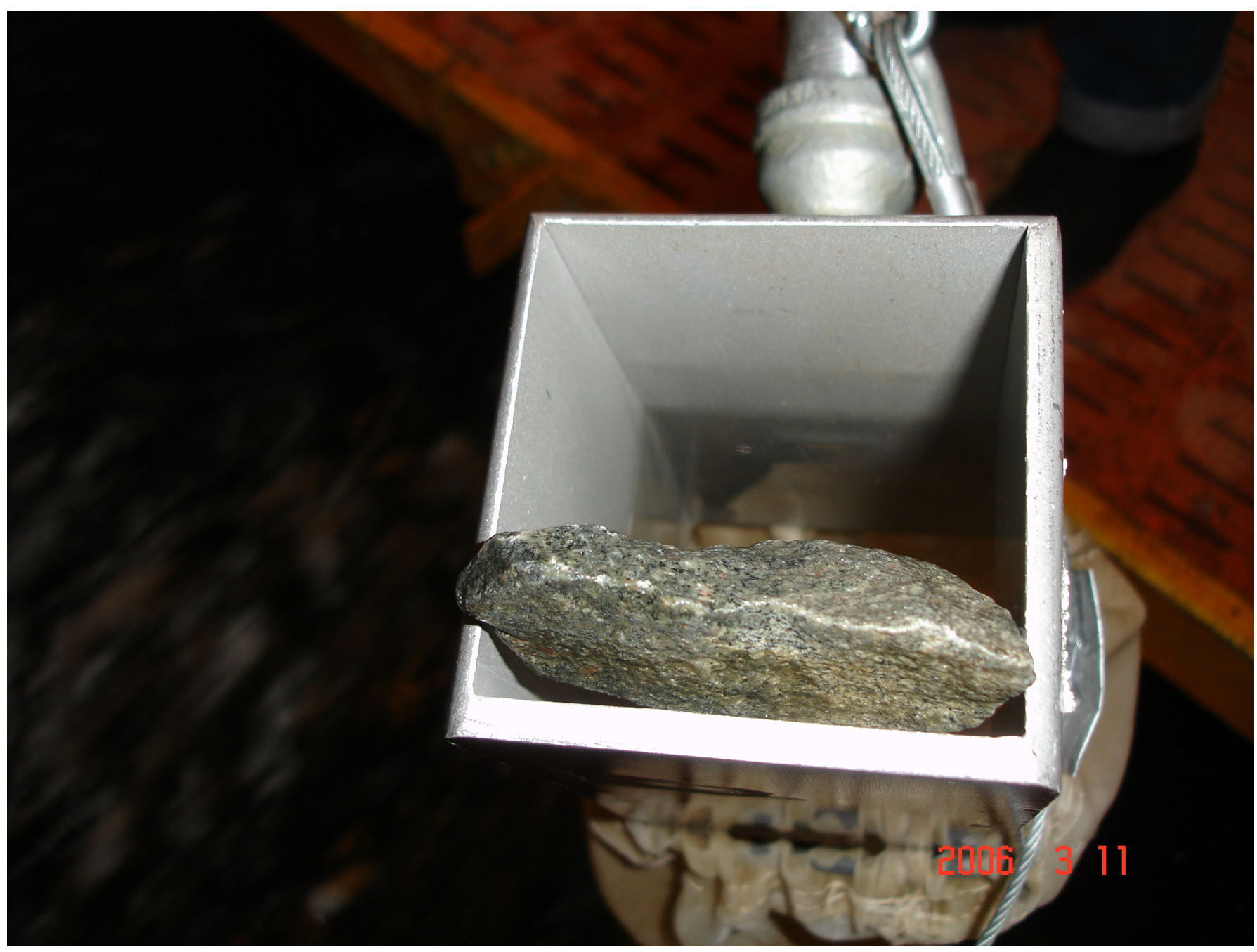

Figure 12. Photograph of a bedload clast lodged in the entrance of the 76-mm-square BLH-84 intake nozzle used on March 11, 2006, during the StreamLab06 gravel-bed experiments. 
Helley-Smith sampler-A Helley-Smith sampler was included in the StreamLab06 experiments:

- Because the preponderance of 20th century bedload data - and some 21st century data - for U.S. rivers and many other rivers from around the world was collected with this type sampler; and

- To evaluate its performance in a sand-bedded system for which it was not originally designed (William Emmett, U.S. Geological Survey, oral commun., 1999), but in which it often has been deployed.

TR-2 sampler-The TR-2 was tested in the gravel-bedded flume primarily as a comparison to its congruously configured "two-thirds scale" Elwha sampler.

BLH-84 sampler-The BLH-84 was calibrated in the sand- and gravel-bedded flume. The primary reason for inclusion of the BLH-84 in the StreamLab06 experiments was its status as the only pressure-difference bedload sampler officially endorsed by the Technical Committee of the FISP (Edwards and Glysson, 1986, 1999; U.S. Geological Survey, 1988; Subcommittee on Sedimentation, written commun., 1995). Thus, the strength of the tests was substantially enhanced by enabling comparisons among the four most commonly used pressure-difference bedload samplers.

The rationale for the 1985 endorsement by the FISP Technical Committee of the BL-84 instead of the Helley-Smith 3.22-flare sampler, however, is not unequivocally supported by graphs appearing in Hubbell and others (1987), even though the results of the Hubbell and others (1987) research were used to justify the BL-84's endorsement and for the USGS's acceptance of that endorsement. According to Edwards and Glysson (1999):

"The standard 3-inch by 3-inch [76-mm-square intake nozzle Helley-Smith bedload] sampler has been calibrated in two different laboratory studies and in an extensive field study. Results of one laboratory study (Helley and Smith, 1971) indicated an average sampling efficiency of about 160 percent. Emmett (1980) concluded from his field study that the overall sampling efficiency was close to 100 percent. A laboratory investigation (Hubbell and others, 1985) of varying bed materials and a range of transport rates indicates that the sampling efficiency of the standard [76-mm-square-nozzle Helley-Smith] sampler varies with particle size and transport rate, displaying an approximate efficiency of 150 percent for sand and small gravel and close to 100 percent for coarse gravel. The standard 6-inch by 6 -inch sampler had generally higher efficiencies. Tests of a Helley-Smith type sampler, which has a [76-mm-square] nozzle with less expansion than the standard nozzle (an area ratio of 1.40 ), resulted in fairly constant efficiencies close to 100 percent for all transport rates and particle sizes [italics added]. In May 1985, the 1.40 nozzle was approved by the Technical Committee [of the FISP] ... as a provisional standard sampler for use by U.S. Federal agencies. After some modifications to the frame, the [sampler with the 76-mm-square] nozzle with 1.40 expansion ratio was designated the BL-84 sampler. The Water Resources Division of the USGS endorses the use of this new sampler with the 1.40-area-ratio nozzle; however, until additional testing is done, [bedload and ancillary] data obtained using the original 3.22-area-ratio Helley Smith sampler will continue to be accepted [for storage in and dissemination from the USGS National Water Information System]."

The veracity of the above-quoted qualitative rationale for endorsing the BL-84 may be inconsistent with the data on which the endorsement was based. Figure 13 shows the Hubbell and Stevens (1986) trapping-efficiency plots for the BL-84 (referred to anachronistically as the "Helley-Smith") for three bed-material particle-size ranges: 1.4-4.0, 4.0-8.0, and $11.3-32.0 \mathrm{~mm}$. For comparison, similar-type plots are shown in figure 14 for the Helley-Smith sampler and the same size ranges (Hubbell and Stevens, 1986). The trapping efficiency of the largest size range is consistently near unity over a sampling rate of 0-3.0 kilograms per second-meter $(\mathrm{kg} /(\mathrm{s}-\mathrm{m}))$. The trapping efficiency for the smallest size range is about 75 percent over the sampled-rate interval of $0-0.75$ $\mathrm{kg} /(\mathrm{s}-\mathrm{m})$. The intermediate size range trapping efficiency is uniformly less than unity and diminishes with increasing sampled rate, described in approximate terms as follows:

- 87 percent at a sampled rate $0-1 \mathrm{~kg} /(\mathrm{s}-\mathrm{m})$

- 75 percent at a sampled rate $1-2 \mathrm{~kg} /(\mathrm{s}-\mathrm{m})$

- 63 percent at a sampled rate $2-3 \mathrm{~kg} /(\mathrm{s}-\mathrm{m})$

The minutes of the April 18-19, 1995, meeting of the FISP Technical Committee (written commun., 1995) state that "[the] FISP continues to tentatively endorse the BL-84." This endorsement was reaffirmed in spite of the observations that "the committee... recognizes that there is no conclusive scientific evidence proving that the BL-84 provides more accurate data [than the Helley-Smith]....although there is evidence that the BL-84 is an improved sampler relative to the Helley-Smith."

A comparison of figures 13 and 14 infers that the BL-84 bedload-trapping coefficient for the coarsest size fraction tested was substantially closer to unity than that for the Helley-Smith bedload sampler. Although both samplers exhibited sub-efficient trapping efficiencies in the mid- and finest-size fractions tested, those for the BL-84 were closer to unity than those for the Helley-Smith. 


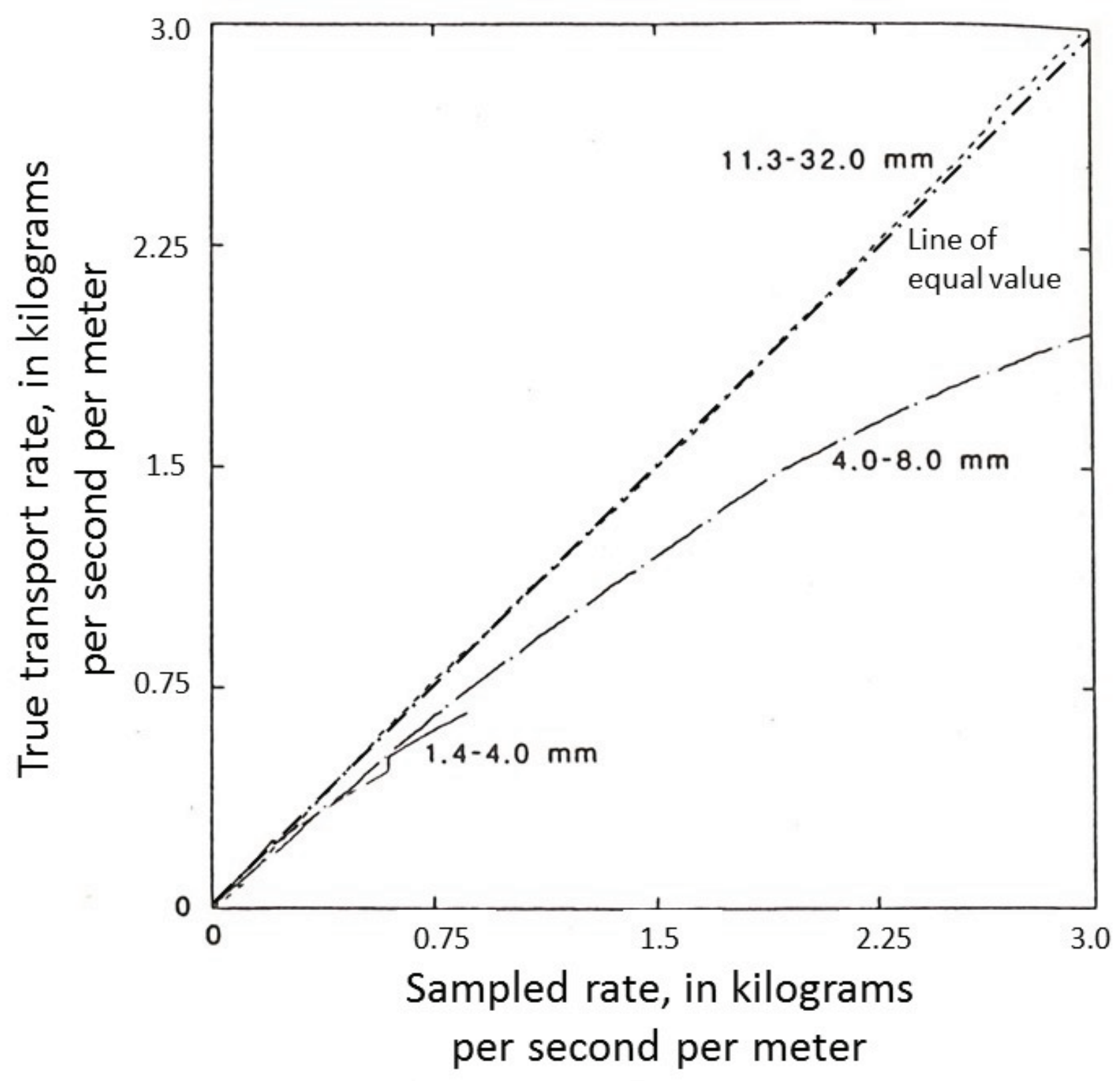

Figure 13. Plot of calibration curves for the BL-84. The three bed-material particle-sizes (shown by the three lines additional to the line of equal value) range from 1.4-4.0, 4.0-8.0, and 11.3-32.0 millimeters (mm). Figure modified from Hubbell and Stevens (1986, fig. 3B, p. 4-24). 


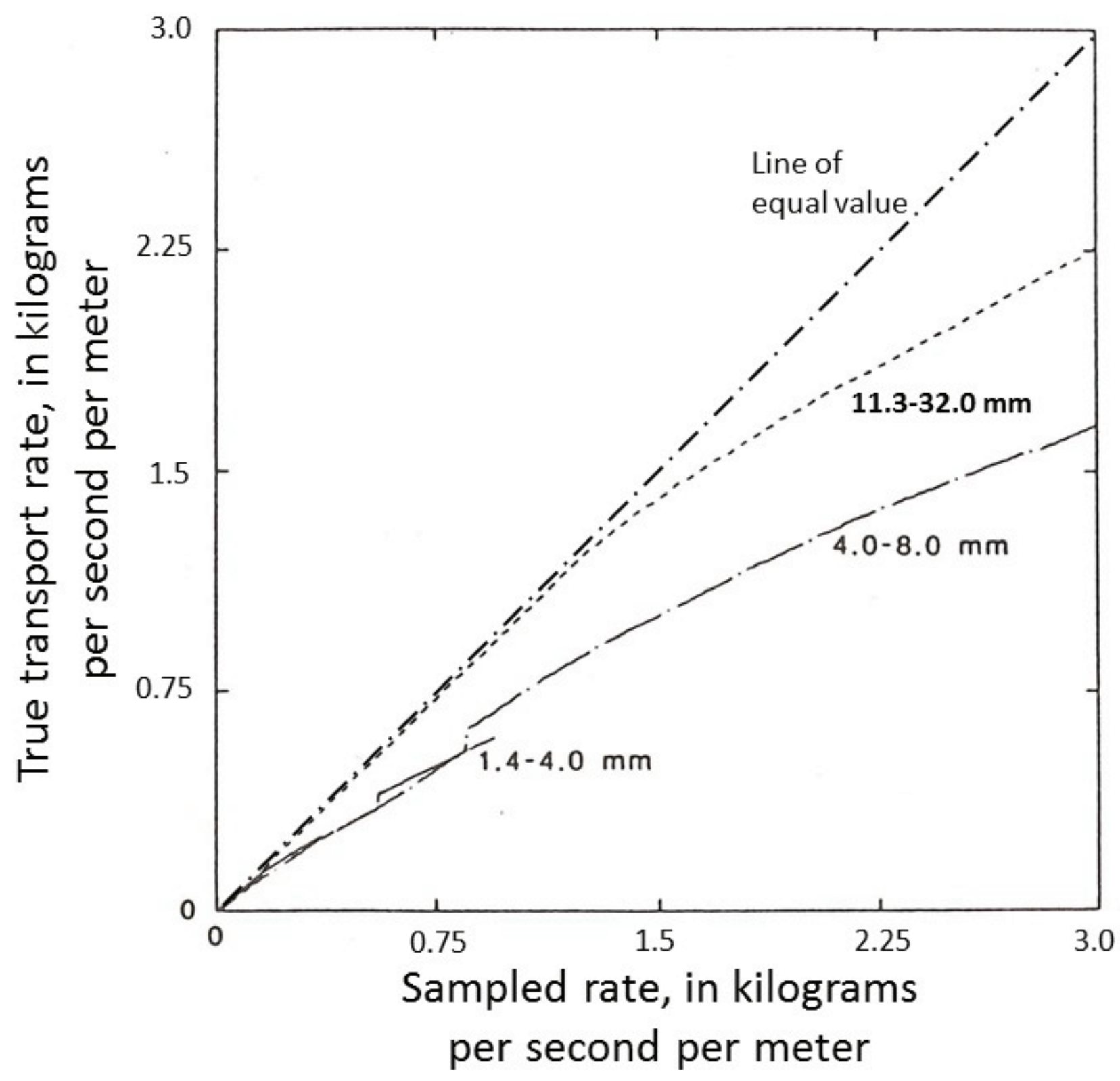

Figure 14. Plot of calibration curves for the standard Helley-Smith. The three bed-material particle-sizes (shown by the three lines) range from 1.4-4.0, 4.0-8.0, and 11.3-32.0 millimeters (mm). Figure modified from Hubbell and Stevens (1986, fig. 3A, p. 4-24). 
The following list summarizes the reasons for performing bedload-sampler trapping-efficiency tests as part of Phases I and II of the StreamLab06 experiments:

1. Unlike the other three bedload samplers that benefited from calibration tests, the Elwha bedload sampler had never been calibrated. This reason alone was sufficient to take advantage of the offer to participate in the StreamLab06 experiments.

2. The justification for the FISP's 1985 provisional endorsement of the BL-84 (and, implicitly, the BLH-84) was only partly consistent with the graphical data supporting its endorsement (Hubbell and Stevens, 1986); thus, the BLH-84 was deemed worthy of additional testing.

3. The FISP's previously mentioned "provisional" endorsement of the BL-84 in 1985-restated in 1990, and again in 1995 as a "tentative" endorsement by the FISP — remained unchanged in 2006 when the StreamLab06 experiments took place. By 1990, the USGS endorsed use of samplers "with the 1.4-flare ratio" (for example, the BL-84, an endorsement that remains unchanged at the time of this report's publication).

4. The USGS's endorsement of the BL-84 is inconsistent with the Edwards and Glysson $(1988,1999)$ guidance to continue to use the Helley-Smith until the BL-84 was "tested further and [became] available for use," given there is no evidence of additional testing of the BL-84 between 1988 and 1990. Resolving dissonance between the FISP's and USGS's tentative or unqualified endorsements of the BL-84 was another potential outcome for the StreamLab06 bedload-sampler tests.

5. Thomas and Lewis (1993) not only raised doubt of the statistical treatment of bedload data in Hubbell and others (1987), but they provided a statistically rigorous "new model" for calibrating bedload samplers that warranted application.

6. Inclusion of a bedload-sampler comparison component as part of the requisite calibrations was anticipated to increase the usefulness of the experiments, in part because of any potentially unique influences the main flume might have that would be common to all samplers tested.

7. The refurbished St. Anthony Falls Laboratory main flume with state-of-the-art monitoring capabilities offered unprecedented precision and data-storage capabilities to automatically produce bedload-transport time-series data.

8. The considerable costs associated with refurbishing the main flume, plus its operation as part of StreamLab06 Phases I and II experiments, were borne by the NCED and St. Anthony Falls Laboratory (SAFL). These capital investments enabled the participating organizations and researchers to provide their own, relatively affordable resources to participate in the experiments.

\section{The StreamLab06 Bedload-Sampler Trapping-Efficiency Tests}

\section{St. Anthony Falls Laboratory Main Flume}

\section{Background}

In May 2000, the lead author of this report, his colleague Larry Schmidt - acting in their capacities as USGS and U.S. Forest Service representatives, respectively, of the FISP Technical Committee - and Basil Gomez of Indiana State University visited the SAFL to investigate the potential for the FISP to use the main flume to calibrate the Elwha and other selected bedload samplers. The SAFL Director, Dr. Gary Parker, explained that the main-flume Sediment Monitoring and Recirculation System (SMRS) had fallen into disrepair and would require substantial rehabilitation before it could be reused for bedload-sampler testing. Dr. Parker estimated that $\$ 1.5$ million in 2000 dollars would be required over a 3- to 5-year period to rehabilitate the flume and perform the bedload-sampler calibration tests sought by the FISP. Such resource requirements substantially exceeded those available to the FISP.

In 2005, as part of the NCED's investment in communitywide experimental earth-surface dynamics research, several improvements were made to the main flume. The goal of the NCED - funded by the National Science Foundation as a Science and Technology Center-was to equip the main flume with state-of-the-art technologies and make the facility available for use by the broader community for advancing science and practice of river ecohydromorphodynamics. The upgrades - completed in time for the initiation of StreamLab06 Phase I tests in January 2006-included enhancements to the flow-control and sediment-recirculation systems, and a state-of-the-art sediment-flux monitoring system (Singh and others, 2013).

\section{Description}

The main flume is capable of conveying field-scale flows and recirculating known quantities of introduced sediments ranging from sand size to medium-gravel size continuously for days at a time. These characteristics, along with the automatic bedload weighing capability, led the FISP to use the flume for advancing sediment-transport research and bedload-monitoring technologies beginning in the early 1980s (Hubbell and others, 1987). 
The main flume (figs. 15 and 16) is composed of an open rectangular concrete channel with flow- and stage-controlling devices. Water from the Mississippi River upstream from St. Anthony Falls is diverted through a screened intake to the flume's entrance, taking advantage of the static head differential created by the falls. A sluice gate controls flow to the flume at rates of $0-8.5 \mathrm{~m}^{3} / \mathrm{s}$. The diverted flow courses through the flume and returns to the Mississippi River (that is, the flow is not recirculated) downstream from the falls.

The 80 -m-long concrete flume is $2.74 \mathrm{~m}$ wide with sidewalls that rise $1.8 \mathrm{~m}$ from the bed. An adjustable sharp-crested weir at the flume's tailwater controls the stage of flow. Stage and weir elevations are automatically monitored and, coupled with a theoretical stage-discharge relation, are used to continuously meter water discharge. Sand-size (January-February 2006) and gravel-size material (March 2006) were laid atop the concrete bed for StreamLab06 Phases I and II tests, respectively.

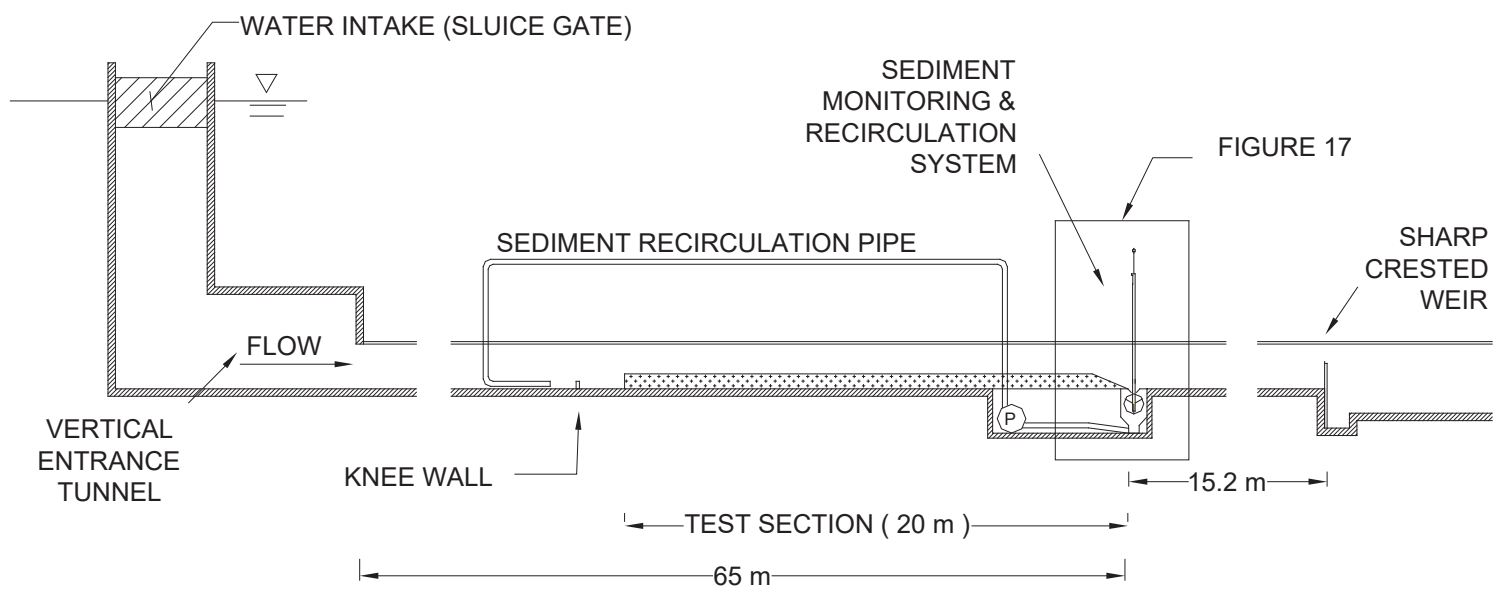

Figure 15. Side-view schematic of the St. Anthony Falls Laboratory main flume showing the entire facility from the water intake to the tailwater of the sharp-crested weir. Some length measurements are not to scale. Modified from Marr and others (2010b, fig. 1).

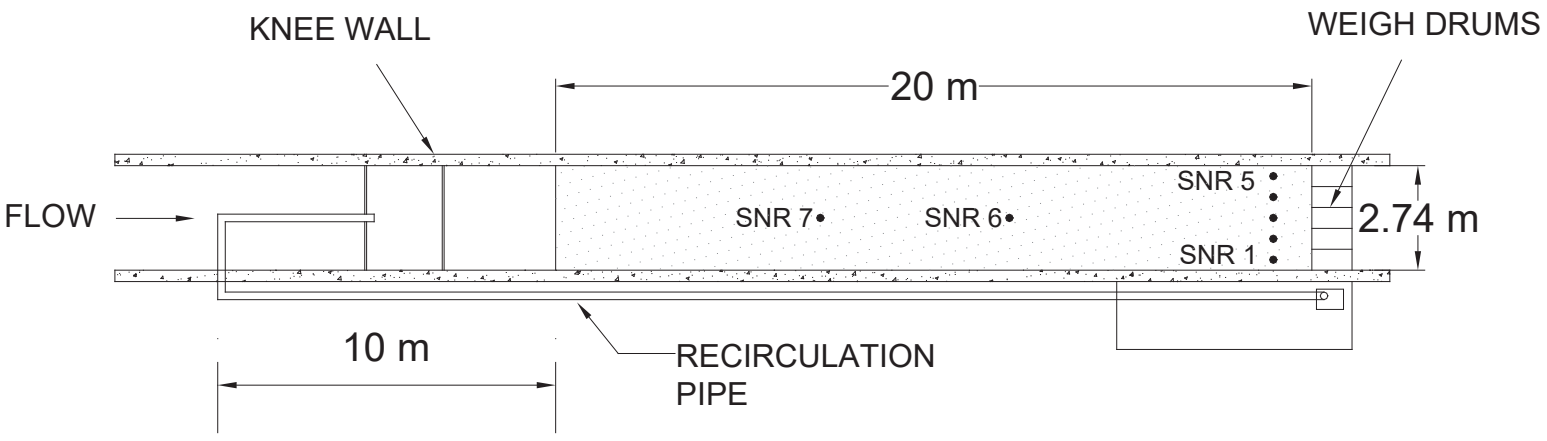

Figure 16. Plan-view schematic of the St. Anthony Falls Laboratory main flume showing the section in which bedload is captured by the weigh drums and recirculated to the upstream approach section to the knee wall. The acronym SNR is for the 7 sonars (SNR) and their locations deployed upstream from the flume slot. From Marr and others (2010b, fig. 5).

Abbreviation: $m$, meters.

\section{Sediment Monitoring and Recirculation System}

A fundamentally important aspect of the main flume is the Sediment Monitoring and Recirculation System (SMRS), the sediment-collection location of which is approximately $65 \mathrm{~m}$ downstream from the flume entrance and $15.2 \mathrm{~m}$ upstream from the sharp-crested weir. The SMRS is capable of continuously monitoring bedload flux during an experimental run.

The SMRS has the following principal components:

1. A full-width bedload slot (trap) into which bedload particles fall.

2. A sediment-flux monitoring component (see next section) that automatically and continuously collects and weighs the captured bedload in drums (pans) located inside the slot. Each of the weigh drums independently discards its trapped sediments to the bottom of the slot before exceeding a preset value of mass. 
3. A horizontally imposed auger at the base of the pit that conveys captured sediments to a pumping system that flushes sediments as large as $76 \mathrm{~mm}$ to the flume about $25 \mathrm{~m}$ upstream from the slot.

\section{Sediment-Flux Monitoring Component}

The sediment-flux monitoring component of the SMRS was designed, fabricated, and installed by the SAFL in 2005. The SMRS is capable of continuously monitoring bedload flux during a test run.

The monitoring component consists of five identical, contiguous aluminum drums embedded in the slot that spans the width of the flume (fig. 17). Each of the five drums independently and continuously measures the submerged weight of the captured bedload. Hence, each drum weighs the bedload captured in a one-fifth $(0.55-\mathrm{m}$ wide) subsection of the slot. The drums, like the SMRS, can accommodate up to 76-mm-diameter particles.

Each weigh drum hangs from an aluminum frame connected to a load cell affixed to the ceiling above the flume (fig. 18). The system uses load cells manufactured by Interface Advanced Force Measurement (SM-250) that have a capacity of 113 kilograms $(\mathrm{kg})$ and are accurate to \pm 45 grams $^{8}(\mathrm{~g})$. As a safety margin to avoid exceeding the capacity of the weigh-drum system, the drum rotation that voids the contents of each bin is triggered when a user-specified net weight (typically $20-40 \mathrm{~kg}$ ) is reached.

${ }^{8}$ The uncertainty associated with mass-force measurements is a function of the resolution of the analog-to-digital converter board and that of the load cells. The accuracy of the load cells, being an order of magnitude less than the resolution associated with the converter board, is the limiting factor. The combined uncertainty is about 0.04 percent, which for the $113.4-\mathrm{kg}$ load cells is equivalent to $45 \mathrm{~g}$.

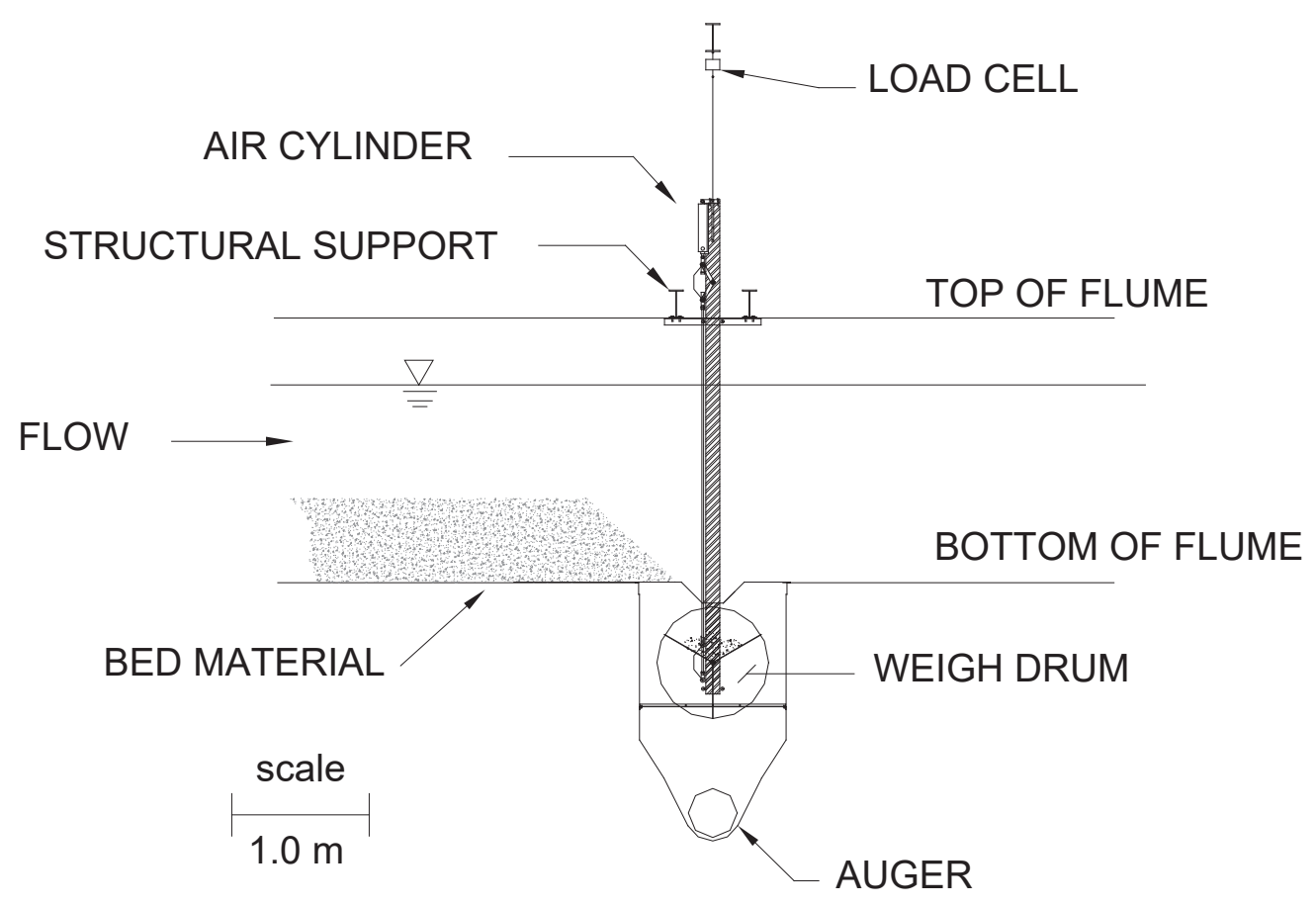

Figure 17. Schematic of the Sediment Monitoring and Recirculation System, showing the right-most of the five weigh drums in the cross-channel slot over the auger in the bottom of the slot. View is from the right side of the flume proper to the slot. From Marr and others (2010b, fig. 2). Abbreviation: m, meters. 

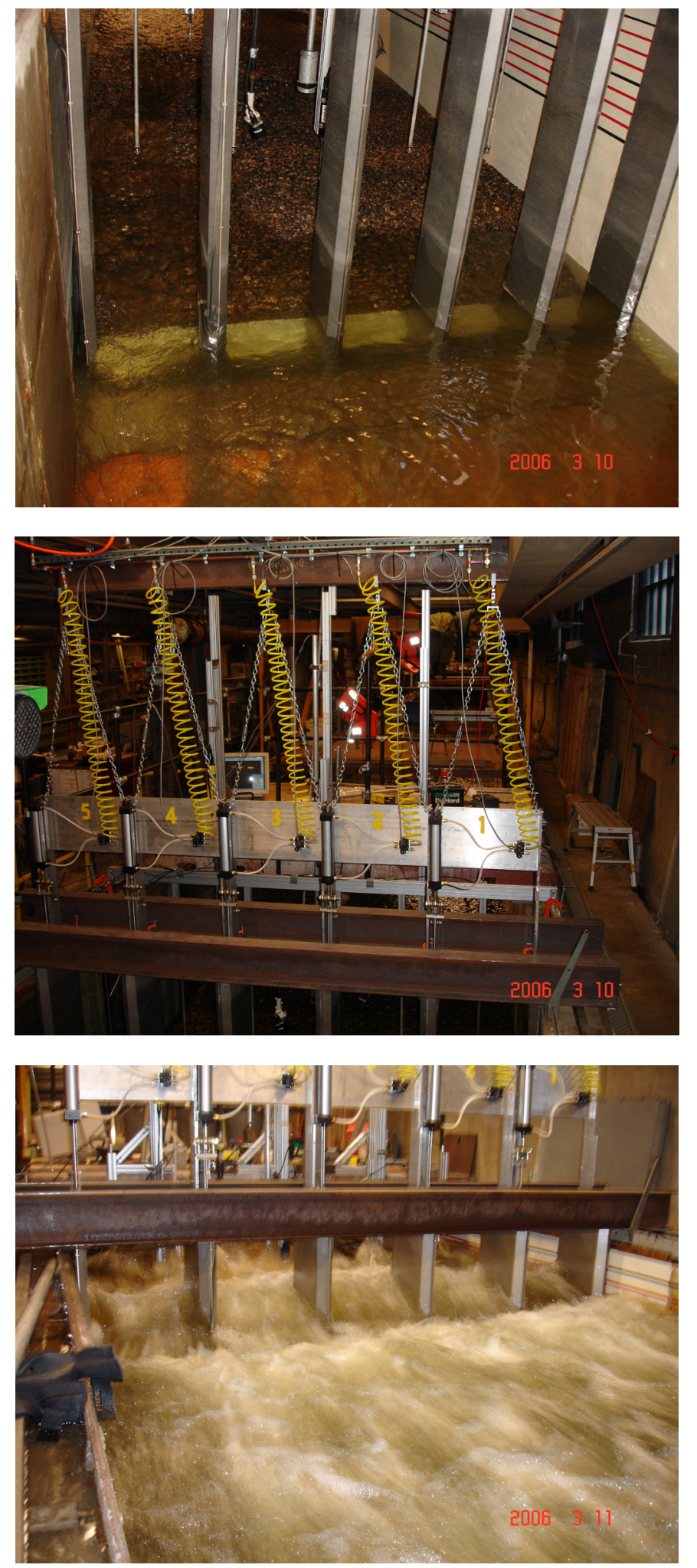

Figure 18. Photographs of the main flume sediment-flux monitoring component of the Sediment Monitoring and Recirculation System. Top, the slot in the partially drained flume. Middle, the non-submerged part of the weigh-drum apparatus. Bottom, the non-submerged apparatus during a test run.
Stainless steel cover plates with 45.2-centimeter $(\mathrm{cm})$ by $15.2-\mathrm{cm}$ slots located under the bed trap (not shown in fig. 18) serve to funnel the intercepted bedload downward into the weigh drums. Each aluminum drum has three radial baffles welded to a common 3.8-cm-diameter hub and two 81.3-cm-diameter end plates. The drums are oriented horizontally and orthogonal to the long axis of the flume under the sediment trap. The three radial baffles form two adjacent 120-degree "V"-shaped bins, each of which has a capacity of 62 liters (L). The submerged weight of sediment in a bin at maximum capacity is $62 \mathrm{~kg}$. Each drum operates independently using a tipping-bucket arrangement with "tips" consisting of alternating 120-degree clockwise and counterclockwise rotations. When the sediment in a weigh drum reaches a specified threshold mass, a pneumatic piston actuates (either extending or retracting based on the ambient drum position), causing the drum to rotate 120 degrees. This action results in dumping the contents of one bin and repositioning the adjacent, empty bin under the funnel to continue collecting bedload without interruption. All the bedload falling into each trap is continuously weighed and dumped in this manner.

The submerged weights of each drum measured continuously by the respective load cell are monitored by a central data-acquisition (CDAQ) system. Figure 19 shows the CDAQ console and an operator.

Data on water temperatures and water-surface elevations measured by sensors located $6 \mathrm{~m}$ upstream from the weir, as well as the weir elevation, were also continuously monitored. All data acquired by the CDAQ system were automatically recorded and stored as an ASCII-formatted file. The measurements were recorded by the CDAQ system at 5,000 hertz $(\mathrm{Hz})$ for a user-specified period of time. Typically, 4,000 values of mass were measured in a 0.8 -second interval. A mean value from the 4,000 measurements was stored in the ASCII file. Each measurement, processing, and recording cycle, the duration of which was user-defined, took about 1.1 seconds to complete during the StreamLab06 experiments. Thus, the data produced by each weigh drum were stored about every 1.1 seconds.

The drum-weigh data were used to estimate bedload mass flux by calculating the rate of change of the submerged weight of sediment trapped in each drum. As entrapped bedload falls into an initially empty bin of a drum, the load cell records an increasing weight of material in the drum. When the drum rotates and dumps the contents of one bin, high-frequency (positive and negative) oscillations about the ambient sediment mass resulting from vibrations in the weigh drums result from the water turbulence induced by the motion of sediment being dumped. The data recorded during and immediately after a drum tip, as turbulence around the drum dampens, are spurious. Post-processing of the data, including removal of these spurious data and applying averaging techniques to the data to remove the oscillation noise, is required for computation of reliable sediment-flux values at $1 \mathrm{~Hz}$ at each of five distinct lateral locations across the flume. 


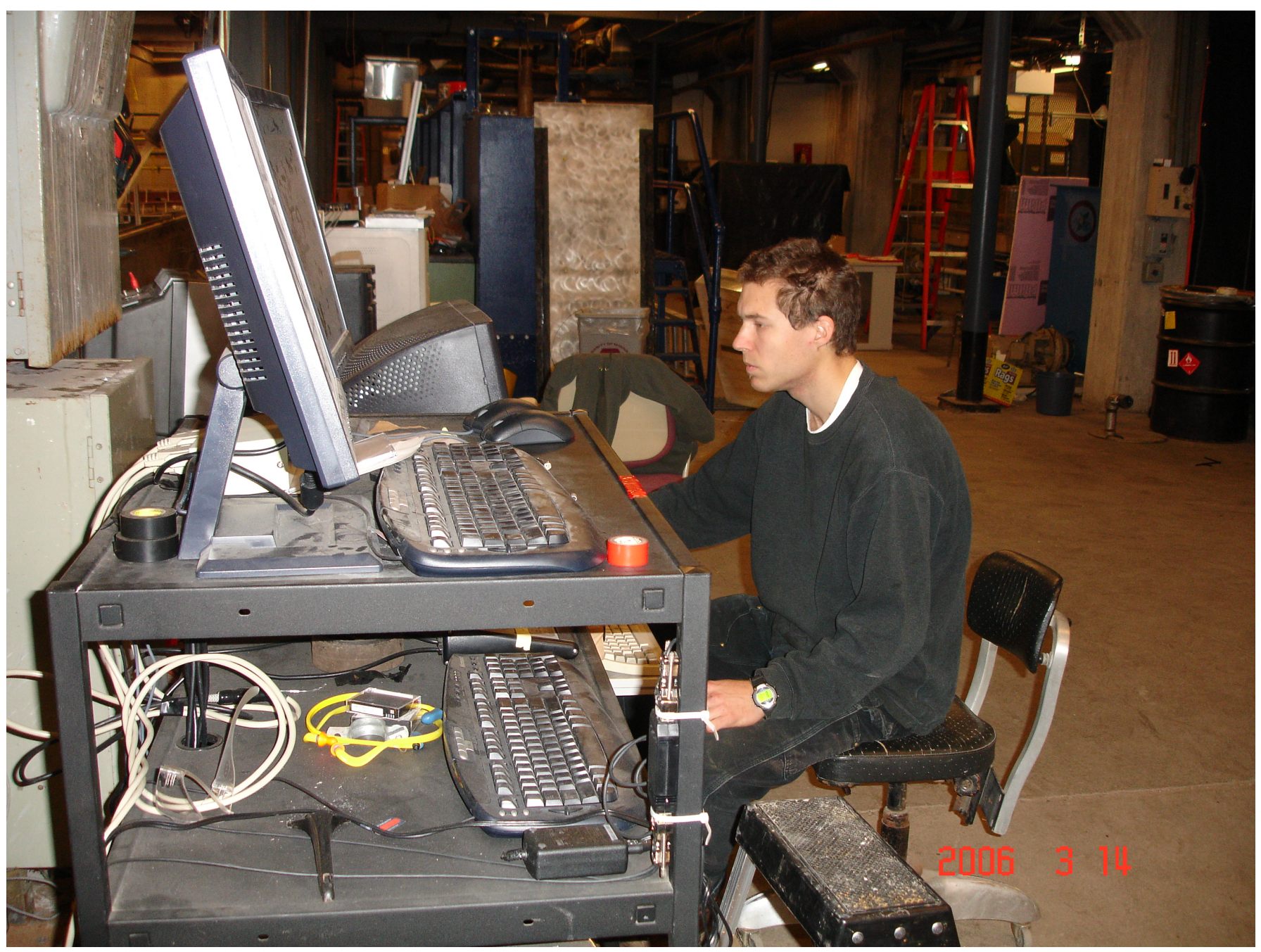

Figure 19. Photograph of the operations controller seated at the main flume sediment-flux monitoring component's central data-acquisition system console.

The first step for post-processing these data is to rectify data recorded during tipping events and to render the dataset to be continuous. An algorithm was developed to identify and correct for the spurious data recorded as part of a tipping event. Based on examination of the data associated with a large number of tipping events, it was determined that no more than eight consecutive mass values recorded in the 8.8-second period following a tipping event are spurious. To estimate mass-accumulation values for these intervals, the algorithm performs a linear regression on the 30 mass-accumulation values leading up to the tipping event. The slope and offset associated with the regression relation are used to estimate mass-force accumulations during the tipping event and to replace the spurious data in that interval with the regression-computed values. Use of the normal accumulation algorithm is continued following the removal of the tipping event. The tipping events were brief compared to the total run time of the experiments (less than 1 percent of data points were associated with tipping events); thus, computational errors introduced by the tipping events and the regression-estimating algorithm are unlikely to be of consequence in the computation of continuous bedload transport at the flume slot. For example, with the drum net weight limit set at $40 \mathrm{~kg}$ and a typical mean full channel submerged flux rate of 0.17 kilogram per second $(\mathrm{kg} / \mathrm{s} ; 0.1-\mathrm{kg}$ dry weight), tips occur on average every 19.5 minutes, and the approximately 9 seconds of lost data per tip accounted for only 0.7 percent of the full dataset. A diagram of a tipping event and the procedure for removing the associated spurious data are shown in figure 20. 


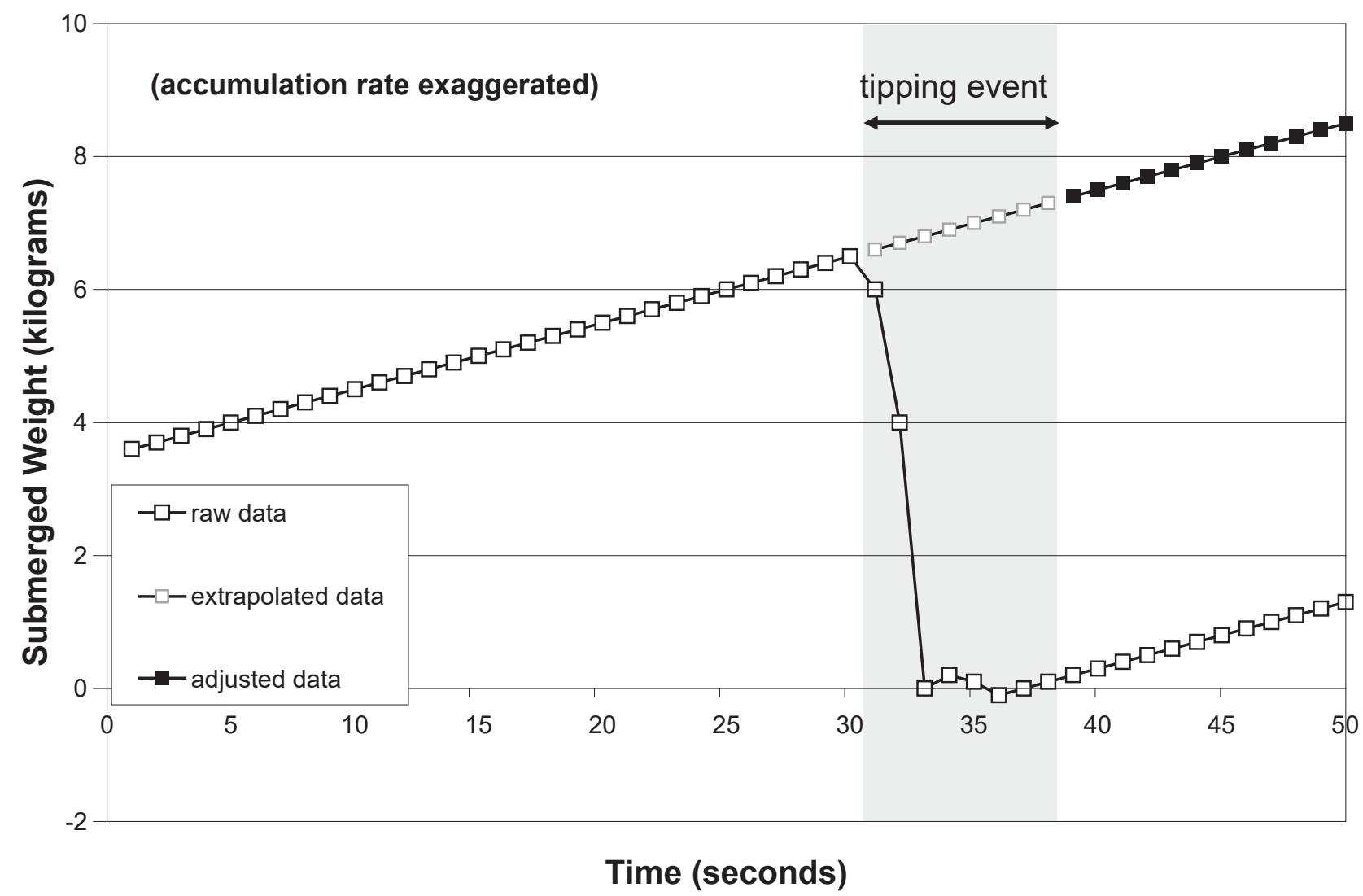

Figure 20. Graph of weigh-drum accumulation data and the removal of spurious data caused by vagaries in weights measured during drum-tipping events (gray area). Note that the accumulation rate is idealized and exaggerated to demonstrate the method for correcting spurious drum-tip data. Modified from Marr and others (2010b, fig. 3).

\section{Sediment-Recirculation Component}

Another feature of the SAFL main flume is its capability to continuously and efficiently recirculate medium-gravel-sized sediments at a rate up to about $20 \mathrm{~kg} / \mathrm{s}$ to a point $55 \mathrm{~m}$ upstream from the SMRS, thus enabling continuous, long-duration bedload-transport research. The system was designed in the early 1980s by the FISP as part of a program for ground-truth testing of several configurations (selected nozzle sizes and ratios of intake-to-outlet nozzle area) of the Helley-Smith (Hubbell and others, 1987).

The recirculation system is capable of entraining and recirculating particles with long-axis diameters of about $76 \mathrm{~mm}$. The recirculation system's intake is in the bed trap beneath the weigh-drum system, where a horizontal auger, driven by a variable-speed motor, spans the full width of the channel (figs. 21 and 22). The rotating auger conveys sediments accumulated from weigh-drum dumps toward an outlet recessed in the right side of the flume and into the recirculation- (dredging-) pump intake. A three-phase, recessed-impeller, centrifugal pump transports the sediments and a small amount of water through a $20-\mathrm{cm}$-diameter steel recirculation pipe at an elevation about $4 \mathrm{~m}$ above the floor of the flume to an upstream location, where the water-sediment mixture is discharged back to the flume (fig. 16). The source of water added to the slurry for the pump's operation - about $0.25 \mathrm{~m}^{3} / \mathrm{s}$ - is from the municipal-water supply and not the Mississippi River. The source of water is important because use of flume water for pump operation would induce a net downward flow of water into the bed trap that could:

1. Potentially result in the suction of sediment into the slot, and

2. Generate a false loading onto the weigh drums, thus potentially resulting in spurious bedload-transport calculations.

The maximum test section length in the main flume is $55 \mathrm{~m}$; however, to minimize the total sediment mass required for the StreamLab06 experiments, the length of the test section during the experiments was shortened to $20 \mathrm{~m}$. The 20-cm-diameter recirculation pipe was extended to approximately $10 \mathrm{~m}$ upstream from the test section (that is, $30 \mathrm{~m}$ upstream from the SRMS). The outlet configuration is shown in figures 15 and 16. Sediments were reintroduced to the channel through a recirculation pipe outlet that was aligned longitudinally along the centerline of the channel bottom with the outlet oriented downstream. 


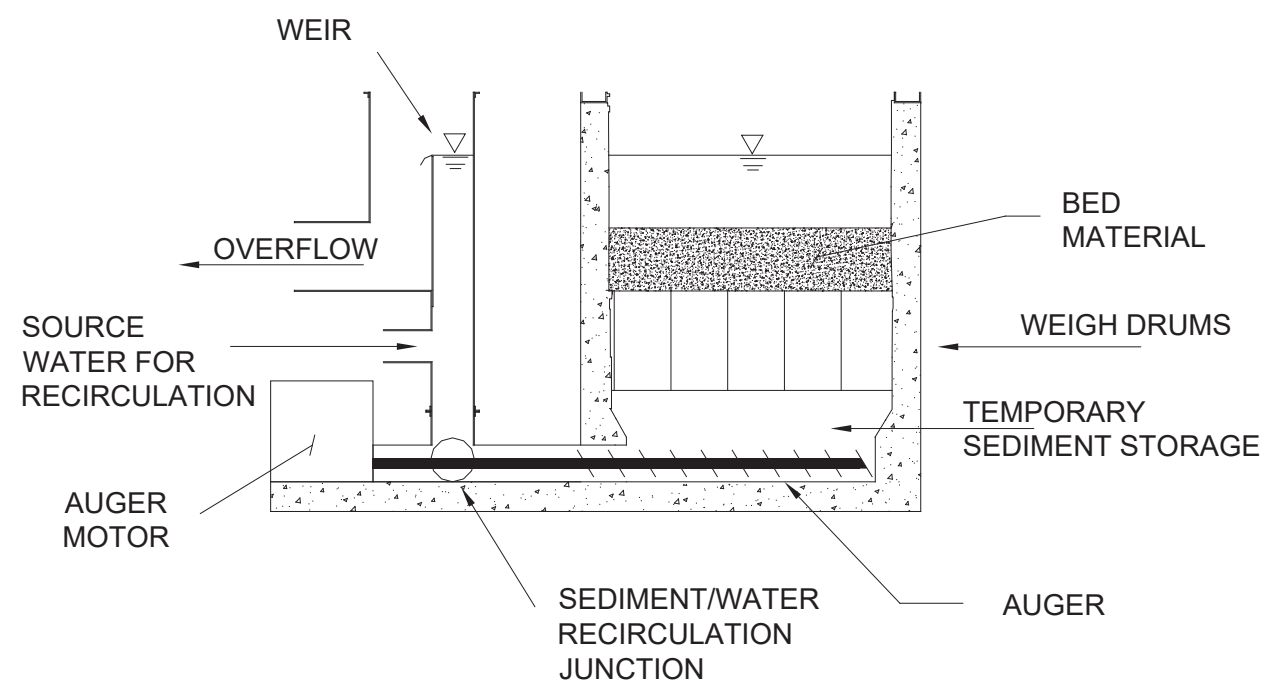

Figure 21. Cross-section schematic (not to scale) of the Sediment Monitoring and Recirculation System's sediment-removal apparatus. View is upstream. Modified from Marr and others (2010b, fig. 4).

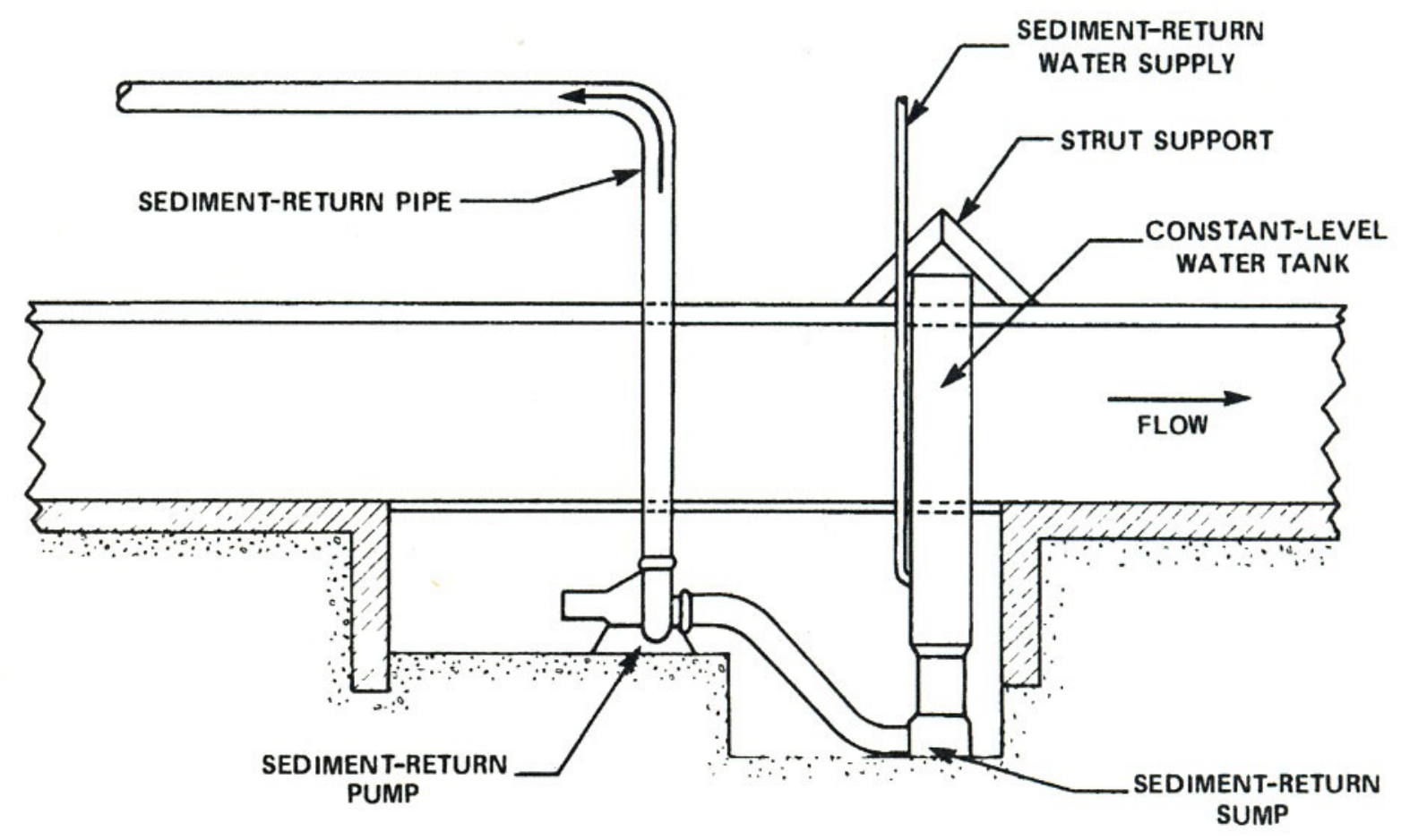

Figure 22. Right-side view schematic (not to scale) of the Sediment Monitoring and Recirculation System. From Hubbell and others (1987). 
A submerged 0.3-m-high knee wall weir located $1 \mathrm{~m}$ downstream from the outlet pipe across the width of the channel was designed to dissipate the large water and sediment velocities exiting the recirculation pipe. Based on bathymetric surveys, asymmetries in bed configuration in the 3 - to $5-\mathrm{m}$ reach of the flume downstream from the knee wall were attributable to water and sediment discharges from the return pipe. The bedload samplers were deployed about $20.5 \mathrm{~m}$ downstream from the knee wall.

\section{Supporting and Ancillary Instruments}

In addition to data obtained continuously by the SMRS, several other types of measurements were made during the experiments. Details on the specific instrumentation and data-collection techniques used in the experiments are given below.

- Water Temperatures-Water temperatures were continuously recorded at the SRMS using a Yellow Springs Instruments thermistor that has a measurement accuracy of \pm 0.1 degrees Celsius $\left({ }^{\circ} \mathrm{C}\right)$. The thermistor was mounted on the right SRMS pier (near the right-most weigh-drum 5) at the bottom of the channel.

- Water-Surface Elevations (Stage) - The downstream tailwater surface was continuously measured using a sonic range finder, Model M5000/220 manufactured by Massa Products Corporation. The sensor was located $6 \mathrm{~m}$ upstream from the flume tailwater sharp-crested weir and has a measurement accuracy of $0.5 \mathrm{~mm}$.

- Water Discharges-Discharges were computed by the CDAQ software using a calibrated sharp-crested weir equation, stage data, and weir-crest elevation data. Stage was monitored by a potentiometer connected to a float by way of a wheel and tape. The measured discharge was the total flow passing the bed trap and included the water supplied through the flume's vertical entrance tunnel and the water supplied through the recirculation system.

- Bottom Tracking Sonar-During most of the experimental runs, temporal point measurements of bed elevation were obtained at seven locations using a down-looking submersible pulse-echo sonar system. Five of the transducers were located $1 \mathrm{~m}$ upstream from the centerline of each of the five weigh drums. The other two transducers were located near the flume centerline at 8 and $13 \mathrm{~m}$ upstream from the weigh drums. Data from these probes were used to determine bed elevation under each probe. One data point for each probe was recorded to an ASCII output data file every 10 seconds. The location of the seven bottom-tracking sonar probes is shown in figure 16 and tabulated in table 1 .
- Water and Bed Slopes-Mean water-surface slope was calculated by measuring the water-surface elevation at two locations upstream from the weigh drums and dividing the difference in elevation by the distance between the measuring points. Water-surface slope measurements were made manually with point gages (Rickly Hydrological Company, accuracy of $+/-0.1 \mathrm{~mm}$ ) referenced to a common datum. Bed slope was similarly calculated by measuring the difference in bed elevation at zero flow and two locations within the test section and dividing by their separation distance. Bed elevation measurements were obtained using staff rods (accuracy of $+/-1 \mathrm{~mm}$ ). In addition, bed slope was computed from the $0.1-\mathrm{Hz}$ bed elevation time-series data recorded by the submersible bed-sonar system.

\section{Pressure-Difference Bedload-Sampler Trapping Efficiency Tests}

Pressure-difference-type bedload samplers were deployed as part of the StreamLab06 experiments during episodic, steady flows in the main flume between January 31 and March 28, 2006. The research involved ground-truth testing of physical bedload samplers over a range of flow and transport conditions and two compositions of bed material.

The experiments involved manipulations of the main flume bed compositions and flow rates, coupled with separate deployments of the four bedload samplers. A number of researchers participated in the bedload-sampler deployments; the researchers and their affiliations are listed in appendix 1.

Table 1. Location of submersible sonar probes in the main flume.

[See figure 16 for schematic of the main flume. Note that distances are measured from the upstream limit of the test section and the left wall of the flume. Abbreviation: m, meters. From Marr and others (2010b)]

\begin{tabular}{lcc}
\hline Transducer & $\begin{array}{c}\text { Longitudinal position } \\
(\mathbf{m})\end{array}$ & $\begin{array}{c}\text { Lateral position } \\
(\mathbf{m})\end{array}$ \\
\hline Sonar 1 & 18.98 & 2.615 \\
Sonar 2 & 18.98 & 2.075 \\
Sonar 3 & 18.98 & 1.635 \\
Sonar 4 & 18.98 & 1.005 \\
Sonar 5 & 18.98 & 0.475 \\
Sonar 6 & 12.00 & 1.410 \\
Sonar 7 & 7.00 & 1.500 \\
\hline
\end{tabular}




\section{Experimental Conditions}

The StreamLab06 bedload-sampler trapping-efficiency trials were composed of a total of 13 runs; however, bedload-sampler trapping-efficiency trials were conducted during nine of the runs (combinations of the main flume flows of different magnitudes over a sand or gravel bed) (table 2). Phase I of the StreamLab06 trials (January 31-February 9, 2006) involved five steady flows of different magnitudes over a sand bed. Phase II (March 11-28, 2006) involved four steady flows over a gravel bed.

The sand introduced to the main flume for the Phase I tests consisted of well-sorted siliceous material ranging from 0.6 to $1.8 \mathrm{~mm}(\mathrm{~d} 50=1.0 \mathrm{~mm})$ in diameter. Upon completion of the Phase I tests, the sand was removed and replaced with a comparatively broad distribution of mostly gravel-size material $(1-32 \mathrm{~mm}$; $\mathrm{d} 50=11.2 \mathrm{~mm})$ for the Phase II tests (Marr and others, 2010b). The sieved grain-size distributions for the sand-bed and gravel-bed materials are shown in figure 23.

Figure 24 shows the main flume in three periods: Left to right, after flow ceased over a sand bed before March 2006; On March 11, 2006, during a Phase II flow of $5.5 \mathrm{~m}^{3} / \mathrm{s}$ over a gravel bed; and during zero flow on March 10, 2006, before the bedload samplers were deployed in the gravel-bedded flume.

For each new discharge and for a shorter period of time at the beginning of each sampling session, it was necessary to operate the flume and recirculation system to establish a dynamic bed equilibration. Achievement of dynamic equilibrium in bedload-transport rates was inferred by observing stabilization of the computed 60 -minute mean sediment-flux rates. The 60 -minute mean bedload-rate value was continuously computed and displayed by the CDAQ software.

\section{Pressure-Difference Bedload Samplers Used in the Tests}

Data for calculating the trapping efficiency of the Helley-Smith bedload sampler and three other manually deployed samplers of the Helley-Smith (pressure-difference) type, all of which operate on the pressure-difference principle, were collected as part of Phases I and II of the StreamLab06 tests (fig. 10, table 3). The hydraulic efficiency of a given sampler is determined by a number of factors, including the sampler's expansion ratio, its entrance nozzle size, the ambient flow velocity in the vicinity of the sampler, the bag mesh size, the percentage that the collection bag is filled, and the presence of particles (inorganic or organic) of the same or larger size as that of the mesh sieve openings that might clog the bag. Druffel and others (1976) determined that filling the sampler bag less than about 40 percent had no measurable effect on the hydraulic efficiency of the six variations of the Helley-Smith sampler that they tested. The bedload samplers used in StreamLab06 experiments had hydraulic efficiencies ranging from 1.35 to 1.54 (Hubbell and others, 1987).

Table 2. Summary of main flume experimental conditions as part of StreamLab06 bedload-sampler trapping-efficiency tests.

[Table column headers (variables) explained-Qw, design: design water discharge for the run; Bed composition: bed material type; Time, total: total duration of time at the design discharge including equilibration period; Time, eq: total duration of time at equilibrium bed condition; Temp, mean: mean water temperature; Qw, mean: mean water discharge; qs, mean: mean sediment transport rate computed over total duration; qs-equil, mean: mean sediment transport rate computed for period after equilibration was reached. Abbreviations: gm, grams; hr, hours; $\mathrm{m}^{3}$, cubic meters; ${ }^{\circ} \mathrm{C}$, degrees Celsius; m, meters; ND, not determined; s, seconds]

\begin{tabular}{|c|c|c|c|c|c|c|c|}
\hline $\begin{array}{c}\text { Ow, design } \\
\left(\mathrm{m}^{3} / \mathrm{s}\right)\end{array}$ & $\begin{array}{c}\text { Bed } \\
\text { composition }\end{array}$ & $\begin{array}{l}\text { Time, total } \\
\text { (hr) }\end{array}$ & $\begin{array}{c}\text { Time, eq } \\
\text { (hr) }\end{array}$ & $\begin{array}{c}\text { Temp, mean } \\
\left({ }^{\circ} \mathrm{C}\right)\end{array}$ & $\begin{array}{c}\text { Ow, mean } \\
\left(\mathrm{m}^{3} / \mathrm{s}\right)\end{array}$ & $\begin{array}{c}q s, \text { mean }^{1} \\
(\mathrm{gm} /(\mathrm{m} \times \mathrm{s})-\mathrm{dry})\end{array}$ & $\begin{array}{l}\text { qs-equil, mean } \\
\text { (gm/(m×s)-dry) }\end{array}$ \\
\hline 2.0 & sand & 12.3 & 11.7 & 0.4 & 2.02 & 13 & 13 \\
\hline 2.5 & sand & 15.8 & 14.2 & 0.5 & 2.7 & 45 & 47 \\
\hline 2.9 & sand & 34.3 & 22.3 & 2.3 & 2.95 & 77 & 77 \\
\hline 3.2 & sand & 8.5 & ND & 0.6 & 3.20 & 126 & ND \\
\hline 3.6 & sand & 11.6 & 10.3 & 1.0 & 3.69 & 180 & 176 \\
\hline 4.0 & gravel & 56.0 & 43.0 & 2.2 & 4.01 & 3 & 2 \\
\hline 4.3 & gravel & 36.3 & 13.0 & 3.5 & 4.32 & 11 & 15 \\
\hline 4.9 & gravel & 33.9 & 24.2 & 4.7 & 4.90 & 161 & 168 \\
\hline 5.5 & gravel & 29.0 & 28.2 & 2.7 & 5.51 & 785 & 782 \\
\hline
\end{tabular}

${ }^{1}$ The variable "qs, mean" is computed using a 90-second moving-average window. 


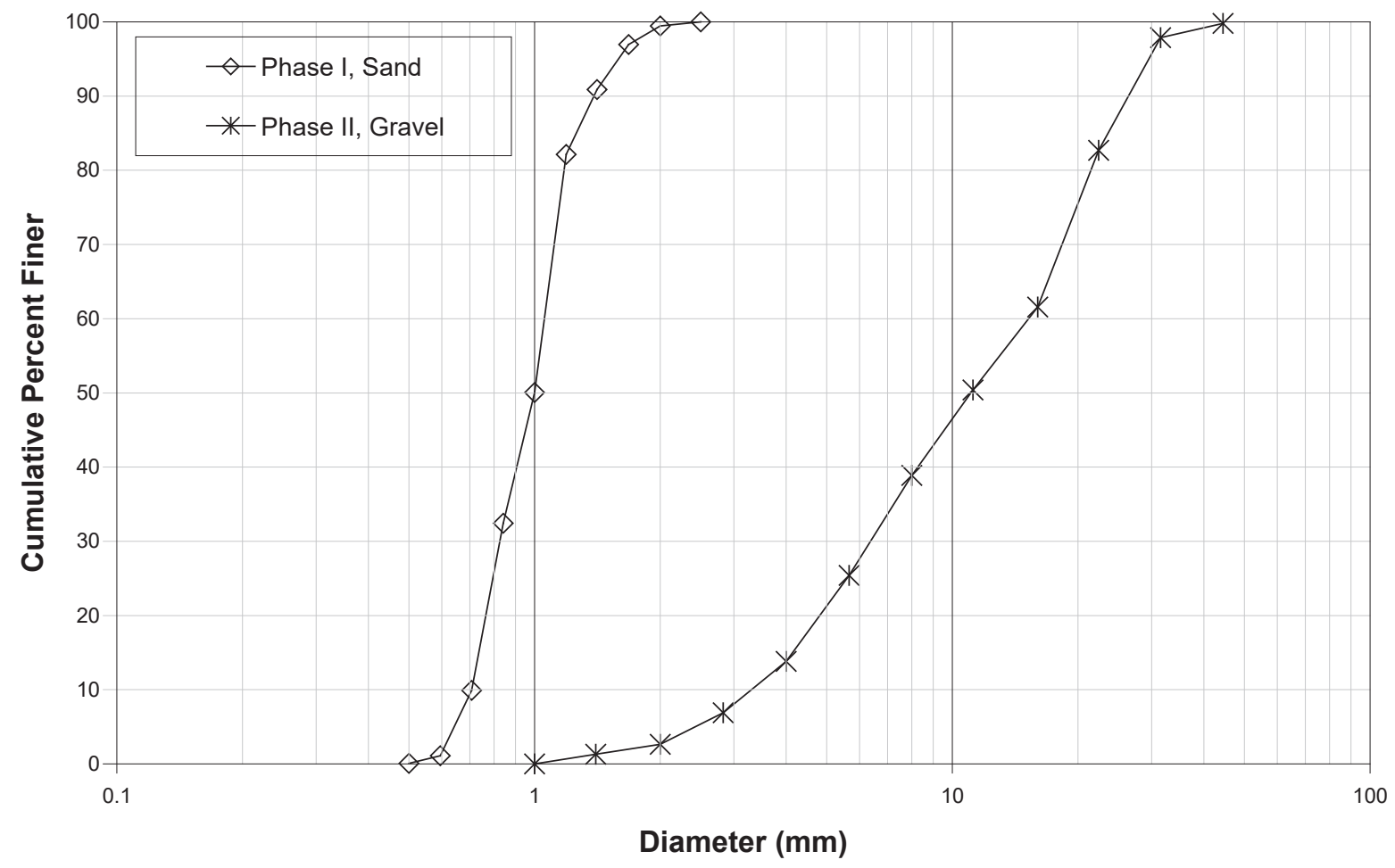

Figure 23. Graph showing the results of the sieved grain-size distributions of the original sand- and gravel-bed materials used in StreamLab06 Phase I and II tests, respectively. Abbreviation: mm, millimeter. From Marr and others (2010, fig. 6).
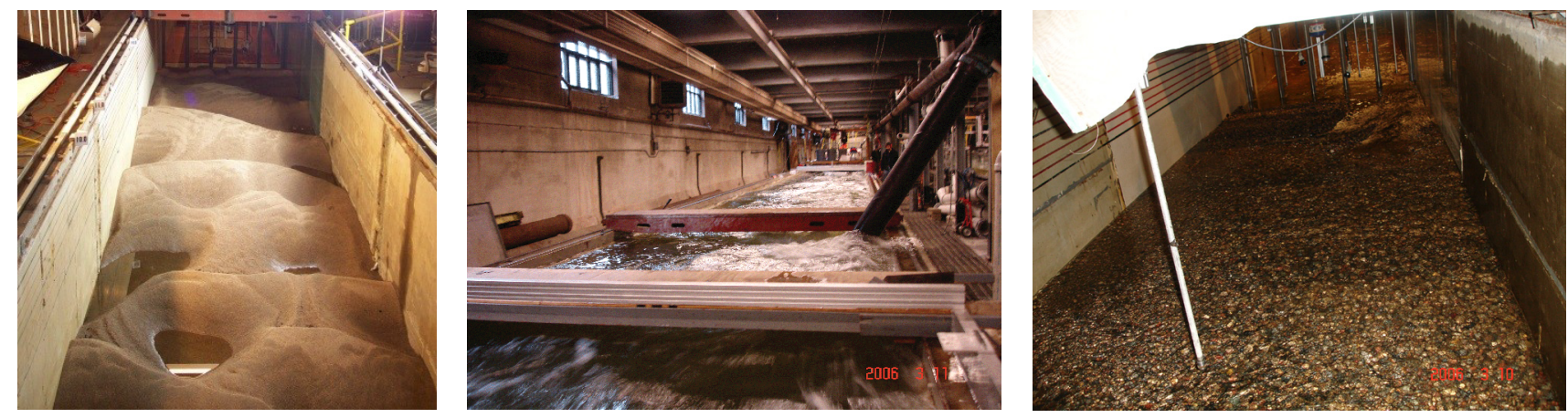

Figure 24. Photographs of three downstream views of the St. Anthony Falls Laboratory main flume. Left, after flow ceased over a sand bed in January or February 2006. Middle, on March 11, 2006, during a Phase II flow of 5.5 cubic meters per second $\left(\mathrm{m}^{3} / \mathrm{s}\right)$ over a gravel bed. Right, during zero flow on March 10, 2006, before the bedload samplers were deployed in the gravel-bedded flume. 
Table 3. Selected characteristics of bedload samplers used in the StreamLab06 Phase I and II tests, and the median bed-material grain size (in millimeters [mm]) in which each bedload sampler was deployed.

[See figure 10 for photograph of bedload samplers. "d50 = 11.2" means 50 percent of the bed composition by mass is smaller than $11.2 \mathrm{~mm}$ and 50 percent of the bed composition by mass is larger than $11.2 \mathrm{~mm}$; and "d50 = 1.0 " means 50 percent of the bed composition by mass is smaller than $1.0 \mathrm{~mm}$ and 50 percent of the bed composition by mass is larger than $1.0 \mathrm{~mm}$ ]

\begin{tabular}{lcccc}
\hline \multicolumn{1}{c}{ Sampler type } & $\begin{array}{c}\text { Nozzle } \\
\text { dimensions; } \\
\text { width }(\mathbf{m m}) \mathbf{x} \\
\text { height }(\mathbf{m m})\end{array}$ & $\begin{array}{c}\text { Nozzle } \\
\text { outlet-to-inlet } \\
\text { area ratio }\end{array}$ & $\begin{array}{c}\text { Bag mesh } \\
\text { size } \\
(\mathbf{m m})\end{array}$ & $\begin{array}{c}\text { Bed composition } \\
(\mathbf{m m})\end{array}$ \\
\hline Toutle River 2 (TR-2) & $305 \times 152$ & 1.4 & 0.5 & Gravel, d50=11.2 \\
Elwha & $203 \times 102$ & 1.4 & 0.5 & Gravel, d50=11.2 \\
US BLH-84 & $76.2 \times 76.2$ & 1.4 & 0.25 & Sand, d50 =1.0 \\
& & & & Gravel, d50 $=11.2$ \\
Helley-Smith & $76.2 \times 76.2$ & 3.22 & 0.25 & Sand, d50 $=1.0$ \\
& & & & Gravel, d50 $=11.2$ \\
\hline
\end{tabular}

Large bedload sampler flare ratios tend to be associated with large hydraulic efficiencies; however, a bedloadsampler's hydraulic efficiency is relevant only as its influence on its trapping efficiency, the derivation of which was the focus of these tests. Generally, larger hydraulic efficiencies occur concomitant with increases in sedimentological efficiencies under supply-unlimited conditions.

\section{Bedload-Sample Collection}

A single bedload sampler was deployed manually by using a hand-held rod (fig. 10) for a given trial. The key element of a hand-held rod versus its similarly designated cable-deployed bedload sampler - the nozzle - is the same for both samplers. The hand-deployed version was composed of a sampler nozzle with a bag affixed to the outlet; a horizontal, narrow-diameter rod extending from and affixed to a connector at the top of the nozzle and the trailing end of the bag; and a rod extending upward from the top of the nozzle to manually deploy the sampler. The deployment rod was graduated in decimeters indexed to the base of the sampler to enable the visual measurement of water depth when the sampler rested on the bed.

Each deployed sampler was connected by a tether line of several meters length that extended from the base of the rod to an upstream ceiling structural beam. The tether line served to stabilize the sampler in the measuring section and ensure a consistent longitudinal location in the measurement cross-section.

The pressure-difference bedload samplers were deployed in a cross-section $8.5 \mathrm{~m}$ upstream from the weigh drums in one or more of five lateral cross-sectional locations ("sections"): $0.27,0.82,1.37,1.92$, and $2.47 \mathrm{~m}$ from the left flume wall; that is, centered at locations directly upstream from the center of each weigh drum (fig. 25). The majority of bedload samples were repeatedly collected "at-a-point" from sections 0.82 or 1.92 . The BLH- 84 was sequentially deployed during some later runs at all five sections using the multiple-equal-width-increment method (Edwards and Glysson, 1999) to identify potential cross-section skew in bedload-transport rates.

Sections $0.27,0.82,1.37,1.92$, and 2.47 were selected for at-a-point sampling for the following reasons:

1. Use of the Thomas-Lewis (Thomas and Lewis, 1993) model required single at-a-point sample sets.

2. The Hubbell and others (1987) bedload-transport data included a large number of at-a-point sample sets, and some value was presumed to be gained from consistency with previous bedload-sampler calibrations in this main flume.

3. Based on an unpublished project summary (Dave Hubbell, U.S. Geological Survey, written commun., early 1980s), the apparent side-wall effect produced minima bedload-transport rates averaged for test runs in the exterior drums and maxima in the interior drums (fig. 26).

In 2006, bedload-sampler deployments in sections 0.82 or 1.92 were hypothesized to have minimum potential sidewall drag effects on bedload-transport rates. Additionally, the center section was considered most likely to exhibit the highest mean transport rate. Neither potential condition was desired for the bedload-sampler tests. Thus, all at-a-point sequential bedload samples (as opposed to cross-section samples) were collected at 0.82 or $1.92 \mathrm{~m}$ from a sidewall. 


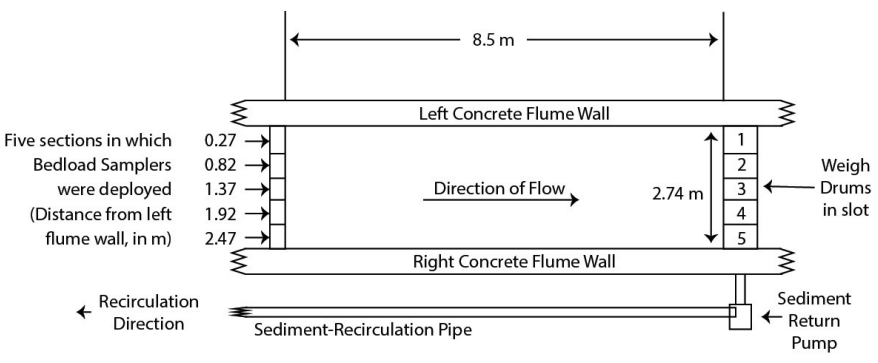

Figure 25. A plan-view schematic of the section of the main flume showing the cross-section in which the pressure-difference bedload samplers were manually deployed to the weigh drums within the cross-channel slot. The schematic is approximately to scale. Abbreviation: $m$, meters.

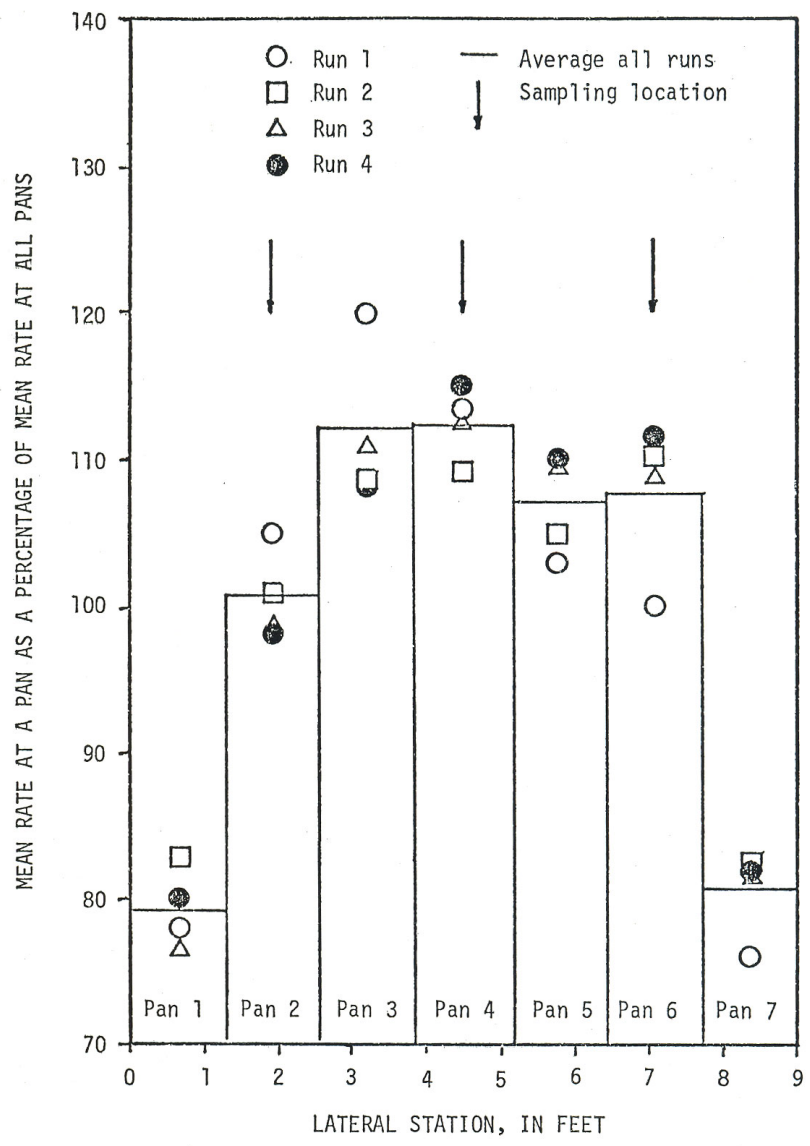

Figure 26. Mean lateral distribution of mean transport rate in the seven main flume weigh drums (David Hubbell, U.S. Geological Survey, p. 17 of an unpublished project summary, written commun., early 1980s) shown in the original English units.
Each trial involved repeatedly deploying a given bedload sampler to remain stationary on the bed for one of the following durations: $15,30,45,60,90,120$ or 180 seconds (seven of the 2,030 discrete bedload sampler deployments added no more than six seconds to the selected deployment duration). The duration that the sampler rested on the bed was, with some exceptions, constant for a given trial, and was selected to minimize the potential for the volume of trapped bedload to exceed about half of the mesh bag's capacity.

A crew of 2 to 3 hydrographers collaborated to deploy, retrieve, and empty the sampler, and subsequently weighed each of the sand-bedload samples during a given trial by a wet-weigh method described by Carey (1984) (fig. 27). Gravel samples were dry- or moist-weighed on a floor-mounted scale.

One hydrographer deployed the bedload sampler from a platform spanning the flume. Each successive deployment included setting the sampler on the bed, measuring the water depth on the graduated-sampler rod, and, on cue from a second flume-side hydrographer after a pre-determined duration on the bed, retrieving the sampler.

The retrieved sampler was transferred in a nozzle-up orientation to the flume-side hydrographer, with the deployment hydrographer retaining a firm grip on the deployment rod. A bag was placed over the nozzle, the rod was rotated to a nozzle-down orientation, and the contents of the mesh bag and residual material in the sampler nozzle were dumped into the sample bag. Each sample bag was labeled with the information relevant to that single bedload sample that it contained. Figure 27 shows photographs of the bedload-sampler deployment-and-emptying sequence.

The wet-weighing process involved suspending the bagged samples from a hanging scale and submerging the sample bag into a bucket of river water, taking care to ensure that no air remained trapped in the bag. The submerged mass was recorded in an Excel spreadsheet, and the dry mass of the trapped bedload was calculated according to equation 1 :

$$
W_{d s}=\frac{S G_{s}}{S G_{s}-1} \times W_{s s}
$$

where

$W_{d s} \quad$ is the dry mass of bedload trapped by the pressure-difference bedload sampler, in grams,

$W_{s s} \quad$ is the submerged (wet) mass measured by the scale, in grams, and

$S G_{s} \quad$ is the mean specific gravity of the sediment material (for example, 2.65 for quartz). 

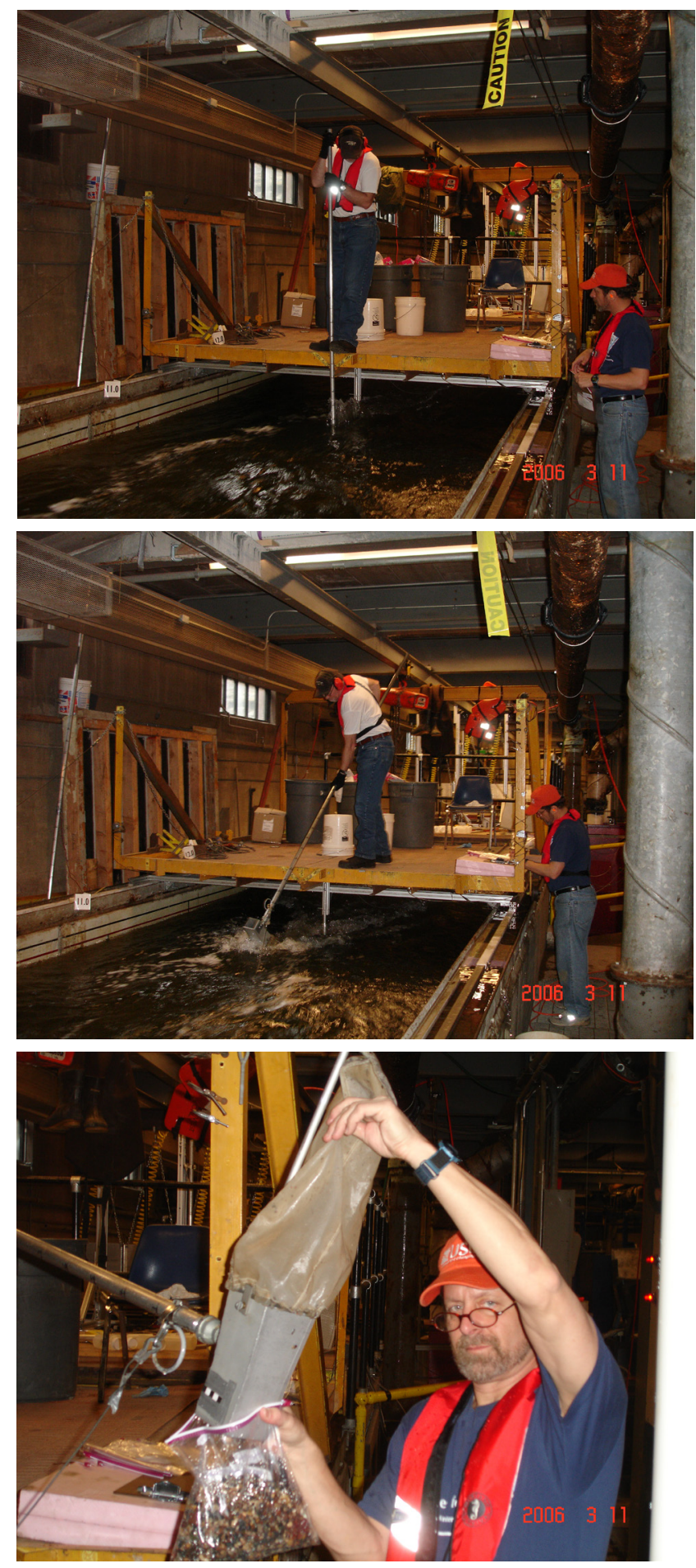

Figure 27. Photographs showing the sequence of deploying a bedload sampler in the gravel-bedded main flume, St. Anthony Falls Laboratory, March 6, 2006. Top, a hydrographer holds a graduated rod affixed to a BLH-84 sampler resting on the bed of the main flume; the rod is held 0.82 meter from the left wall and 8.5 meters upstream from the weigh-drum slot. Center, after recording the water depth, the BLH-84 is retrieved from the bed after a pre-determined duration on the bed. Bottom, a hydrographer empties the contents of the BLH-84 bag for weighing.
Samples were subsequently stored, and some eventually dried and sieved to derive grain-size distribution statistics (all samples have since been discarded). Several samples that had been wet-weighed were oven-dried to compare the actual dry weight to the computed dry weight from the wet-weigh process. Dry-weight comparisons to same-sample values computed by equation 1 confirmed the applicability of the wet-weighing system.

The dry mass of a captured bedload was used with ancillary data to compute the bedload-transport rate by equation 2 :

$$
\mathrm{BL}_{\mathrm{q}}=W_{d s} /\left(\left(\mathrm{W}_{\text {sampler }}\right) \times\left(\mathrm{T}_{\text {on bed }}\right)\right)
$$

where

$$
\begin{gathered}
\mathrm{BL}_{\mathrm{q}} \quad \begin{array}{c}
\text { is the transport rate measured by the bedload } \\
\text { sampler, in grams per meter per second, }
\end{array} \\
W_{d s} \quad \begin{array}{c}
\text { is the dry mass of bedload trapped by the } \\
\text { pressure-difference bedload sampler, } \\
\text { in grams, }
\end{array} \\
\mathrm{W}_{\text {sampler }} \quad \begin{array}{l}
\text { is the width of the bedload sampler, in } \\
\text { meters, and }
\end{array} \\
\mathrm{T}_{\text {on bed }} \quad \begin{array}{l}
\text { is the duration that the sampler rested on the } \\
\text { bed, in seconds. }
\end{array}
\end{gathered}
$$

\section{Suspended-Sediment Sample Collection}

Depth-integrated suspended-sediment samples were collected isokinetically upstream and downstream from the weigh drums before and after several of the bedload-sampler deployment runs to determine whether sand-size sediments were being introduced from the Mississippi River or if any sand-size material was bypassing the bed trap either as suspended sediment or as saltating bedload (the latter of which was of particular concern during the sand-bed experiments). A rod-deployed DH-48 suspended-sediment sampler (Edwards and Glysson, 1999; Davis, 2005; Gray and others, 2008; Gray and Landers, 2014, 2015) was used to collect the water-sediment samples. The USGS Cascade Volcano Observatory Sediment Laboratory analyzed the samples for suspended-sediment concentrations and, in some cases, the percentage of sand ( $>0.062 \mathrm{~mm}$ ) in the sample (Guy, 1969; ASTM International, 2000). 


\section{Bedload and Ancillary Data}

The primary goal of the StreamLab06 Phase I and II bedload experiments was to identify the trapping efficiencies of each of four types of pressure-difference bedload samplers deployed over sand and gravel beds, and to compare those efficiencies among the tested bedload samplers. To this end, data were manually collected with the pressure-difference samplers, and ground-truth bedload measurements were made by the main flume automated Sediment Monitoring and Recirculation System (SMRS).

Bedload-transport data automatically collected from the main flume and ancillary data are available through the:

- St. Anthony Falls Laboratory NCED Data Repository (https://repository.nced.umn.edu/) under the heading "St. Anthony Falls Lab/Streamlab 2006," and

- USGS data release (Groten and Gray, 2021).

Manually collected bedload-transport and ancillary data are also available in the USGS data release (Groten and Gray, 2021).

The following sections describe the types of the bedload and ancillary data produced as part of Phases I and II of the StreamLab06 experiments.

\section{Bedload Accumulation, Flux, and Ancillary Data Measured by the Sediment-Monitoring and Recirculation System}

The bedload time-series flux data automatically measured and stored for each of the five weigh drums - and the average values of the data - are available for use in developing trapping-efficiency values in conjunction with the data produced by the pressure-difference bedload samplers.

In the "Streamlab 2006" directory within the "Metadata/" folder is a spreadsheet, "StreamLab Metadata.xls." The spreadsheet describes the experimental conditions, data collected, and file names for those data collected during the experiments. This folder includes a comprehensive report, "StreamLab06_FinalReport.docx," which is also archived at the University of Minnesota digital conservancy (http://purl.umn.edu/144023) that provides details on the experimental setting and the instrumentation used in these experiments.

Per USGS data-storage requirements, the weigh-drum data - which were not collected by any USGS-approved technique or stored consistent with USGS data-archiving protocols - were duplicated and are available in a USGS data release (Groten and Gray, 2021).

A number of methods can be used to compute bedload fluxes from the accumulation data. The most appropriate method depends on the time scale of fluxes sought by the user. For this reason, only the most basic form of the data, weight accumulation in each weigh drum, is provided by the
SAFL, and researchers are free to choose their own method of computing bedload flux. SAFL also provides flux data for each weigh drum and the mean flux value for all weigh drums corrected for weigh-drum tipping events using the method described below.

Sediment flux was computed by:

1. Computationally filtering the equivalent dry sediment accumulation data with a 90 -second moving average window, and

2. Computing flux by subtracting filtered weights lagged in time and dividing by the lag time (90 seconds) (eq. 3).

Qs $(t)=\frac{\text { accumulation }}{\text { time }}=\frac{\frac{1}{n} \sum_{i=t}^{t+n} \text { weight }(i)-\frac{1}{n} \sum_{i=t-n}^{t} \text { weight }(i)}{n}$

where

$$
\begin{gathered}
\text { Qs }(t) \quad \text { is the sediment discharge for a given time } \\
\text { interval, and } \\
\text { is the selected averaging window size and } \\
\text { differencing period (typically } 90 \text { seconds). }
\end{gathered}
$$

Appendix 2 is a series of temporal plots depicting bedload-transport, water-discharge, and ancillary information for each run. Spurious data caused by vagaries in weight measurements during drum-tipping events have been replaced by smoothed data in the temporal plots in appendix 2 .

\section{Bedload Flux and Ancillary Data Measured by Pressure-Difference Bedload Samplers}

Bedload-transport rates and associated ancillary data associated with each bedload sample are available through the USGS data release (Groten and Gray, 2021). Summary statistics related to each bedload sampler sand-bed trial are provided in table 4.

Particle-size distributions were performed on 145 of the gravel-bedload samples collected from the pressure-difference samplers (Groten and Gray, 2021). Median diameters of clasts were calculated for size percentiles from the samples as were percentages of the bedload-mass collected for half -phi sieve sizes. A table listing statistics associated with each of the gravel-bedload sample analyzed for size distribution is available in Groten and Gray (2021). Summary statistics related to each bedload sampler gravel-bed trial are provided in table 5.

Suspended-sediment samples collected with the DH-48 suspended-sediment sampler upstream and downstream from the weigh-drum slot were analyzed for concentrations and in some cases, the percentage of sand in the samples. A table listing concentrations and percentages of sand versus fine material in the suspended-sediment samples is available in Groten and Gray (2021). 
Table 4. Summary statistics for bedload-sampler trapping-efficiency trials in flows over a sand bed (d50=1.0 millimeter) during Phase I of the StreamLab06 experiments, January 31 through February 9, 2006.

[The pressure-difference bedload samplers were deployed at one or more of five selected points in a cross-section 8.5 meters upstream from the weigh-drum slot spanning the 2.74-meter-wide main channel flume. Backslash (/) when used in the 11th column shows the most common duration on the bed (first number), next most common duration on the bed (second number), and least most common duration on the bed (last number). Abbreviations: ID, identification number; $\mathrm{m}^{3}$, cubic meters; s, seconds; temp., temperature; m, meters; v, velocity; g, a constant for the acceleration of gravity; d, depth; No., number; ${ }^{\circ} \mathrm{C}$, degrees Celsius; $\mathrm{kg}$, kilograms; m, meters; $\mathrm{s}$, seconds; varies, sampler location varied in the flume during the trial]

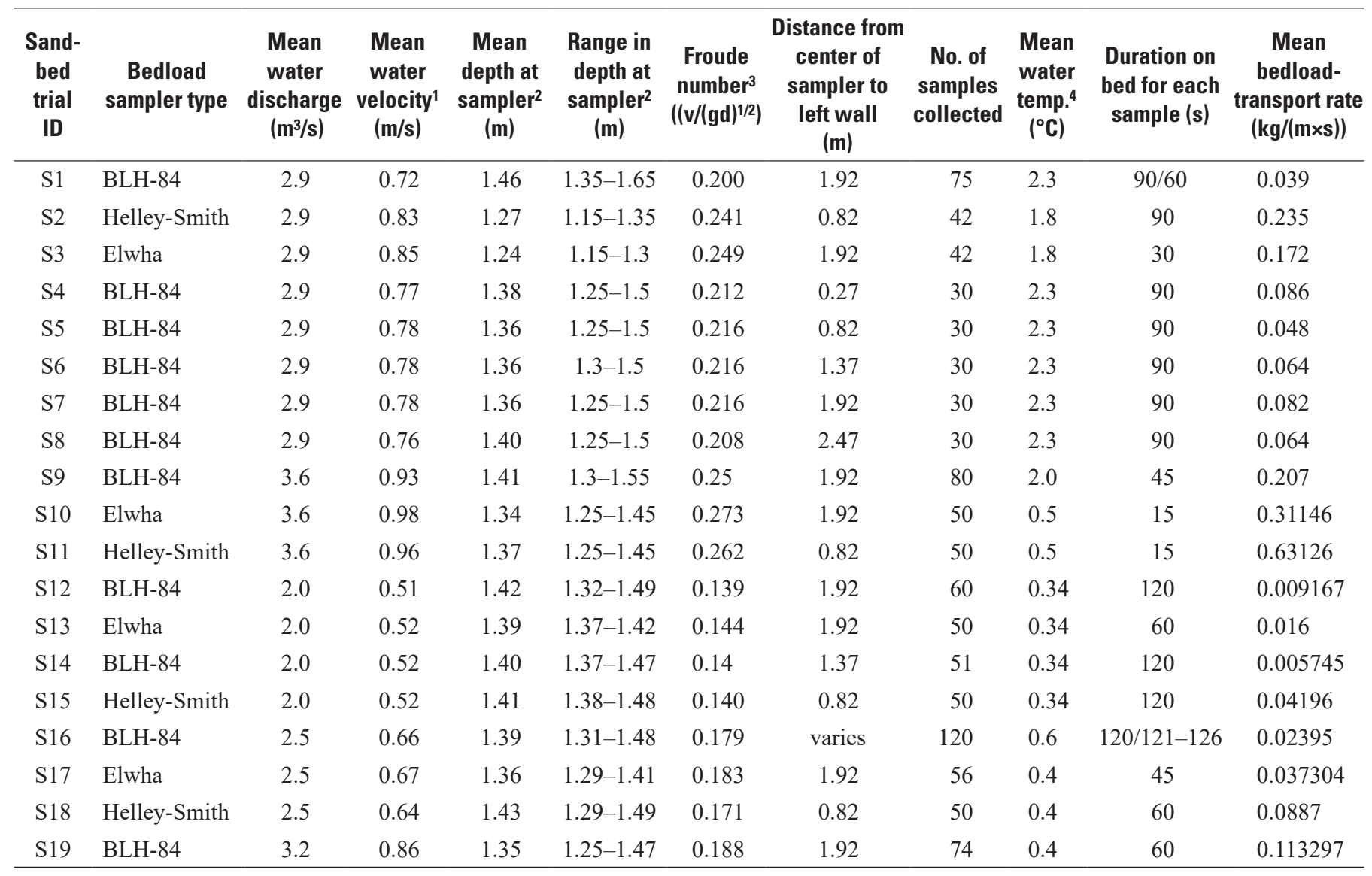

${ }^{1}$ Mean velocity computed as a product of the 2.74 -m-wide flume and the mean value of depths measured at the sampling vertical(s) and divided by the water discharge during a bedload-sampler trial.

${ }^{2}$ Depth from bottom of the bedload sampler resting on the bed to the water surface as indicated on the graduated deployment rod.

${ }^{3}$ Froude number equals mean flow velocity divided by the square root of the product of the acceleration of gravity and mean depth of flow.

${ }^{4}$ Water temperatures over the duration of a trial rarely varied more than $0.2^{\circ} \mathrm{C}$ from the mean value, and never varied by more than $0.5^{\circ} \mathrm{C}$. 
Table 5. Summary of bedload-sampler trials during runs over a gravel bed ( $d_{50}=11.2$ millimeters) during Phase II of the StreamLab06 experiments, March 11 through March 28, 2006.

[The pressure-difference bedload samplers were deployed at selected points in a cross-section 8.5 meters upstream from the 2.74-meter-wide main channel flume weigh-drum slot. Backslash (/) when used in the 11th column shows the most common duration on the bed (first number), next most common duration on the bed (second number), and least most common duration on the bed (last number). Abbreviations: ID, identification number; $\mathrm{m}^{3}$, cubic meters; $\mathrm{s}$, seconds; m, meters; temp., temperature; v, velocity; g, gravity; d, depth; No., number; ${ }^{\circ} \mathrm{C}$, degrees Celsius; kg, kilogram; m, meters; s, seconds; cross-section, multiple samples collected from the cross-section of the flume; varies, sampler location varied in the flume during the trial]

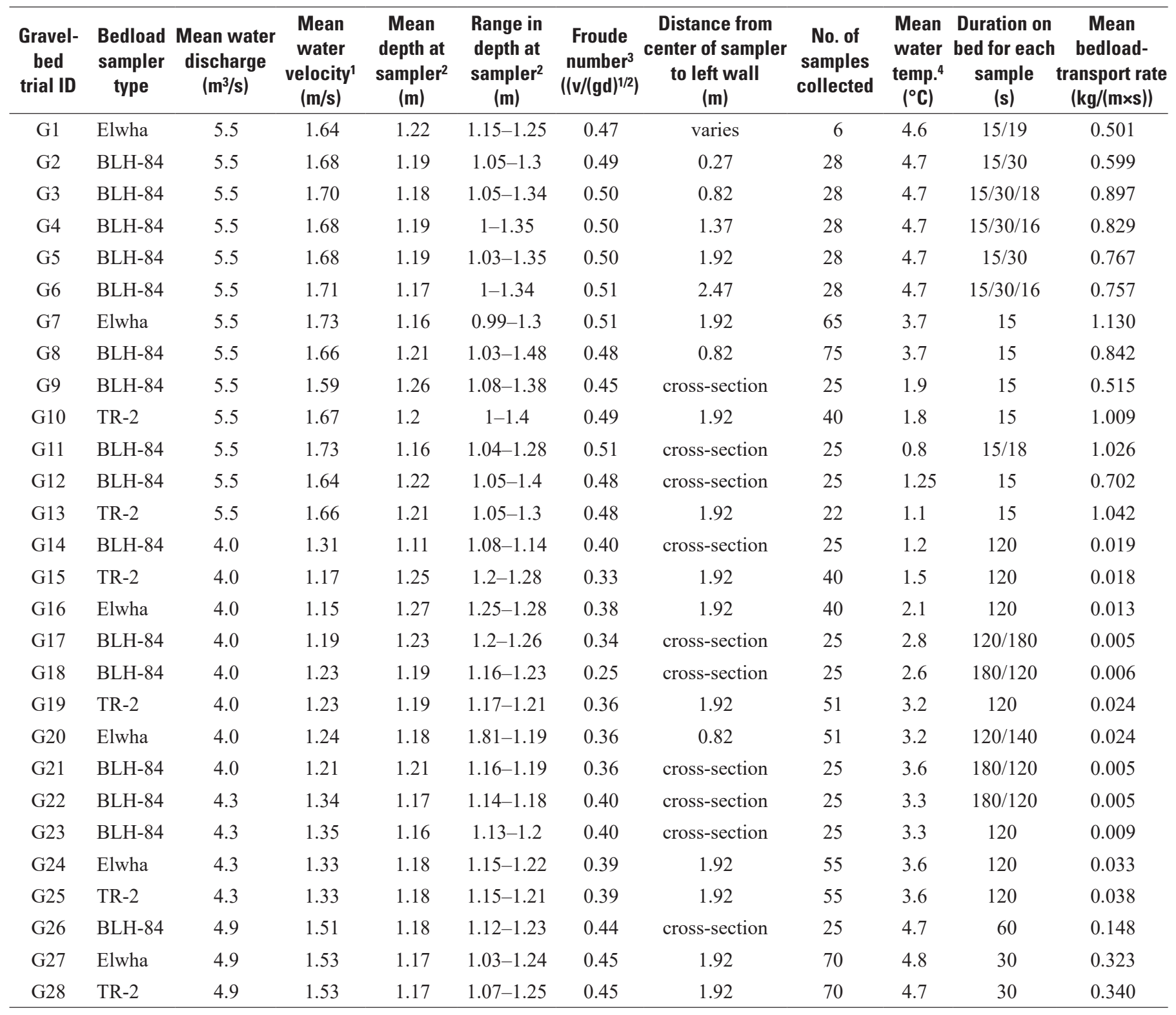

${ }^{1}$ Mean velocity computed as a product of the 2.74 -m-wide flume and the mean value of depths measured at the sampling vertical(s) and divided by the water discharge during a bedload-sampler trial.

${ }^{2}$ Depth from bottom of the bedload sampler resting on the bed to the water surface as indicated on the graduated deployment rod.

${ }^{3}$ Froude Number equals mean flow velocity divided by the square root of the product of the acceleration of gravity and mean depth of flow.

${ }^{4}$ Water temperatures over the duration of a trial rarely varied more than $0.2^{\circ} \mathrm{C}$ from the mean value, and never varied by more than $0.5^{\circ} \mathrm{C}$. 


\section{Experimental Caveats}

Most if not all recirculating flumes have unique characteristics that might affect the comparability of the data produced and the validity of subsequent analyses. A number of factors associated with the St. Anthony Falls main flume facility during the StreamLab06 experiments warrant description for those considering use of the derived data, including the following:

1. Test section entrance condition-The entrance condition into the test section near the discharge end of the recirculation pipe was altered several times at the beginning of the sand runs. Various issues including air entrained by plunging inflow complicated the sonar measurements, and jet plumes and secondary circulation resulted in scour along the sidewalls in the upstream-most 3-5 $\mathrm{m}$ over the $20-\mathrm{m}$ test section length. The final configuration shown in figure 19 was considered to be the most amenable for the bedload-sampler experiments.

2. Test section exit condition-The sand and gravel at the end of the test section ending at the slot terminated in a slope at an angle of repose. Movement of sediment down this sloping face was often episodic, occurring as sloughing events that were asynchronous with the rate of bedload in transport upstream from the face of the slope. Similar observations were made in the earlier Hubbell and others (1987) experiments. These slough events may influence the sediment accumulation measurements and should be considered when selecting a time step for computing sediment flux.

3. Transport equilibration-In all but one case (run number 4 at about 11 a.m. local time) the flume was operated for at least a half hour prior to initiation of sample collection as part of a bedload-sampler trial to enable "equilibration" of the bedload-transport process in the flume. The determination of (dynamic) equilibrium in bedload-transport rates was inferred by observing continuous plots of sediment accumulation in the weigh drums and computing 60-minute averages of sediment flux using the CDAQ system. Future experiments could adopt more rigorous methods of determining when the flume is in transport equilibrium.

4. Water-surface slope-Estimates of water-surface slopes were made using relatively infrequent point measurements of stage at multiple points in the section of the flume upstream from the weigh drums. Water-surface slope is a key variable in the flow-energy calculation, which in turn has a direct bearing on estimates of bedload-transport capacity (Meerovich and others, 1998). Although water-surface slope was not a variable in the derivation of bedload-sampler trapping coefficients, future experiments would benefit from state-of-the-art continuous recording technologies for stage at multiple points in the flume to provide more accurate water-surface slope values. The measurements could also benefit from the inclusion of a physical means for damping short-term water-surface elevation fluctuations, such as by enclosing the sensor in a static tube.

\section{References Cited}

Abraham, D.D., and Kuhnle, R., 2006, Using high resolution bathymetric data for measuring bed-load transport, in Proceedings of the Eighth Federal Interagency Sedimentation Conference, April 2-6, 2006, Reno, Nev., Subcommittee on Sedimentation, p. 619-626. [Also available at https://pubs.usgs.gov/misc/FISC_19472006/pdf/1st-7thFISCs-CD/8thFISC/Session\%209C2_Abraham.pdf.]

Advisory Committee on Water Information, 2017, Advisory Committee on Water Information [ACWI] web page, accessed December 12, 2017, at http://acwi.gov/sos/.

ASTM International, 2000, ASTM standard D3977—Standard test methods for determining sediment concentration in water samples: West Conshohocken, Pa., ASTM International, v. 11.02, Water (II), p. 395-400.

ASTM International, 1998, ASTM standard D4410-98Terminology for fluvial sediment: West Conshohocken, Pa., ASTM International, 6 p. [Also available at https://doi.org/10.1520/d4410-98.]

Barton, J.S., and Pittman, S.A., 2010, Passive-transducer hydroacoustics, section 2.2.2 of Gray, J.R., and Gartner, J.W., eds., Surrogate technologies for monitoring bed-load transport in rivers, chap. 2 of Poleto, C., and Charlesworth, S., eds., Sedimentology of aqueous systems: Hoboken, N.J., Wiley-Blackwell, p. 65-69, accessed 2018, at https://doi.org/10.1002/9781444317114.ch2.

Beschta, R.L., O'Leary, S.J., Edwards, R.E., and Knoop, K.D., 1981, Sediment and organic matter transport in Oregon Coast Range streams: Corvallis, Oreg., School of Forestry, Oregon State University, prepared for Office of Water Research Technology, U.S. Department of the Interior, grant no. 14-34-0001-7078. [Also available at https://ir.library.oregonstate.edu/downloads/hh63t118c.]

Beverage, J., 1988, A nozzle reminder: U.S. Geological Survey Water Resources Division Instrument News, September 1988, p. 3. 
Bunte, K., Potyondy, J.P., and Abt, S.R., 2005, Development of an improved bedload trap for sampling gravel and cobble bedload in coarse mountain streams, in appendix 4 of Gray, J.R., ed., Proceedings of the Federal Interagency Sediment Monitoring Instrument and Analysis Research Workshop, September 9-11, 2003, Flagstaff, Arizona: U.S. Geological Survey Circular 1276, 8 p., accessed May 12, 2021, at https://water.usgs.gov/osw/techniques/ sediment/sedsurrogate2003workshop/bunte.pdf. [Full text of Circular available at https://doi.org/10.3133/cir1276.]

Bunte, K., and Abt, S.R., 2009, Transport relationships between bedload traps and a 3-inch Helley-Smith sampler in coarse gravel-bed streams and development of adjustment functions: Fort Collins, Colo., Colorado Water Institute, Colorado State University, Completion report no. 218, 138 p. [Also available at http://hermes.cde.state.co.us/ drupal/islandora/object/co:7523/datastream/OBJ/view.]

Bunte, K., and Swingle, K.W., 2007, Continued development and testing of bedload trap technology through flume experiments at the National Center for Earth-Surface Dynamics (NCED) at the St. Anthony Falls Laboratory: Report submitted to Streams System Technology Center, USDA Forest Service, Rocky Mountain Research Station, Fort Collins, Colo., 72 p.

Bunte, K., Swingle, K.W., and Abt, S.R., 2010, Necessity and difficulties of field calibrating signals from surrogate techniques in gravel-bed streams-Possibilities for bedload trap samplers, in Gray, J.R., Laronne, J.B., and Marr, J.D.G., Bedload-surrogate monitoring technologies: U.S. Geological Survey Scientific Investigations Report 2010-5091, p. 107-129, accessed March 4, 2019, at http://pubs.usgs.gov/sir/2010/5091/papers/listofpapers.html.

Carey, W.P., 1984, A field technique for weighing bedload samples: American Water Resources Association-Water Resources Bulletin, v. 20, no. 2, p. 261-265. [Also available at https://doi.org/10.1111/j.1752-1688.1984.tb04681.x.]

Carey, W.P., 2005, A brief history of the development and calibration of bedload samplers, in National Center for Earth Surface Dynamics: U.S. Geological Survey, Bedload Monitoring Technologies Workshop, Dec. 1-2, 2005, Minneapolis, Minn., papers and manuscripts, $18 \mathrm{p}$.

Childers, D., 1999, Field comparisons of six pressure-difference bedload samplers in high-energy flow: U.S. Geological Survey Water-Resources Investigations Report 92-4068, 59 p., accessed March 6, 2019, at https://doi.org/10.3133/wri924068.

Colby, B.R., 1963, Fluvial sediments a summary of source, transportation, deposition, and measurement of sediment discharge, chap. A of Contributions to general geology 1963: U.S. Geological Survey Bulletin 1181-A, 47 p., accessed March 6, 2019, at https://doi.org/10.3133/b1181A.
Davis, B.E., 2005, A guide to the proper selection and use of federally approved sediment and water-quality samplers: U.S. Geological Survey Open-File Report 2005-1087, 20 p., accessed March 6, 2019, at https://doi.org/10.3133/ofr20051087.

Diplas, P., Kuhnle, R., Gray, J., Glysson, D., and Edwards, T., 2008, General, section 5.1 in Sediment-transport measurements, chap. 5 of Garcia, M.H., ed., Sedimentation engineering —Processes, measurements, modeling, and practice: Reston, Va., American Society of Civil Engineers [ASCE], ASCE manuals and reports on engineering practice no. 110, p. 307-309. [Also available at https://doi.org/10.1061/9780784408148.ch05.]

Druffel, L., Emmett, W.W., Schneider, V.R., and Skinner, J.V., 1976, Laboratory hydraulic calibration of the Helley-Smith bedload sampler: U.S. Geological Survey Open-File Report 76-752, 63 p. [Also available at https://doi.org/10.3133/ofr76752.]

Edwards, T.K., and Glysson, G.D., 1988, Field methods for measurement of fluvial sediment: U.S. Geological Survey Open-File Report 86-531, 118 p., accessed March 6, 2019, at https://doi.org/10.3133/ofr86531.

Edwards, T.K., and Glysson, G.D., 1999, Field methods for measurement of fluvial sediment: U.S. Geological Survey Techniques of Water-Resources Investigations, book 3, chap. C2, 89 p., accessed March 6, 2019, at https://doi.org/10.3133/twri03C2.

Emmett, W.W., 1980, A field calibration of the sediment-trapping characteristics of the Helley-Smith bedload sampler: U.S. Geological Survey Professional Paper 1139, 44 p., accessed March 6, 2019, at https://doi.org/10.3133/pp1139.

Emmett, W.W., 1981, Measurement of bed load in rivers, in Erosion and transport measurement symposium: Proceedings of the Florence Symposium, June 22-26, 1981 [title in English and French]: Washington, D.C., International Association of Hydrological Sciences, no. 133, p. 3-15. [Also available at https://iahs.info/uploads/dms/iahs_133_0003.pdf.]

Federal Interagency Sedimentation Project, 1940, Equipment used for sampling bed-load and bed material: Iowa City, Iowa, University of Iowa, A study of methods used in measurement of sediment loads in streams, report no. 2, 57 p., accessed March 6, 2019, at https://water.usgs.gov/fisp/docs/Report_2.pdf.

Federal Interagency Sedimentation Project [FISP], 2009, FISP technical committee approval of the use of bedload traps in wadeable coarse-bedded streams: FISP technical committee memorandum 2009.01, 6 p., accessed March 6, 2019, at https://water.usgs.gov/fisp/docs/FISP_Tech_Memo_20091_Bedload_Traps.pdf. 
Fienberg, K., Singh, A., Foufoula-Georgiou, E., Jerolmack, D., and Marr, J.D.G., 2010, A theoretical framework for interpreting and quantifying the sampling time dependence of gravel bedload transport rates, a paper submitted as part of Gray, J.R., Laronne, J.B., and Marr, J.D.G., eds., Bedload-surrogate monitoring technologies: U.S. Geological Survey Scientific Investigations Report 2010-5091, p. 171-184, accessed March 6, 2019, at https://pubs.usgs.gov/sir/2010/5091/papers/Fienberg.pdf.

Gaskin, J., and Rennie, C.D., 2010, Active hydroacoustics with a acoustic doppler current profiler, section 2.2.1 in Barton, J.S., Gaskin, J., Pittman, S.A., Rennie, C.D., Gray, J.R., and Gartner, J.W., eds., Surrogate technologies for monitoring bed-load transport in rivers, chap. 2 of Poleto, C., and Charlesworth, S., eds., Sedimentology of aqueous systems: Hoboken, N.J., Wiley-Blackwell, p. 58-64, accessed March 6, 2019, at https://water.usgs.gov/ osw/techniques/sed_aq_sys_chap_2_pdf_from_wb_3_16 2010.pdf.

Geay, T., Belluedy, P., Gervaise, C., Habersack, H., Aigner, J., Kreisler, A., Seitz, H., and Laronne, J.B., 2017, Passive acoustic monitoring of bed load discharge in a large gravel bed river: Journal of Geophysical Research-Earth Surface, v. 122, no. 2, p. 528-545, accessed March 6, 2019, at https://doi.org/10.1002/2016JF004112.

Gomez, B., Hubbell, D.W., and Stevens, H.H., Jr., 1990, At-a-point bed load sampling in the presence of dunes: Water Resources Research, v. 26, no. 11, p. 2717-2731. [Also available at https://doi.org/10.1029/wr026i011p02717.]

Gomez, B., 2006, The potential rate of bed-load transport: Proceedings of the National Academy of Sciences, v. 103 , no. 46 , p. 17170-17173. [Also available at https://doi.org/10.1073/pnas.0608487103.]

Gray, J.R., ed., 2005, Proceedings of the Federal Interagency Sediment Monitoring Instrument and Analysis Workshop, September 9-11, 2003, Flagstaff, Arizona: U.S. Geological Survey Circular 1276, 46 p. [Also available at https://pubs.usgs.gov/circ/2005/1276/.]

[Appendix 4 is available only at https://pubs.usgs.gov/circ/2005/1276/pdf/Appendix4.pdf.]

Gray, J.R., Webb, R.H., and Hyndman, D.W., 1991, Low-flow sediment transport in the Colorado River, in Proceedings of the Fifth Federal Interagency Sedimentation Conference, March 18-21, 1991, Las Vegas, Nevada: [Washington, D.C.], Federal Energy Regulatory Commission, Interagency Advisory Committee on Water Data, Subcommittee on Sedimentation, v. 1, p. 4-63 to 4-71.
Gray, J.R., Glysson, G.D., and Edwards, T.E., 2008, Suspended-sediment samplers and sampling methods, section 5.3 of Diplas, P., Kuhnle, R., Gray, J., Glysson, D., and Edwards, T., Sediment transport measurements, chap. 5 in Marcelo G., ed., Sedimentation engineeringProcesses, measurements, modeling, and practice: Reston, Va., American Society of Civil Engineers [ASCE], ASCE manuals and reports on engineering practice, no. 110, p. 320-339, accessed March 6, 2019, at https://doi.org/10.1061/9780784408148.ch05.

Gray, J.R., and Gartner, J.W., 2010, Surrogate technologies for monitoring bed-load transport in rivers, in Poleto, C., and Charlesworth, S., eds., Sedimentology of aqueous systems, London, Wiley-Blackwell, chap. 2, p. 45-79, accessed March 4, 2019, at http://water.usgs.gov/osw/techniques/sed aq_sys_chap_2_pdf_from_wb_3_16_2010.pdf.

Gray, J.R., and Landers, M.N., 2014, Measuring suspended sediment, chap. 1.10 in Ahuja S., ed., Comprehensive water quality and purification: Waltham, Mass., Elsevier, v. 1, p. 157-204. [Also available at https://doi.org/10.1016/B978-0-12-382182-9.00012-8.]

Gray, J.R., and Landers, M.N., 2015, History of the Federal Interagency Sedimentation Project, part V, in Proceedings of the Joint Federal Interagency Conference 2015Proceedings of papers of the 5th Federal Interagency Hydrologic Modeling Conference and the 10th Federal Interagency Sedimentation Conference: [Washington, D.C.], Joint Federal Interagency Conference on Sedimentation and Hydrologic Modeling, Reno, Nev., April 19-23, 2015, p. 264-275, accessed March 6, 2019, at http://acwi.gov/sos/pubs/3rdJFIC/Contents/2C-Gray.pdf.

Gray, J.R., Laronne, J.B., and Marr, J.D.G., eds., 2010, Bedload-surrogate monitoring technologies: U.S. Geological Survey Scientific Investigations Report 2010-5091, 37 p., accessed March 6, 2019, at https://doi.org/10.3133/sir20105091.

Gray, J.R., Laronne, J.B., and Marr, J.D.G., 2007, eds., Measuring bed load discharge in rivers-BedloadSurrogate Monitoring Workshop, Minneapolis, Minnesota, April 11-14, 2007: Eos, Transactions American Geophysical Union, v. 88, no. 45, p. 471, accessed March 6, 2019, https://doi.org/10.1029/2007eo450008.

Gray, J.R., and Simões, F.J.M., 2008, Estimating sediment discharge, appendix D of Garcia, M., ed., Sedimentation engineering-Processes, measurements, modeling, and practice: Reston, Va., American Society of Civil Engineers (ASCE), ASCE manuals and reports on engineering practice no. 110, p. 1067-1088. [Also available at https://doi.org/10.1061/9780784408148.apd.] 
Groten, J.T., and Gray, J.R., 2021, Data describing the trapping efficiency of four types of pressure-difference bedload samplers, St. Anthony Falls Laboratory, Minneapolis, Minnesota, 2006: U.S. Geological Survey data release, https://doi.org/10.5066/P9VBB2YF.

Guy, H.P., 1969, Laboratory theory and methods for sediment analysis: U.S. Geological Survey Techniques of Water Resources Investigations, book 5, chap. C1, 58 p. [Also available at https://pubs.usgs.gov/twri/twri5c1/.]

Hamamori, A., 1962, A theoretical investigation on the fluctuation of bed-load transport: Delft, The Netherlands, Hydraulics Laboratorium Delf, Report R4, 14 p.

Holmes, R.R., Jr., 2010, Measurement of bedload transport in sand-bed rivers - A look at two indirect sampling methods, a paper submitted as part of Gray, J.R., Laronne, J.B., and Marr, D.G., eds., Bedload-surrogate monitoring technologies: U.S. Geological Survey Scientific Investigations Report 2010-5091, p. 236-252, accessed March 6, 2019, at https://pubs.usgs.gov/sir/2010/5091/papers/Holmes.pdf.

Helley, E.J., and Smith, W., 1971, development and calibration of a pressure-difference bedload sampler: U.S. Geological Survey Open-File Report 73-108, 18 p., accessed March 6, 2019, https://doi.org/10.3133/ofr73108.

Hubbell, D.W., 1964, Apparatus and techniques for measuring bedload: U.S. Geological Survey Water-Supply Paper 1748, 74 p., accessed March 6, 2019, at https://doi.org/10.3133/wsp1748.

Hubbell, D.W., and Stevens, H.H., 1986, Factors affecting accuracy of bedload sampling, in Proceedings of the Fourth Federal Interagency Sedimentation Conference: Federal Interagency Sedimentation Conference, Las Vegas, Nev., March 24-27, 1986, v. 1, p. 4-20 to 4-29, accessed March 6, 2019, at https://acwi.gov/sos/pubs/4thFISC/4Fisc-V1/4Fisc1-4.PDF.

Hubbell, D.W., Stevens, H.H., Jr., Skinner, J.V., and Beverage, J.P., 1985, New approach to calibrating bed load samplers: Journal of Hydraulic Engineering, v. 111, no. 4, p. 677-694. [Also available at https://doi.org/10.1061/(asce)07339429(1985)111:4(677).]

Hubbell, D.W., Stevens, H.H., Jr., Skinner, J.V., and Beverage, J.P., 1987, Laboratory data on coarse-sediment transport for bedload-sampler calibrations: U.S. Geological Survey Water-Supply Paper 2299, 31 p., accessed March 6, 2019, at https://pubs.er.usgs.gov/publication/wsp2299.
International Standards Organization, 1992, Liquid flow in open measurement in open channels-Sampling and analysis of gravel-bed material: Geneva, Switzerland, ISO, Technical Committee ISO/TC 113/SC 6 Sediment Transport, ISO 9195-1992, 9 p. [Also available at https://www.iso.org/standard/16820.html.]

Kuhnle, R.A., 1991, Bed load transport on two small streams, in section 4 of Proceedings of the Fifth Federal Interagency Sedimentation Conference: Federal Interagency Sedimentation Conference, Las Vegas, Nev., March 18-21, 1991, Interagency Advisory Committee on Water Data, Subcommittee on Sedimentation, v. 1, p. 4-139 to 4-146, accessed March 6, 2019, at https://pubs.usgs.gov/misc/ FISC_1947-2006/pdf/1st-7thFISCs-CD/5thFISC/5Fisc-V1/ 5Fisc1-4.PDF\#page $=141$.

Kuhnle, R.A., 2008, Bed load samplers, section 5.4 in Diplas, P., Kuhnle, R., Gray, J., Glysson, D., and Edwards, T., Sediment transport measurements, chap. 5 of Marcelo G., ed., Sedimentation engineering-Processes, measurements, modeling, and practice: Reston, Va., American Society of Civil Engineers (ASCE), ASCE manual 110, p. 339-353, accessed March 6, 2019, at https://ascelibrary.org/doi/10.1061/9780784408148.ch05.

Laronne, J.B., Marr, J.D.G., and Gray, J.R., 2007, Initial recommendations from the International Bedload-Surrogate Monitoring Workshop, Minneapolis, Minnesota, April 11-14, 2007: U.S. Forest Service Stream Notes, October 2007, p. 5-7, accessed March 6, 2019, at https://www.fs.fed.us/biology/nsaec/assets/sn_10_07.pdf.

Leopold, L.B., and Emmett, W.W., 1976, Bedload measurements, East Fork River, Wyoming: Proceedings of the National Academy of Sciences, v. 73, no. 4, p. 1000-1004, accessed March 6, 2019, at https://doi.org/10.1073/pnas.73.4.1000.

Leopold, L.B., and Emmett, W.W., 1997, River hydraulics and sediment transport-Some inferences from the East Fork River, Wyoming: U.S. Geological Survey Professional Paper 1583, 52 p., accessed March 4, 2019, at https://pubs.er.usgs.gov/publication/pp1583.

Marineau, M., Minear, J.T., and Wright, S., 2015, Using hydrophones as a surrogate monitoring technology to detect temporal and spatial variability in bedload transport, in Proceedings of the Joint Federal Interagency Conference 2015-Proceedings of papers of the 5th Federal Interagency Hydrologic Modeling Conference and the 10th Federal Interagency Sedimentation Conference: Joint Federal Interagency Conference on Sedimentation and Hydrologic Modeling, 3rd, Reno, Nev., April 19-23, 2015, p. 617-628, accessed March 6, 2019, at https://acwi.gov/sos/pubs/3rdJFIC/Proceedings.pdf. 
Marineau, M.D., Wright, S.A., and Gaeuman, D., 2016, Calibration of sediment-generated noise measured using hydrophones to bedload transport in the Trinity River, California, USA, in Constantinescu, G., García, M., and Hanes, D.M., eds., River Flow 2016-Proceedings of the International Conference on Fluvial Hydraulics, St. Louis, USA, July 11-14, 2016: Iowa City, Iowa, International Conference on Fluvial Hydraulics, 2016, CRC Press/Balkema, 9 p., accessed March 6, 2019, at https://www.researchgate.net/publication/305280105 Calibration_of_sediment_generated_noise_measured_ using_hydrophones_to_bedload_transport_in_the_Trinity River_California_USA.

Marr, J., Wilcock, P., Hondzo, M., Foufoula-Georgiou, E., Johnson, S., Hill, C., Leonardson, R., Nelson, P., Venditti, J., O’Connor, B., Ellis, C.R., Mullin, J., Jefferson, A., and Clark, J., 2010a, StreamLab06Overview of experiments, instrumentation, and data collection: [Minneapolis and St. Paul, Minn.], National Center for Earth-Surface Dynamics, St. Anthony Falls Laboratory, 32 p., accessed March 24, 2017, at http://conservancy.umn.edu/handle/11299/144023.

Marr, J.D.G., Gray, J.R., Davis, B.E., Ellis, C., and Johnson, S., 2010b, Large-scale laboratory testing of bedload-monitoring technologies - Overview of the StreamLab06 experiments, a paper submitted as part of Gray, J.R., Laronne, J.B., and Marr, J.D.G., eds., Bedload-surrogate monitoring technologies: U.S. Geological Survey Scientific Investigations Report 2010-5091, p. 266-282, accessed March 24, 2017, at https://pubs.usgs.gov/sir/2010/5091/papers/Marr.pdf.

Meerovich, L., Laronne, J.B., and Reid, I., 1998, The variation of water-surface slope and its significance for bedload transport during floods in gravel-bed streams: Journal of Hydraulic Research, v. 36, no. 2, p. 147-157. [Also available at https://doi.org/10.1080/00221689809498630.]

Ramooz, R., and Rennie, C.D., 2007, Laboratory measurement of bedload with an ADCP, a paper submitted as part of Gray, J.R., Laronne, J.B., and Marr, J.D.G., eds., Bedload-surrogate monitoring technologies: U.S. Geological Survey Scientific Investigations Report 2010-5091, p. 367-378, accessed March 6, 2019, at https://pubs.usgs.gov/sir/2010/5091/papers/Ramooz.pdf.

Rickenmann, D., and Fritschi, B., 2010, Bedload transport measurements using piezoelectric impact sensors and geophones, a paper submitted as part of Gray, J.R., Laronne, J.B., and Marr, J.D.G., eds., Sediment-surrogate monitoring technologies: U.S. Geological Survey Scientific Investigations Report 2010-5091, p. 407-423, accessed March 6, 2019, at https://pubs.usgs.gov/sir/2010/5091/ papers/Rickenmann-Fritschi.pdf.
Redolfi, M., Guidorizzi, L., Tubino, M., and Bertoldi, W., 2017, Capturing the spatiotemporal variability of bedload transport - A time-lapse imagery technique: Earth Surface Processes and Landforms, v. 42, no. 7, p. 1140-1147, accessed March 15, 2017, at https://doi.org/10.1002/esp.4126.

Rubin, D.M., Tate, G.G., Topping, D.J., and Anima, R.A., 2001, Use of rotating side-scan sonar to measure bedload, in chap. 3 of Proceedings of the Seventh Federal Interagency Sedimentation Conference, March 25-29, 2001, Reno, Nevada, USA: [Washington, D.C.], Federal Interagency Sedimentation Conference, 7th, Reno, Nev., v. 1, p. 1139-1143, accessed March 6, 2019, at https://pubs.usgs.gov/misc/FISC_1947-2006/pdf/1st7thFISCs-CD/7thFISC/7Fisc-V1/7FISC1-3.pdf.

Ryan, S.E., Bunte, K., and Potyondy, J.P., 2005, Breakout session II, bedload-transport measurement-Data needs, uncertainty, and new technologies, in Gray, J.R., ed., Proceedings of the Federal Interagency Sediment Monitoring Instrument and Analysis Research Workshop, September 9-11, 2003, Flagstaff, Arizona: U.S. Geological Survey Circular 1276, p. 16-28. [Also available at https://pubs.usgs.gov/circ/2005/1276/pdf/circ1276_ web.pdf.]

Ryan, S.E., and Porth, L.S., 1999, A field comparison of three pressure-difference bedload samplers: Geomorphology, v. 30, no. 4, p. 307-322, accessed March 6, 2019, at https://doi.org/10.1016/s0169-555x(99)00059-8.

Singh, A., Foufoula-Georgiou, E., Porté-Agel, F., and Wilcock, P.R., 2012, Coupled dynamics of the co-evolution of gravel bed topography, flow turbulence and sediment transport in an experimental channel: Journal of Geophysical Research, v. 117, no. F4, 20 p., accessed March 6, 2019, at https://doi.org/10.1029/2011JF002323.

Singh, A., Czuba, J.A., Foufoula-Georgiou, E., Marr, J.D.G., Hill, C., Johnson, S., Ellis, C., Mullin, J., Orr, C.H., Wilcock, P.R., Hondzo, M., and Paola, C., 2013, StreamLab Collaboratory-Experiments, data sets, and research synthesis: Water Resources Research, v. 49, no. 3, p. 1746-1752, accessed March 6, 2019, at https://doi.org/10.1002/wrcr.20142.

Tacconi, P., and Billi, P., 1987, Bed load transport measurements by the vortex-tube trap on Virginia Creek, Italy, in Thorne, C.R., Bathurst, J.C., and Hey, R.D., eds., Sediment transport in gravel-bed rivers: New York, Wiley, p. 583-616.

Thomas, R.B., and Lewis, J., 1993, A new model for bed load sampler calibration to replace the probability-matching method: Water Resources Research, v, 29, no. 3, p. 583-597. [Also available at https://doi.org/10.1029/92wr02300.] 
University of Minnesota, 2021, National Center for Earth-Surface Dynamics 2-About: University of Minnesota web page, accessed May 6, 2021, at http://www.nced.umn.edu/.

U.S. Geological Survey, 1988, Distribution of Open-File Report "Field methods for measurement of fluvial sediment" and the proposed Water Resources Division policy on bedload data collection and publication:

U.S. Geological Survey Office of Surface Water Technical Memorandum no. 88.17, accessed March 6, 2019, at http://water.usgs.gov/admin/memo/SW/sw88.17.html.

U.S. Geological Survey, 1990, Programs and plans-Policy and guidelines for the collection and publication of bedload data: U.S. Geological Survey Office of Surface Water Technical Memorandum 90.08, accessed March 6, 2019, at https://water.usgs.gov/admin/memo/SW/sw90.08.html.
Vericat, D., Church, M., and Batalla, R.J., 2006, Bed load bias-Comparison of measurements obtained using two (76 and $152 \mathrm{~mm}$ ) Helley-Smith samplers in a gravel bed river: Water Resources Research, v. 42, no. 1, accessed March 6, 2019, at https://doi.org/10.1029/2005wr004025.

Wood, M.S., 2014, Estimating suspended sediment in rivers using acoustic doppler meters: U.S. Geological Survey Fact Sheet 2014-3038, 4 p., accessed March 6, 2019, at https://pubs.usgs.gov/fs/2014/3038/.

Wyss, C.R., Rickenmann, D., Fritschi, B., Turowski, J.M., Weitbrecht, V., and Boes, R.M., 2016, Measuring bed load transport rates by grain-size fraction using the Swiss plate geophone signal at the Erlenbach: Journal of Hydraulic Engineering, v. 142, no. 5, accessed March 6, 2019, at https://doi.org/10.1061/(asce)hy.1943-7900.0001090. 


\section{Appendix 1.}

Table 1.1. Participants and advisors involved in the bedload monitoring research program and their affiliations (as of 2006) for StreamLab06 bedload-sampler trapping-efficiency tests.

[Those denoted with "*" were involved in the manual deployment of the bedload samplers and (or) in mass determinations of captured bedload. All information herein as of March 2006. Adapted from table 2 in Marr and others (2010b). Abbreviation: NCED, National Center for Earth-Surface Dynamics]

\begin{tabular}{|c|c|}
\hline Name & Affiliation \\
\hline \multicolumn{2}{|c|}{ Project managers } \\
\hline Jeff Marr & NCED, University of Minnesota \\
\hline John R. Gray* & U.S. Geological Survey \\
\hline \multicolumn{2}{|c|}{ NCED partners, visitors, or advisors } \\
\hline Steven Abt & Colorado State University \\
\hline Kristin Bunte & Colorado State University \\
\hline William Carey & Bureau of Land Management \\
\hline Broderick Davis* & Federal Interagency Sedimentation Project \\
\hline Panayiotis Diplas & Virginia Tech \\
\hline William Emmett & U.S. Geological Survey (retired) \\
\hline Dave Gaeuman* & U.S. Geological Survey \\
\hline Basil Gomez & Indiana State University \\
\hline Robert Hilldale* & Bureau of Reclamation \\
\hline Andreas Krause* & Trinity River Restoration Program \\
\hline Roger Kuhnle & Agricultural Research Service \\
\hline Jack Lewis & U.S. Forest Service \\
\hline Johnny McGregor* & Federal Interagency Sedimentation Project \\
\hline John Pitlick* & University of Colorado, Boulder \\
\hline Smokey Pittman* & Graham Mathews and Associates \\
\hline John Potyondy & U.S. Forest Service \\
\hline Rauf Ramooz & University of Ottawa \\
\hline Colin Rennie & University of Ottawa \\
\hline Kurt Swingle & Independent Contractor, Boulder, Colorado \\
\hline Wes Smith* & Graham Mathews and Associates \\
\hline Robert Thomas & U.S. Forest Service \\
\hline Peter Wilcock & Johns Hopkins University \\
\hline \multicolumn{2}{|r|}{ Staff } \\
\hline Richard Christopher & St. Anthony Falls Laboratory \\
\hline Dave Dean* & NCED, University of Minnesota \\
\hline Chris Ellis & NCED, University of Minnesota \\
\hline Ben Erickson & St. Anthony Falls Laboratory \\
\hline Sara Johnson* & NCED, University of Minnesota \\
\hline \multicolumn{2}{|r|}{ Students } \\
\hline Travis Kluthe & NCED, University of Minnesota \\
\hline Adam Markos & NCED, University of Minnesota \\
\hline Nick Olson & NCED, University of Minnesota \\
\hline Andrew Sander & NCED, University of Minnesota \\
\hline
\end{tabular}




\section{Appendix 2.}

Appendix 2 shows the shows the results of weigh-pan bedload-transport rates in kilograms/(meter $\times$ second $)(\mathrm{kg} / \mathrm{m} \times \mathrm{s})$ for each of the nine StreamLab06 Phase I sand and Phase II gravel runs in which bedload samplers were deployed. The following describes information common to the figures:

- There were 13 runs, but manual bedload samples were not collected for four of the runs.

- Each figure (fig. 2.1 to fig. 2.9) depicts the mean transport rate from the run along with the duration of the run. Parts $A$ and $B$ of each figure (for example, fig. 2.1A and 2.1B) reflect the same bedload-transport data.

- Figures are ordered by increasing discharge except for run 1 because runs 4 and 5 were sequential to one another, and run 1 is shown after run 5 in appendix 2.

- During run 4, discharge was increased to 3.2 cubic meters per second $\left(\mathrm{m}^{3} / \mathrm{s}\right)$ near the end of the run. The data-collection systems were not stopped and restarted; thus, sand trial 19 (S19) occurred at the end of run 4 (after discharge was increased) to the same discharge that was maintained for run 5. Run 5, during which no trials occurred, is included in appendix 2 because trial 19 (S19) occurred at the end of run 4 at the same discharge as run 5.

- Each figure represents an individual run, and part $A$ of each figure shows (1) the average, maximum, and minimum bedload transport rates for all five pans, along with the start-and-end of each bedload-sampler trial (top plot in $A$ ); (2) the trapping rates for the individual weigh pans (middle 5 plots in $A$, drums 1-5); and (3) the water-discharge time series in cubic meters per second $\left(\mathrm{m}^{3} / \mathrm{s}\right)$ (bottom plot in $A$ ).

- Part $B$ for each figure shows the accumulation of bedload in each pan and the average accumulation across the five pans expressed in $\mathrm{kg} /(\mathrm{m} \times \mathrm{s})$. 

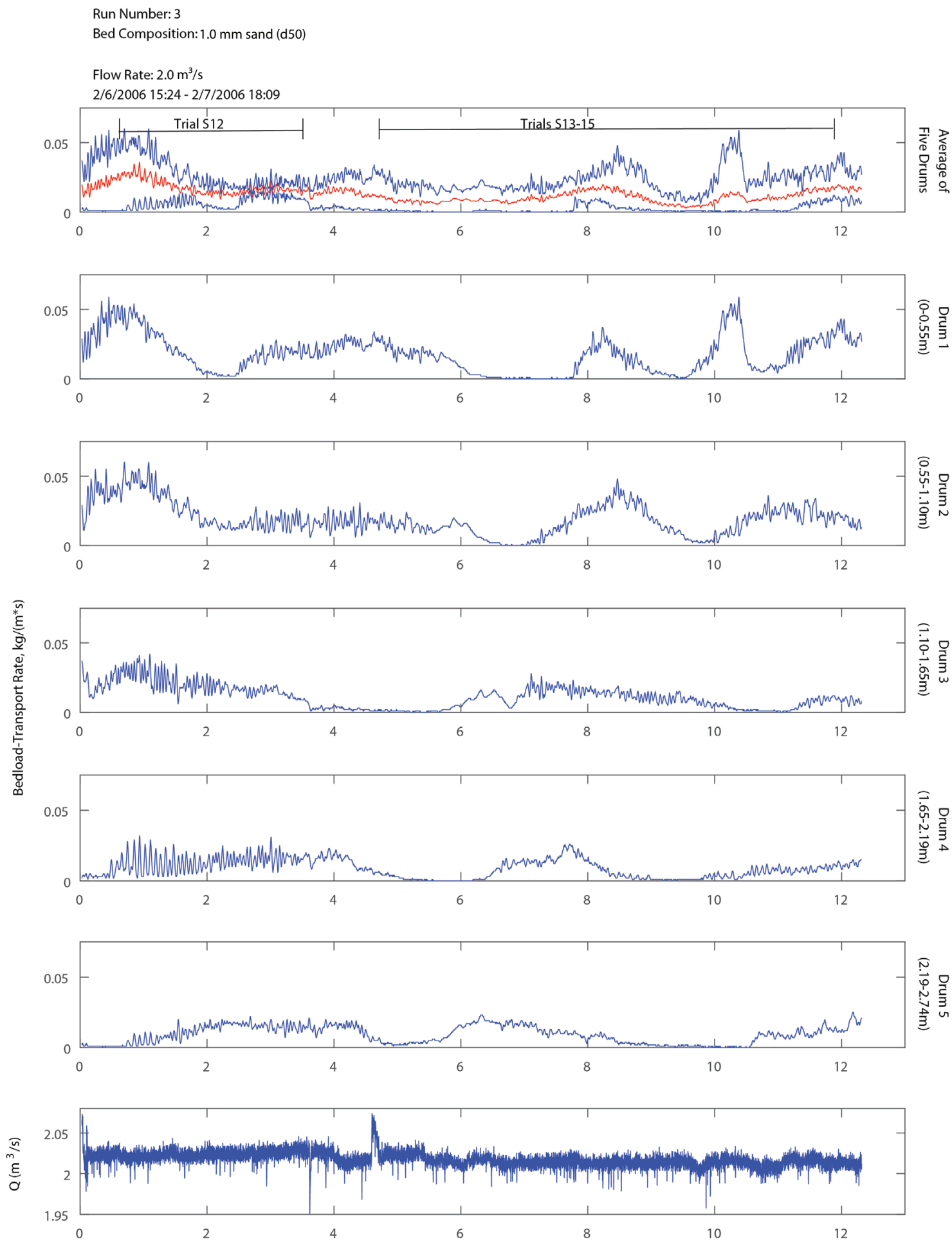

Experimental Time, hours

Figure 2.1. A, Plots showing the results of the StreamLab06 Run No. 3 at a steady flow of $2.0 \mathrm{~m} 3 / \mathrm{s}$ over a sand bed (d50=1.0 $\mathrm{mm}$ ). Starting and ending days and times for the run are shown under the flow rate (top left). Abbreviations: kg, kilograms; $\mathrm{m}$, meters; $\mathrm{mm}$, millimeters; $\mathrm{m}^{3}$, cubic meters; s, seconds; 0 , discharge. " $\mathrm{d} 50$ " means 50 percent of the bed composition by mass is smaller than $1.0 \mathrm{~mm}$ and 50 percent of the bed composition by mass is larger than $1.0 \mathrm{~mm}$. For the explanation of trials, see figure $2.1 B$. 


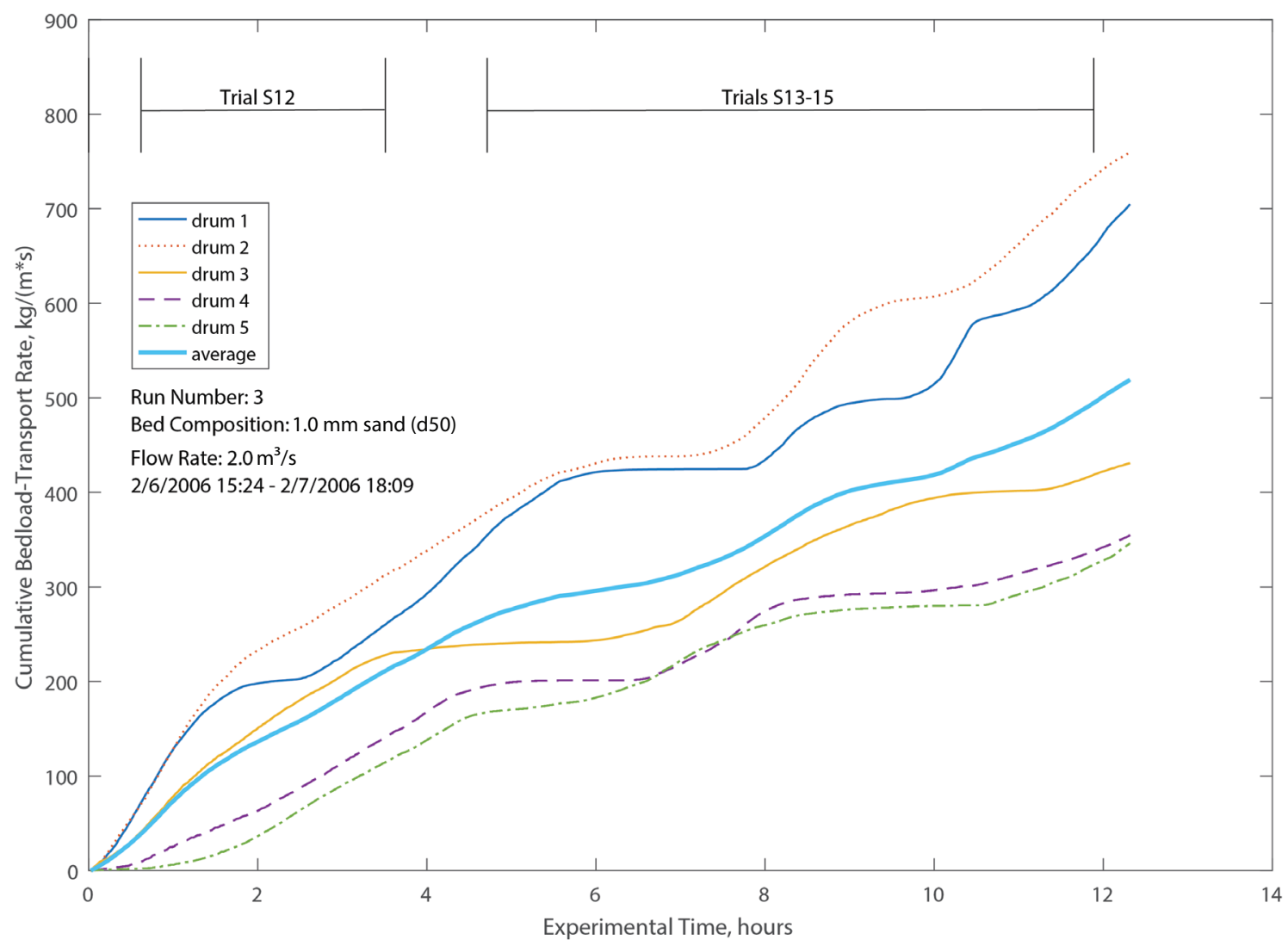

Figure 2.1. B, Plot showing the results of the StreamLab06 Run No. 3 at a steady flow of $2.0 \mathrm{~m}^{3} / \mathrm{s}$ over a sand bed (d50=1.0 mm). Starting and ending days and times for the run are shown under the flow rate (middle left). "d50" means 50 percent of the bed composition by mass is smaller than $1.0 \mathrm{~mm}$ and 50 percent of the bed composition by mass is larger than $1.0 \mathrm{~mm}$. Trial S12: distance from center of sampler to left wall is $1.92 \mathrm{~m}$, and bedload sampler is BLH-84. Trials S13-15: distance from center of sampler to left wall is $1.92 \mathrm{~m}, 1.37 \mathrm{~m}$, and $0.82 \mathrm{~m}$, and bedload samplers are Elwha, BLH-84, and Helley-Smith, respectively. Abbreviations: kg, kilograms; $\mathrm{m}$, meters; $\mathrm{mm}$, millimeters; $\mathrm{m}^{3}$, cubic meters; $\mathrm{s}$, seconds. 

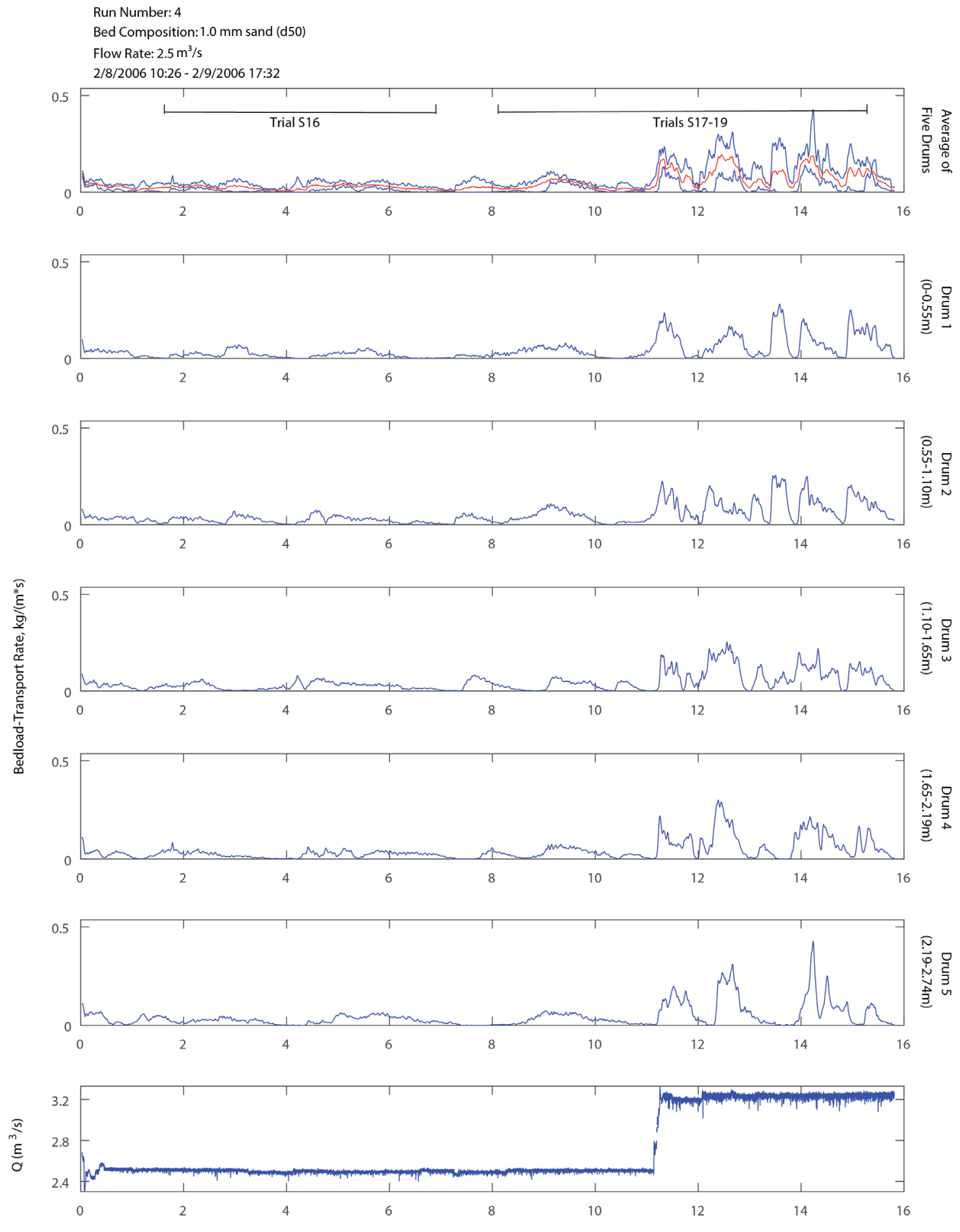

Experimental Time, hours

Figure 2.2. A, Plots showing the results of the StreamLab06 Run Nos. 4 and 5 at steady flows of $2.5 \mathrm{~m}^{3} / \mathrm{s}$ (Run No. 4) and $3.2 \mathrm{~m} / \mathrm{s}$ (Run No. 5) over a sand bed (d50=1.0 mm). Starting and ending days and times for the run are shown under the flow rate (top left). "d50" means 50 percent of the bed composition by mass is smaller than $1.0 \mathrm{~mm}$ and 50 percent of the bed composition by mass is larger than 1.0 mm. Abbreviations: kg, kilograms; m, meters; mm, millimeters; $\mathrm{m}^{3}$, cubic meters; s, seconds; 0 , discharge. For the explanation of trials, see figure $2.2 B$. 


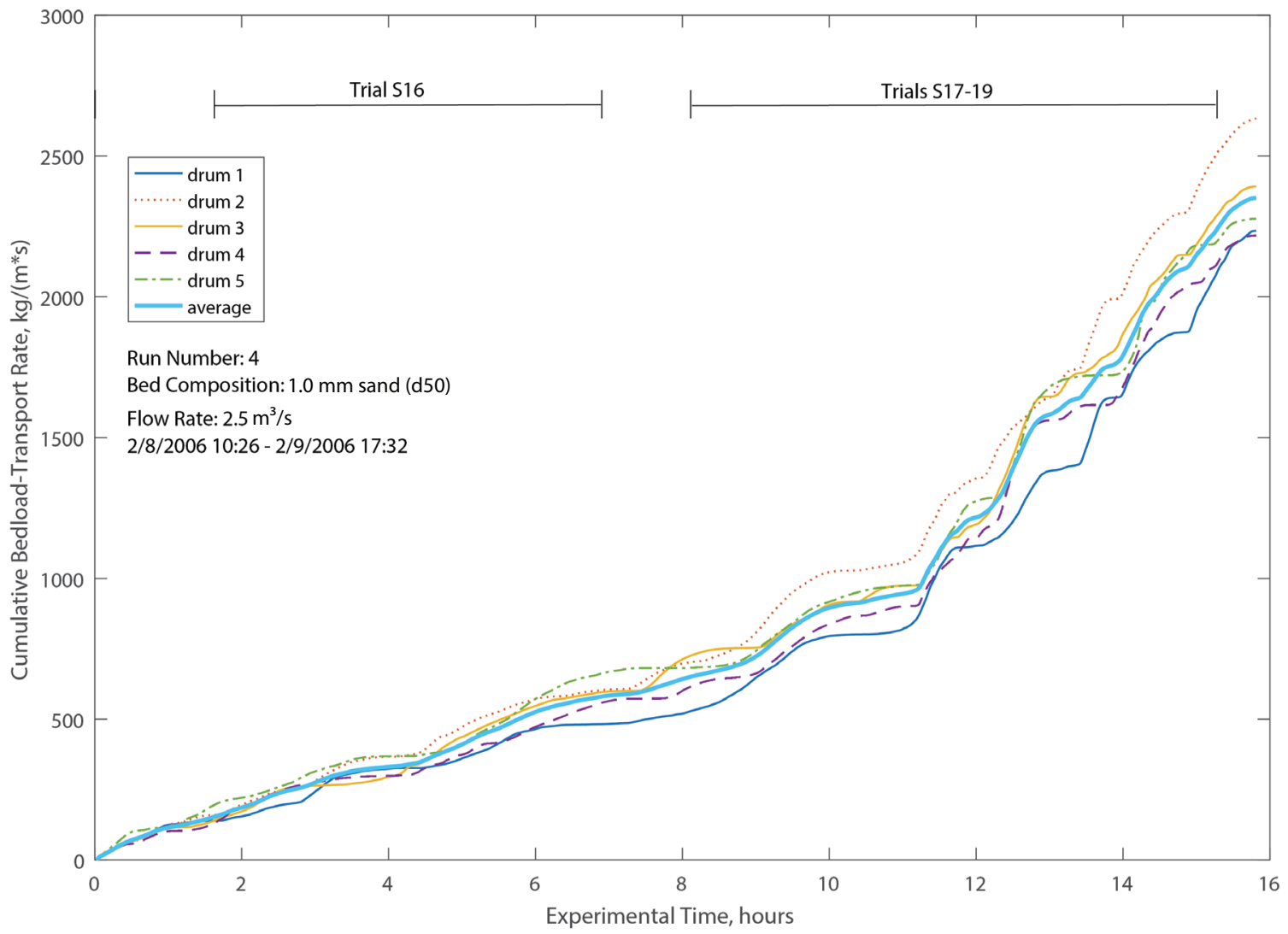

Figure 2.2. B, Plot showing the results of the StreamLab06 Run Nos. 4 and 5 at steady flows of $2.5 \mathrm{~m}^{3} / \mathrm{s}$ (Run No. 4) and $3.2 \mathrm{~m}^{3} / \mathrm{s}$ (Run No. 5) over a sand bed $(\mathrm{d} 50=1.0 \mathrm{~mm})$. Starting and ending days and times for the run are shown under the flow rate (middle left). "d50" means 50 percent of the bed composition by mass is smaller than $1.0 \mathrm{~mm}$ and 50 percent of the bed composition by mass is larger than $1.0 \mathrm{~mm}$. Trial S16: distance from center of sampler to left wall is variable, and bedload sampler is BLH-84. Trials S17-19: distance from center of sampler to left wall is $1.92 \mathrm{~m}, 0.82 \mathrm{~m}$, and $1.92 \mathrm{~m}$, and the bedload samplers are Elwha, Helley-Smith, and BLH-84, respectively. Abbreviations: kg, kilograms; m, meters; mm, millimeters; $\mathrm{m}^{3}$, cubic meters; s, seconds. 


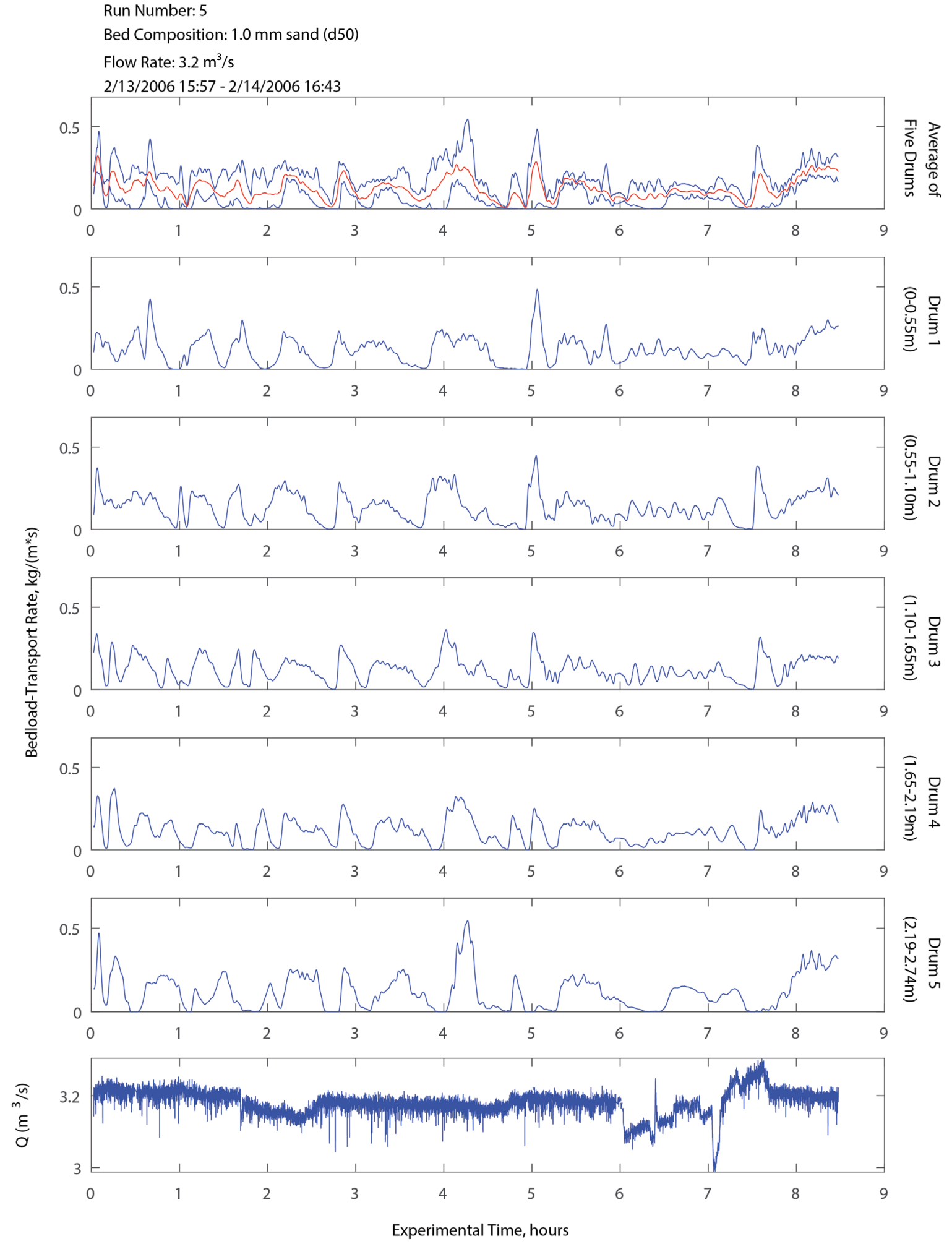

Figure 2.3. A, Plots showing the results of the StreamLab06 Run No. 5 at a steady flow of $3.2 \mathrm{~m} / \mathrm{s}$ over a sand bed ( $\mathrm{d} 50=1.0 \mathrm{~mm}$ ). Starting and ending days and times for the run are shown under the flow rate (top left). " $\mathrm{d} 50$ " means 50 percent of the bed composition by mass is smaller than $1.0 \mathrm{~mm}$ and 50 percent of the bed composition by mass is larger than $1.0 \mathrm{~mm}$. Abbreviations: $\mathrm{kg}$, kilograms; $\mathrm{m}$, meters; mm, millimeters; $\mathrm{m}^{3}$, cubic meters; s, seconds; 0 , discharge. 


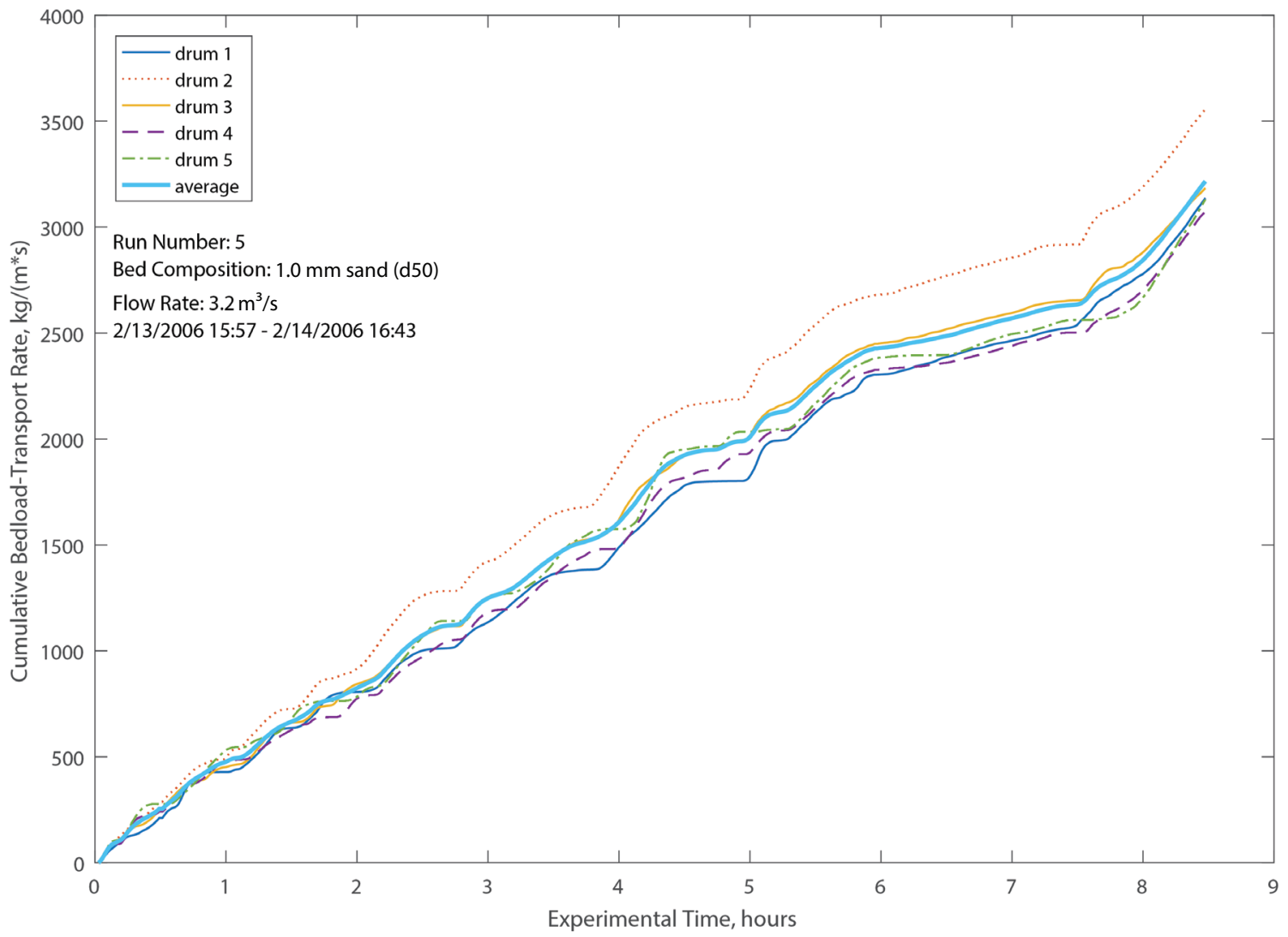

Figure 2.3. B, Plot showing the results of the StreamLab06 Run No. 5 at a steady flow of $3.2 \mathrm{~m} / \mathrm{s}$ over a sand bed (d50=1.0 mm). Starting and ending days and times for the run are shown under the flow rate (middle left). "d50" means 50 percent of the bed composition by mass is smaller than $1.0 \mathrm{~mm}$ and 50 percent of the bed composition by mass is larger than $1.0 \mathrm{~mm}$. Abbreviations: $\mathrm{kg}$, kilograms; $\mathrm{m}$, meters; mm, millimeters; $\mathrm{m}^{3}$, cubic meters; $\mathrm{s}$, seconds. 

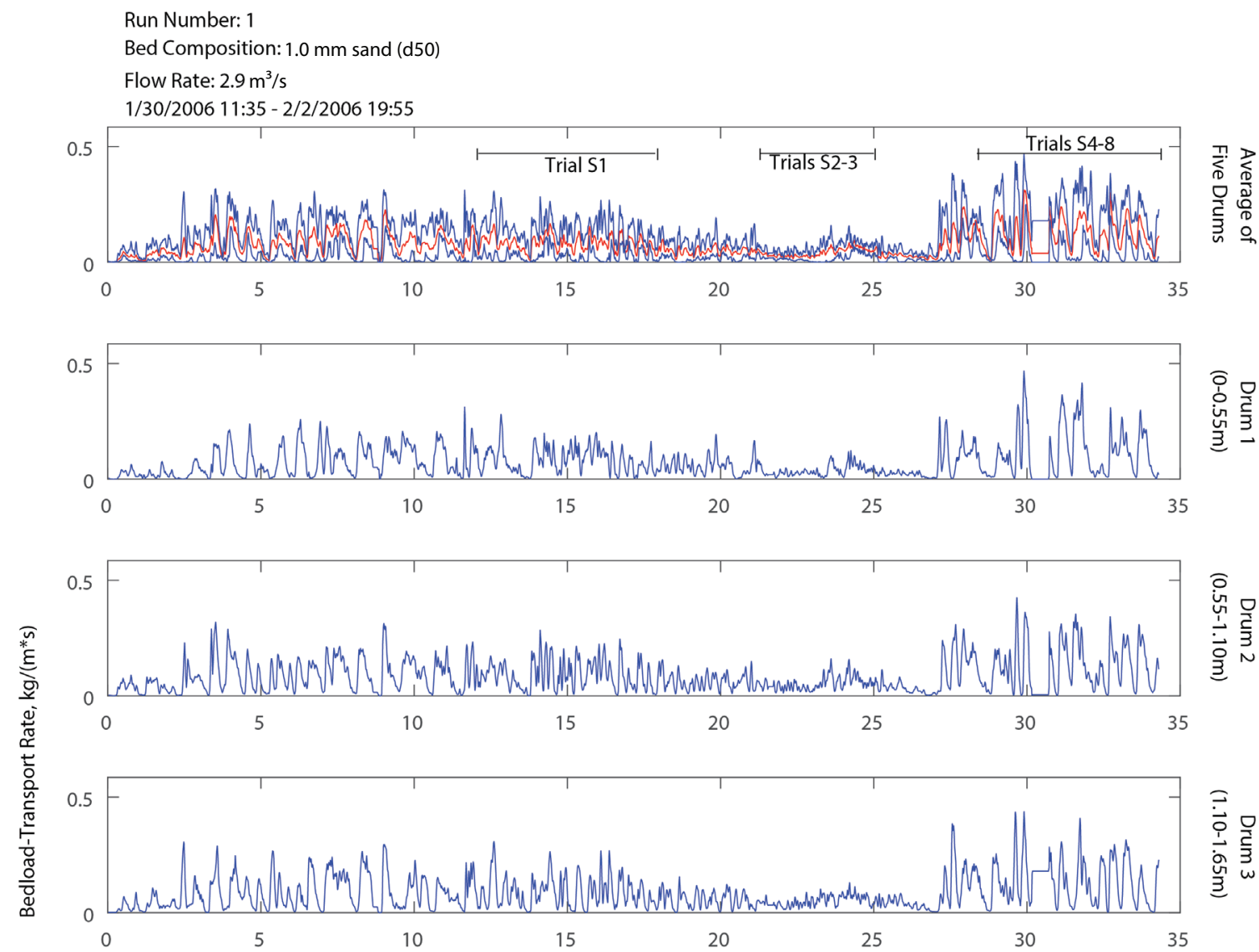

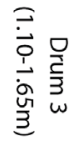
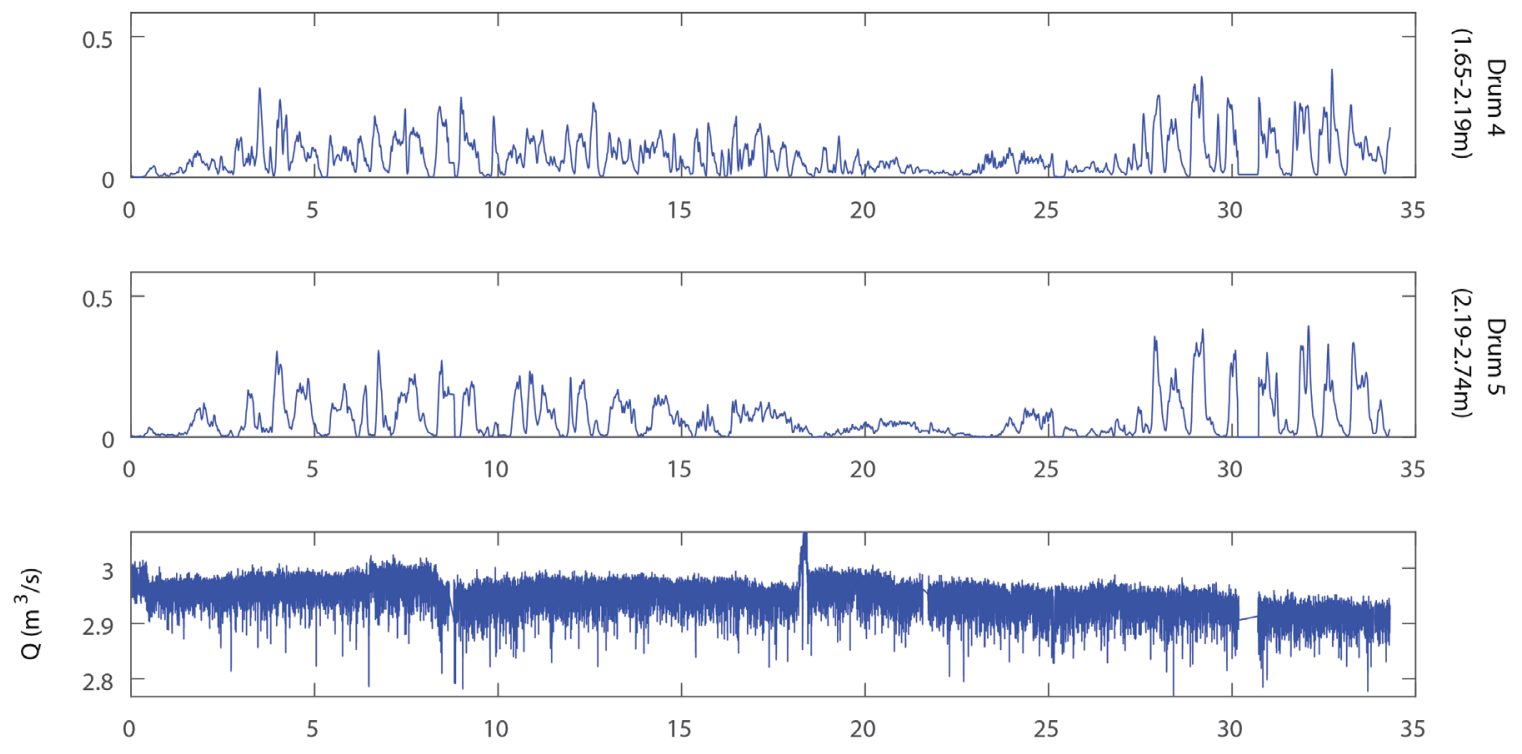

Experimental Time, hours

Figure 2.4. A, Plots showing the results of the StreamLab06 Run No. 1 at a steady flow of $2.9 \mathrm{~m}^{3} / \mathrm{s}$ over a sand bed (d50=1.0 $\mathrm{mm}$ ). Starting and ending days and times for the run are shown under the flow rate (top left). "d50" means 50 percent of the bed composition by mass is smaller than $1.0 \mathrm{~mm}$ and 50 percent of the bed composition by mass is larger than $1.0 \mathrm{~mm}$. Abbreviations: kg, kilograms; $\mathrm{m}$, meters; mm, millimeters; $\mathrm{m}^{3}$, cubic meters; s, seconds; 0 , discharge. For the explanation of trials, see figure $2.4 B$. 


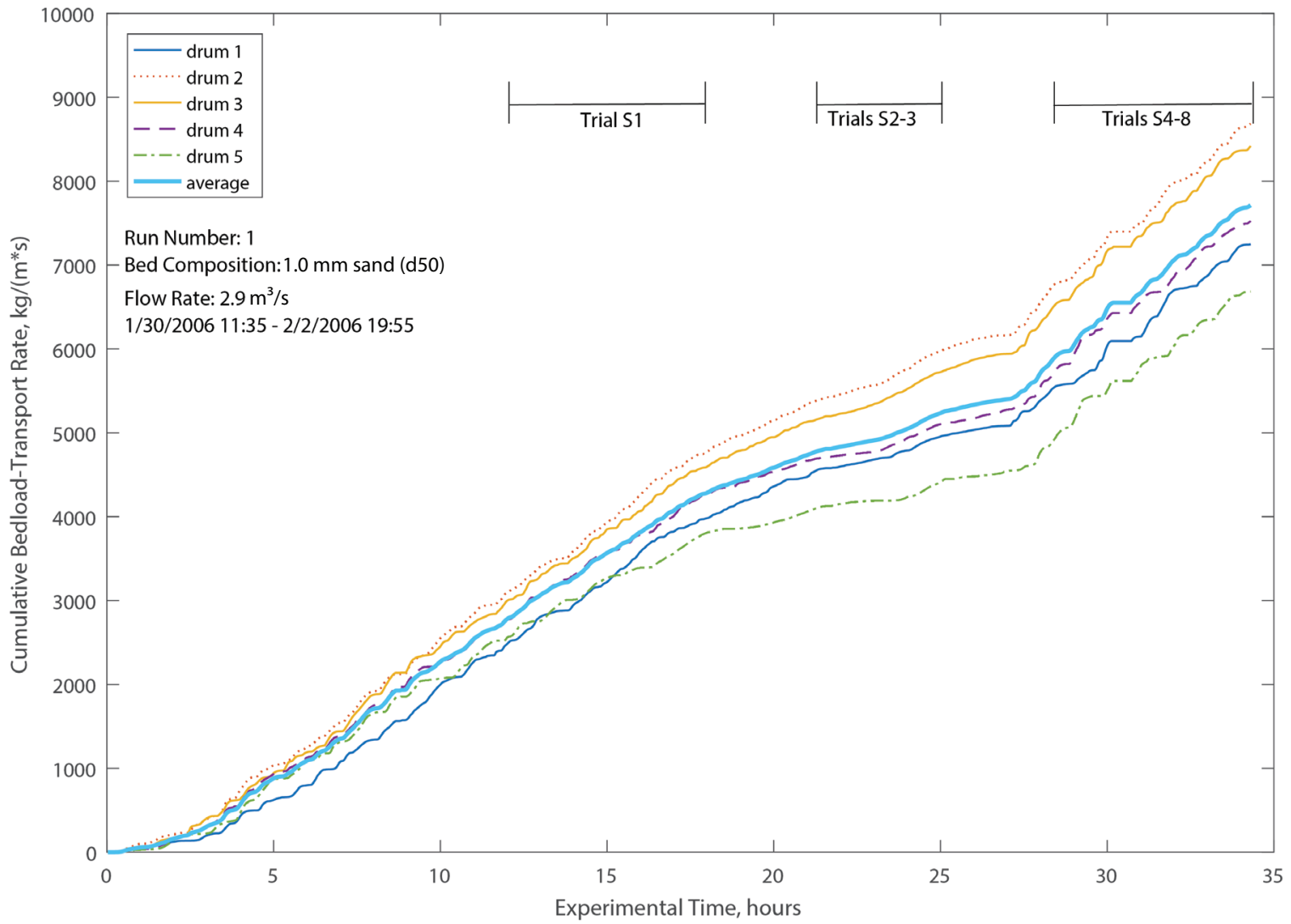

Figure 2.4. B, Plot showing the results of the StreamLab06 Run No. 1 at a steady flow of $2.9 \mathrm{~m}^{3} / \mathrm{s}$ over a sand bed (d50=1.0 mm). Starting and ending days and times for the run are shown under the flow rate (middle left). "d50" means 50 percent of the bed composition by mass is smaller than $1.0 \mathrm{~mm}$ and 50 percent of the bed composition by mass is larger than $1.0 \mathrm{~mm}$. Trial S1: distance from center of sampler to left wall is $1.92 \mathrm{~m}$, and the bedload sampler is BLH-84. Trials S2-3: distance from center of sampler to left wall is $0.82 \mathrm{~m}$ and $1.92 \mathrm{~m}$, and the bedload samplers are Helley-Smith and Elwha, respectively. Trials S4-8: distance from center of sampler to left wall is $0.27 \mathrm{~m}, 0.82 \mathrm{~m}, 1.37 \mathrm{~m}, 1.92 \mathrm{~m}$, and $2.47 \mathrm{~m}$, and the bedload sampler is BLH-84. Abbreviations: kg, kilograms; $\mathrm{m}$, meters; mm, millimeters; $\mathrm{m}^{3}$, cubic meters; s, seconds. 

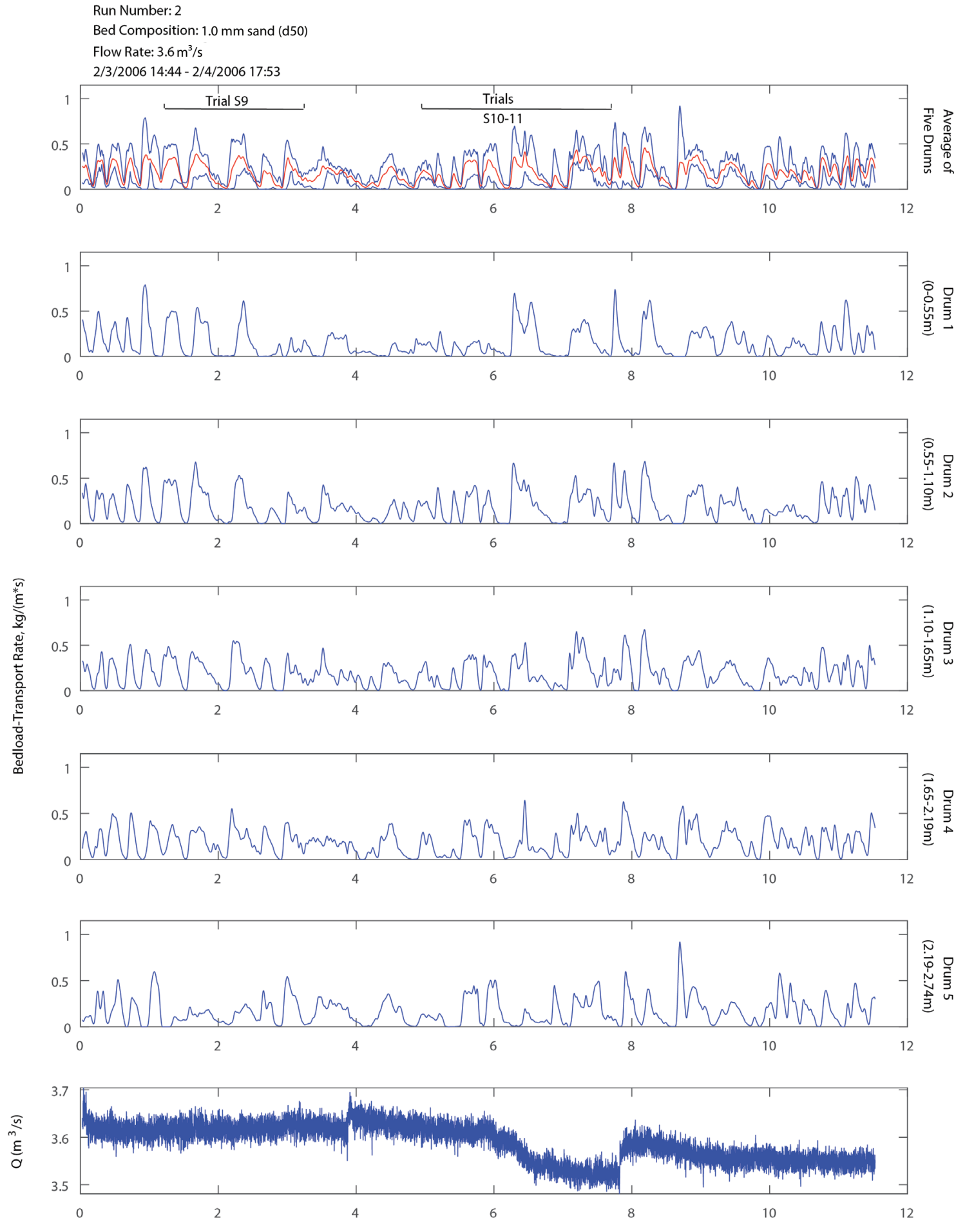

Experimental Time, hours

Figure 2.5. A, Plots showing the results of the StreamLab06 Run No. 2 at a steady flow of $3.6 \mathrm{~m}^{3} / \mathrm{s}$ over a sand bed (d50=1.0 mm). Starting and ending days and times for the run are shown under the flow rate (top left). "d50" means 50 percent of the bed composition by mass is smaller than $1.0 \mathrm{~mm}$ and 50 percent of the bed composition by mass is larger than $1.0 \mathrm{~mm}$. Abbreviations: kg, kilograms; $\mathrm{m}$, meters; $\mathrm{mm}$, millimeters; $\mathrm{m}^{3}$, cubic meters; $\mathrm{s}$, seconds; $\mathrm{Q}$, discharge. For the explanation of trials, see figure $2.5 B$. 


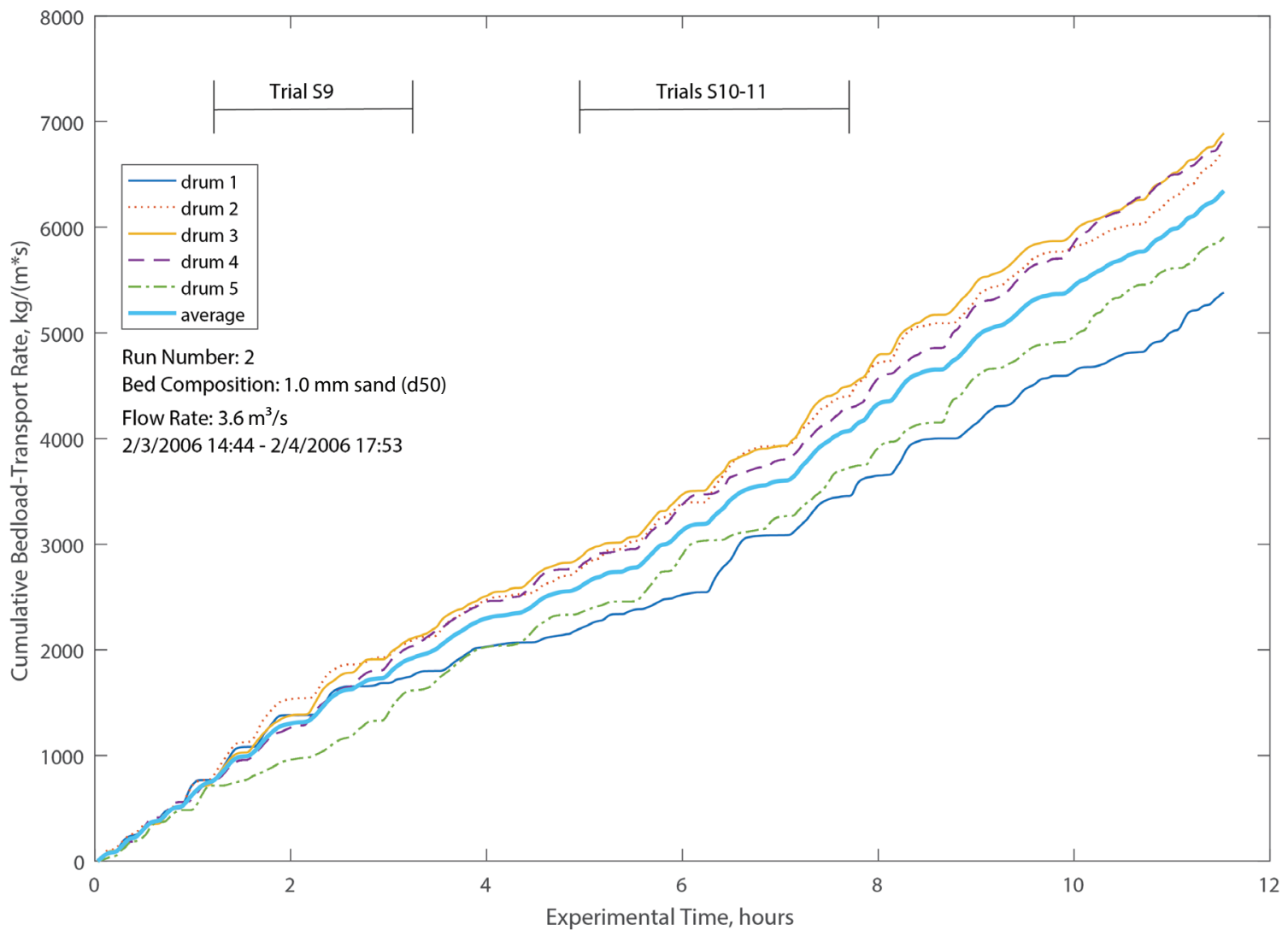

Figure 2.5. B, Plot showing the results of the StreamLab06 Run No. 2 at a steady flow of $3.6 \mathrm{~m}^{3} / \mathrm{s}$ over a gravel bed (d50=1.0 mm). Starting and ending days and times for the run are shown under the flow rate (middle left). "d50" means 50 percent of the bed composition by mass is smaller than $1.0 \mathrm{~mm}$ and 50 percent of the bed composition by mass is larger than $1.0 \mathrm{~mm}$. Trial S9: distance from center of sampler to left wall is $1.92 \mathrm{~m}$, and the bedload sampler is BLH-84. Trials S10-11: distance from center of sampler to left wall is $1.92 \mathrm{~m}$ and $0.82 \mathrm{~m}$, and the bedload samplers are Elwha and Helley-Smith, respectively. Abbreviations: $\mathrm{kg}$, kilograms; $\mathrm{m}$, meters; $\mathrm{mm}$, millimeters; $\mathrm{m}^{3}$, cubic meters; $\mathrm{s}$, seconds. 

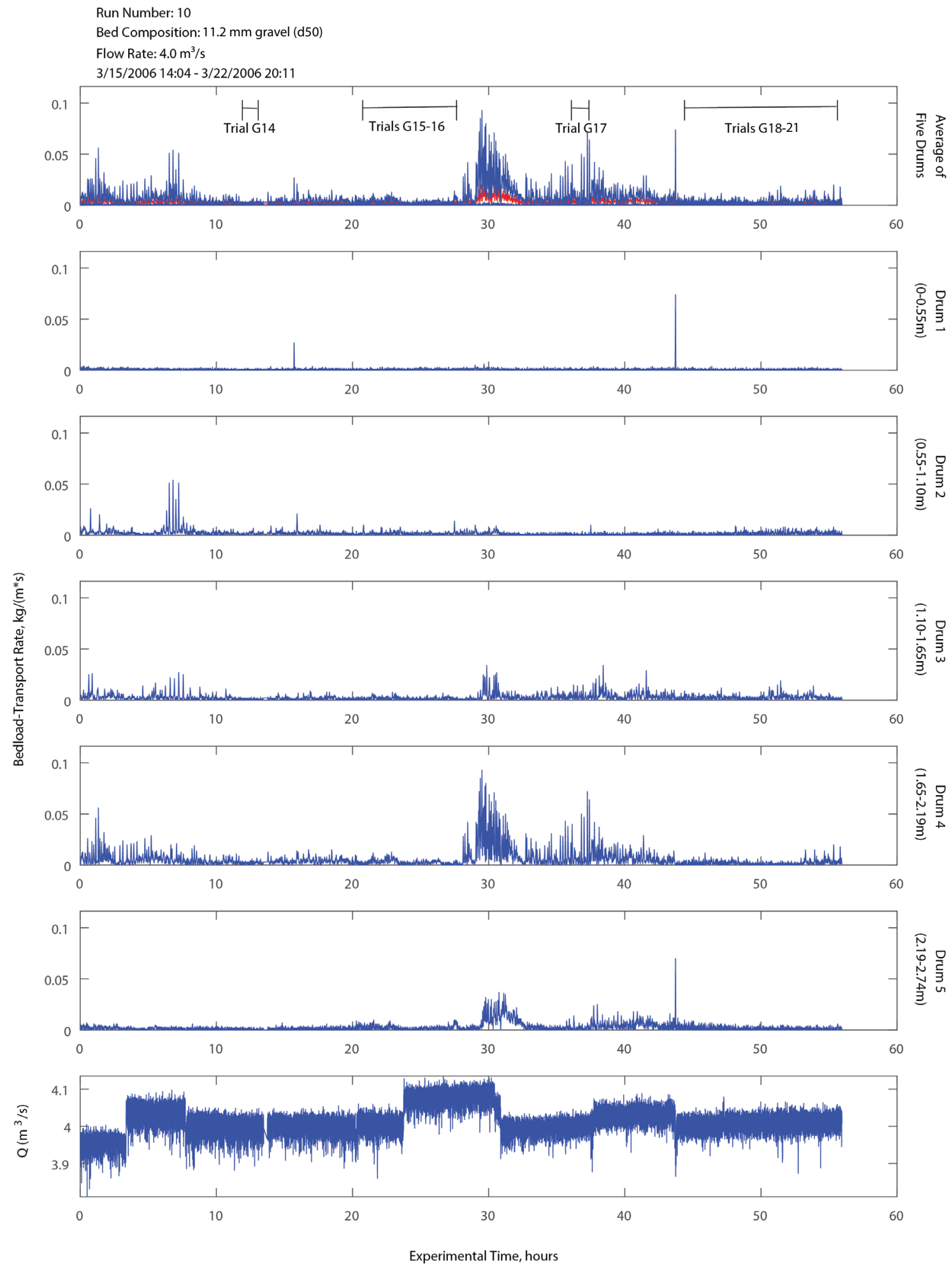

Figure 2.6. A, Plots showing the results of the StreamLab06 Run No. 10 at a steady flow of $4.0 \mathrm{~m}^{3} / \mathrm{s}$ over a gravel bed (d50=11.2 mm). Starting and ending days and times for the run are shown under the flow rate (top left). "d50" means 50 percent of the bed composition by mass is smaller than $11.2 \mathrm{~mm}$ and 50 percent of the bed composition by mass is larger than $11.2 \mathrm{~mm}$. Abbreviations: $\mathrm{kg}$, kilograms; $\mathrm{m}$, meters; mm, millimeters; $\mathrm{m}^{3}$, cubic meters; s, seconds; 0 , discharge. For the explanation of trials, see figure $2.6 B$. 


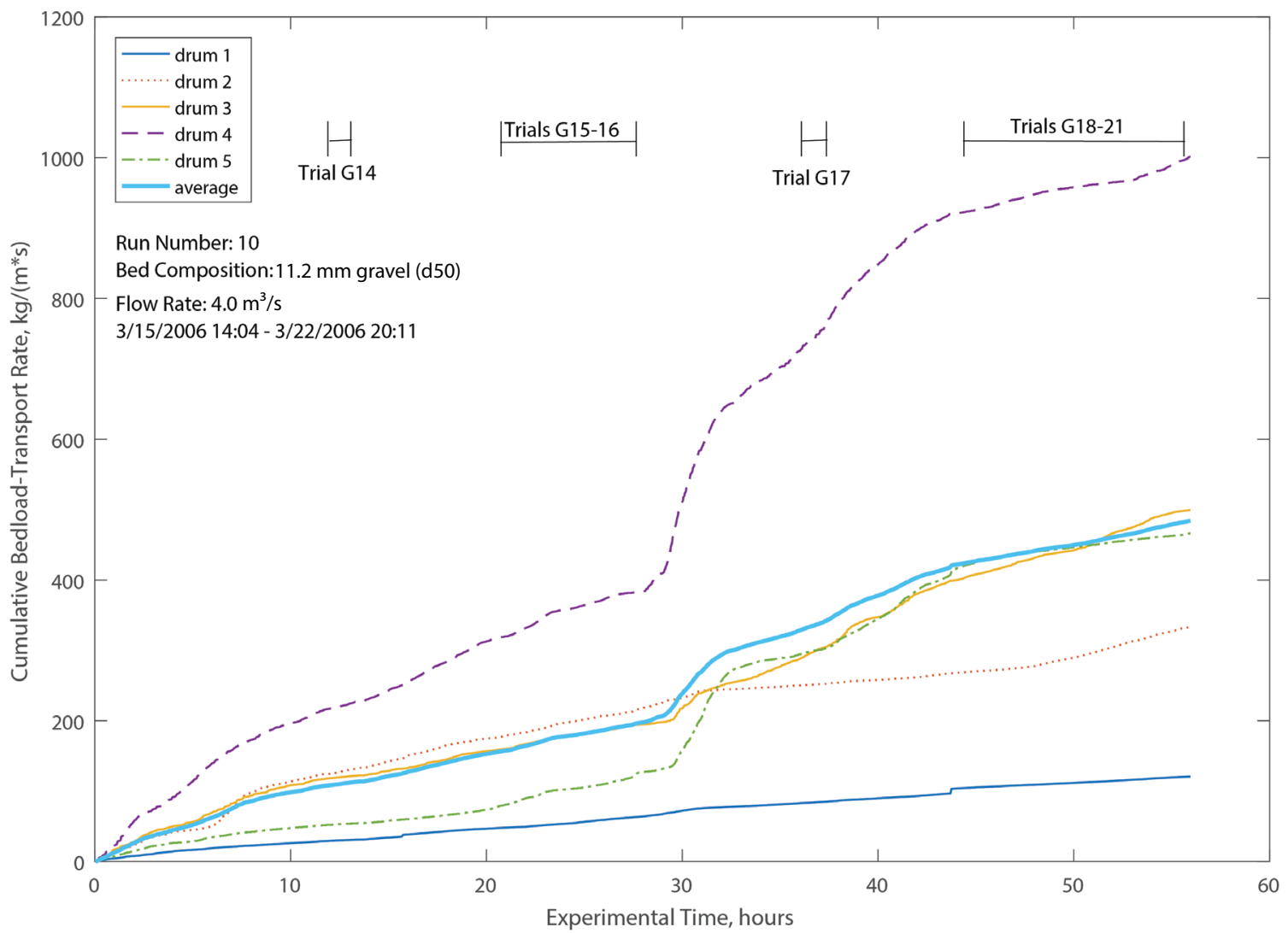

Figure 2.6. B, Plot showing the results of the StreamLab06 Run No. 10 at a steady flow of $4.0 \mathrm{~m}^{3} / \mathrm{s}$ over a gravel bed (d50=11.2 mm). Starting and ending days and times for the run are shown under the flow rate (middle left). "d50" means 50 percent of the bed composition by mass is smaller than $11.2 \mathrm{~mm}$ and 50 percent of the bed composition by mass is larger than $11.2 \mathrm{~mm}$. Trial G14: multiple samples collected from the cross-section of the flume (referred to as "cross-section"), and the bedload sampler is BLH-84. Trials G15-16: distance from center of sampler to left wall is $1.92 \mathrm{~m}$ and $1.92 \mathrm{~m}$, and the bedload samplers are TR-2 and Elwha, respectively. Trial G17: multiple samples collected from the cross-section of the flume ("cross-section"), and the bedload sampler is BLH-84. Trials G18-21: multiple samples collected from the cross-section of the flume ("cross-section," G18), $1.92 \mathrm{~m}$ (G19), $0.82 \mathrm{~m}$ (G20), and multiple samples collected from the cross-section of the flume ("cross-section," G21); and the bedload samplers are BLH-84, TR-2, Elwha, and BLH-84, respectively. Abbreviations: kg, kilograms; m, meters; mm, millimeters; $\mathrm{m}^{3}$, cubic meters; s, seconds. 


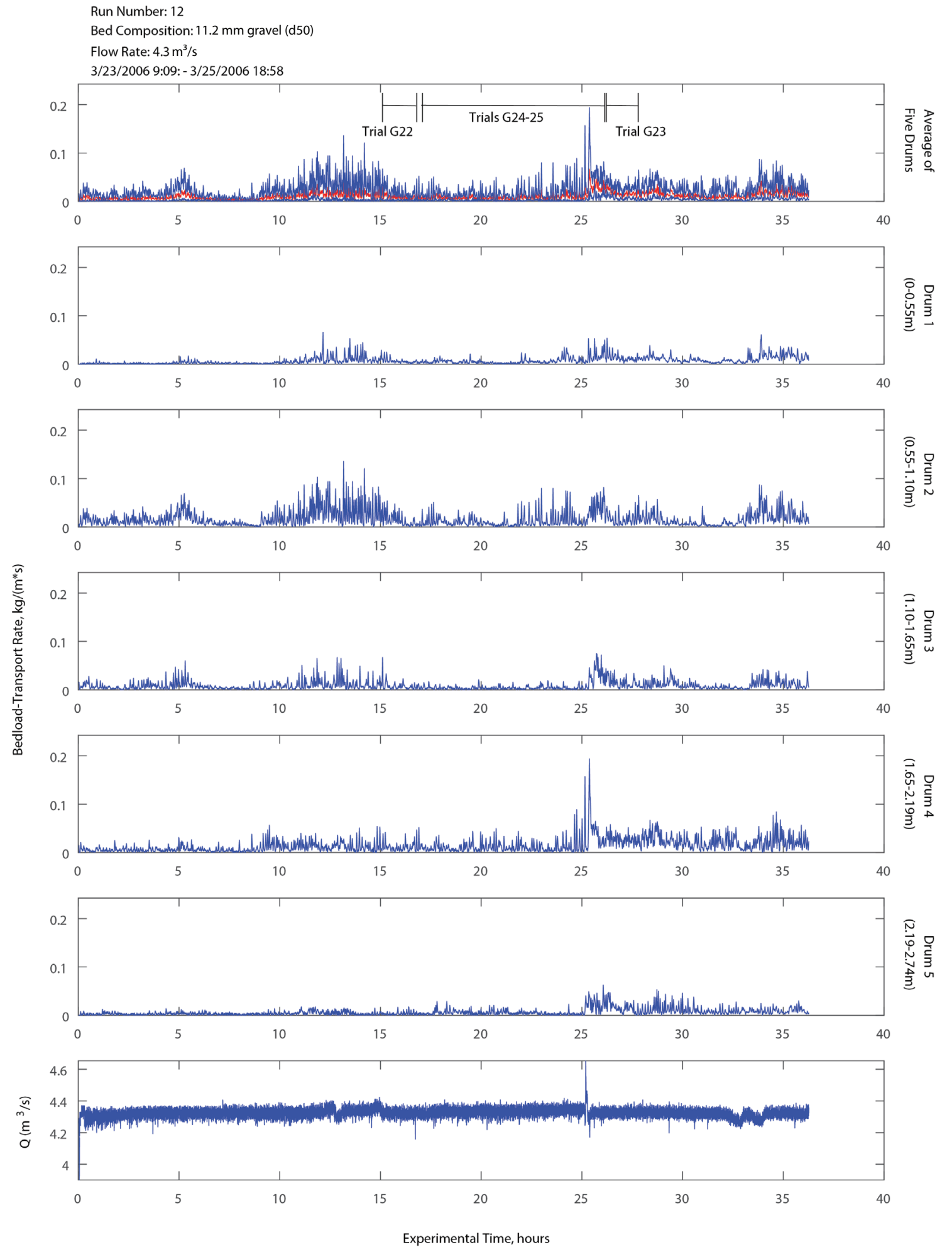

Figure 2.7. A, Plots showing the results of the StreamLab06 Run No. 12 at a steady flow of $4.3 \mathrm{~m} 3 / \mathrm{s}$ over a gravel bed (d50=11.2 $\mathrm{mm}$ ). Starting and ending days and times for the run are shown under the flow rate (top left). "d50" means 50 percent of the bed composition by mass is smaller than $11.2 \mathrm{~mm}$ and 50 percent of the bed composition by mass is larger than $11.2 \mathrm{~mm}$. Abbreviations: $\mathrm{kg}$, kilograms; m, meters; mm, millimeters; $\mathrm{m}^{3}$, cubic meters; s, seconds; 0 , discharge For the explanation of trials, see figure 2.7B. 


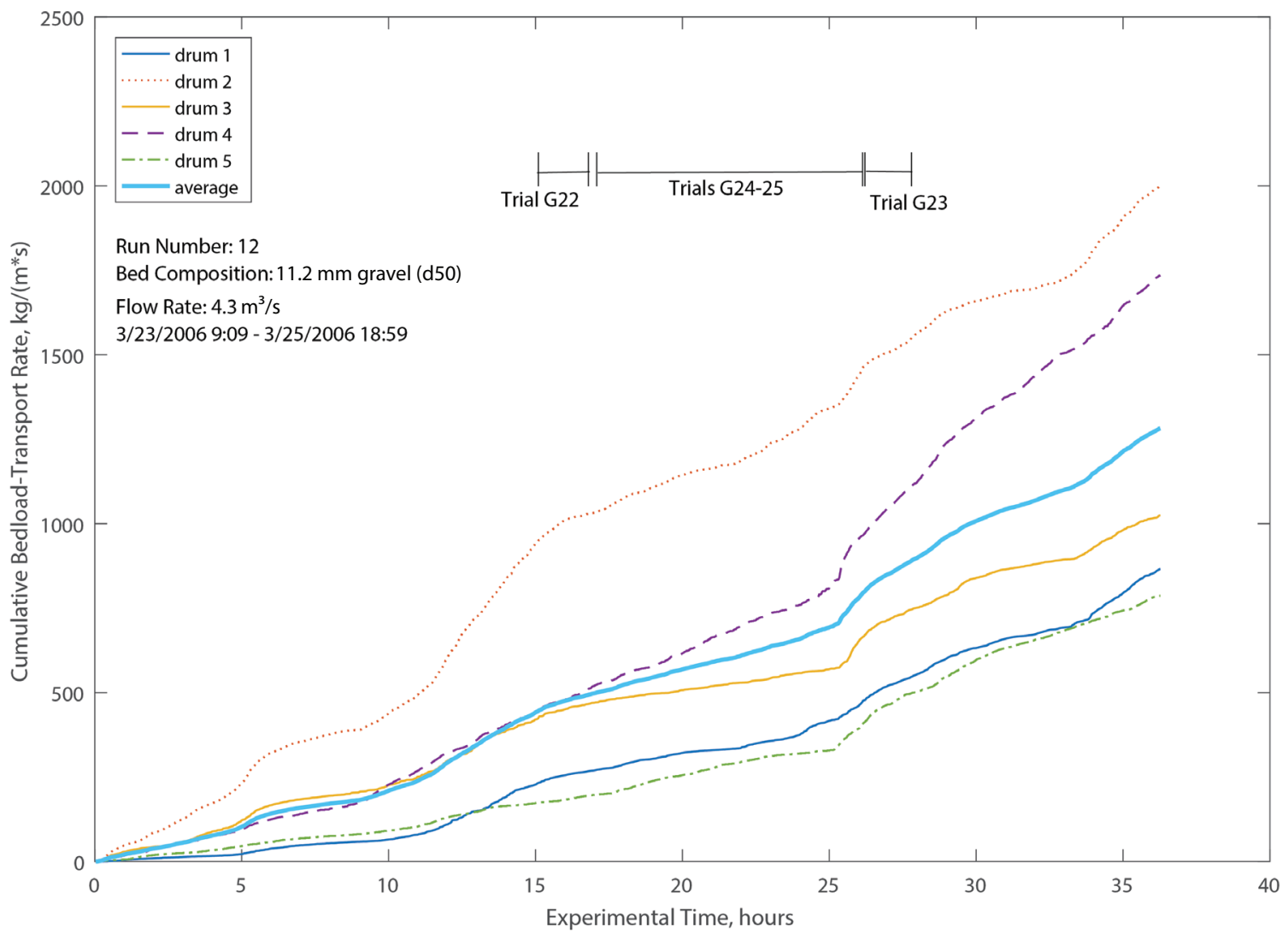

Figure 2.7. B, Plot showing the results of the StreamLab06 Run No. 12 at a steady flow of $4.3 \mathrm{~m}^{3} / \mathrm{s}$ over a gravel bed (d50=11.2 mm). Starting and ending days and times for the run are shown under the flow rate (middle left). "d50" means 50 percent of the bed composition by mass is smaller than $11.2 \mathrm{~mm}$ and 50 percent of the bed composition by mass is larger than $11.2 \mathrm{~mm}$. Trial G22: multiple samples collected from the cross-section of the flume (referred to as "cross-section"), and the bedload sampler is BLH-84. Trial G23: multiple samples collected from the cross-section of the flume ("cross-section"), and the is bedload sampler is BLH-84. Trials G24-25: distance from center of sampler to left wall is $1.92 \mathrm{~m}$ and $1.92 \mathrm{~m}$, and the bedload samplers are Elwha and TR-2, respectively. Abbreviations: $\mathrm{kg}$, kilograms; $\mathrm{m}$, meters; $\mathrm{mm}$, millimeters; $\mathrm{m}^{3}$, cubic meters; $\mathrm{s}$, seconds. 


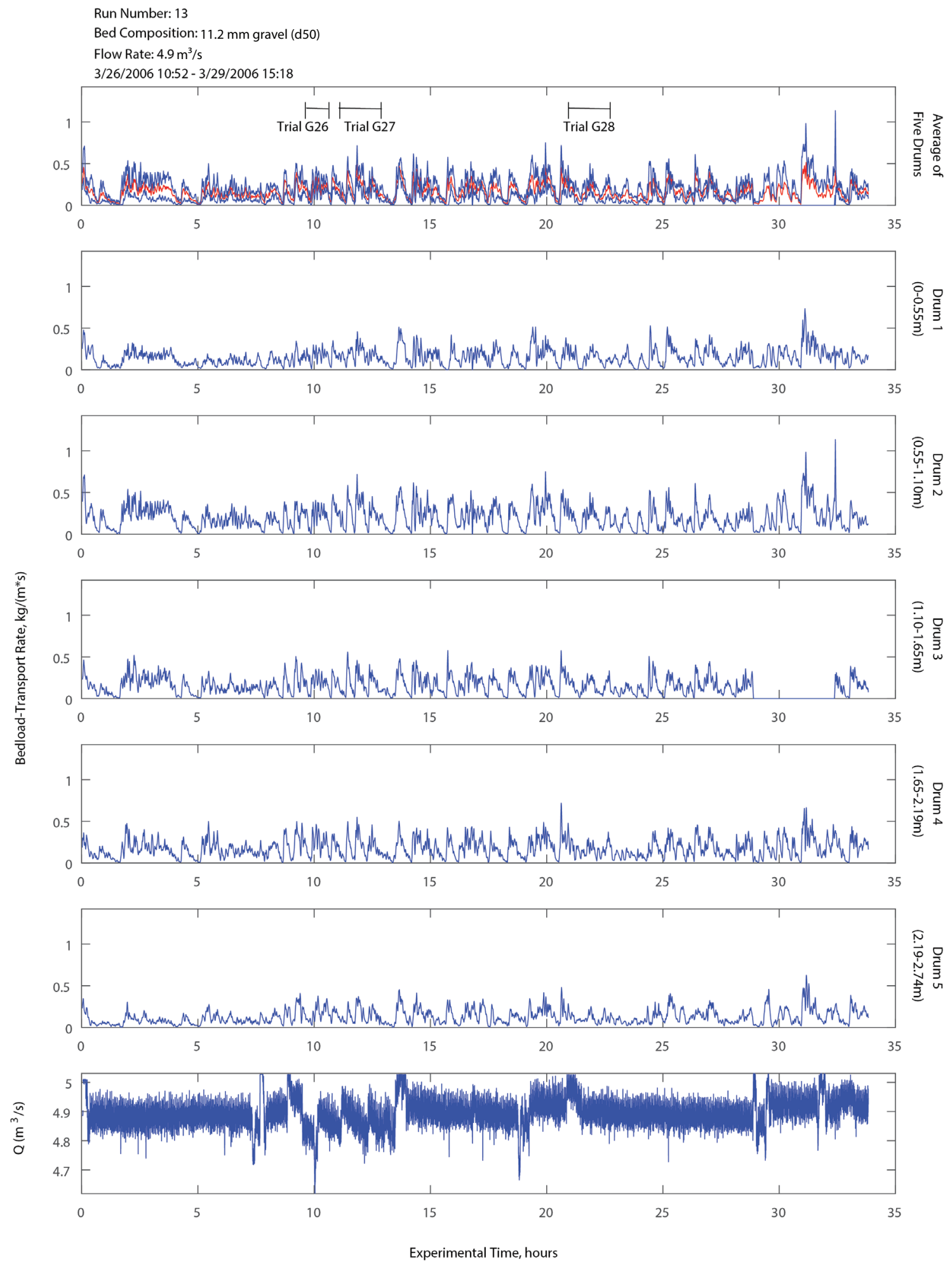

Figure 2.8. A, Plots showing the results of the StreamLab06 Run No. 13 at a steady flow of $4.9 \mathrm{~m}^{3} / \mathrm{s}$ over a gravel bed (d50=11.2 $\mathrm{mm}$ ). Starting and ending days and times for the run are shown under the flow rate (top left). Abbreviations: kg, kilograms; $\mathrm{m}$, meters; mm, millimeters; $\mathrm{m}^{3}$, cubic meters; s, seconds; 0 , discharge. "d50" means 50 percent of the bed composition by mass is smaller than $11.2 \mathrm{~mm}$ and 50 percent of the bed composition by mass is larger than $11.2 \mathrm{~mm}$. For the explanation of trials, see figure $2.8 B$. 


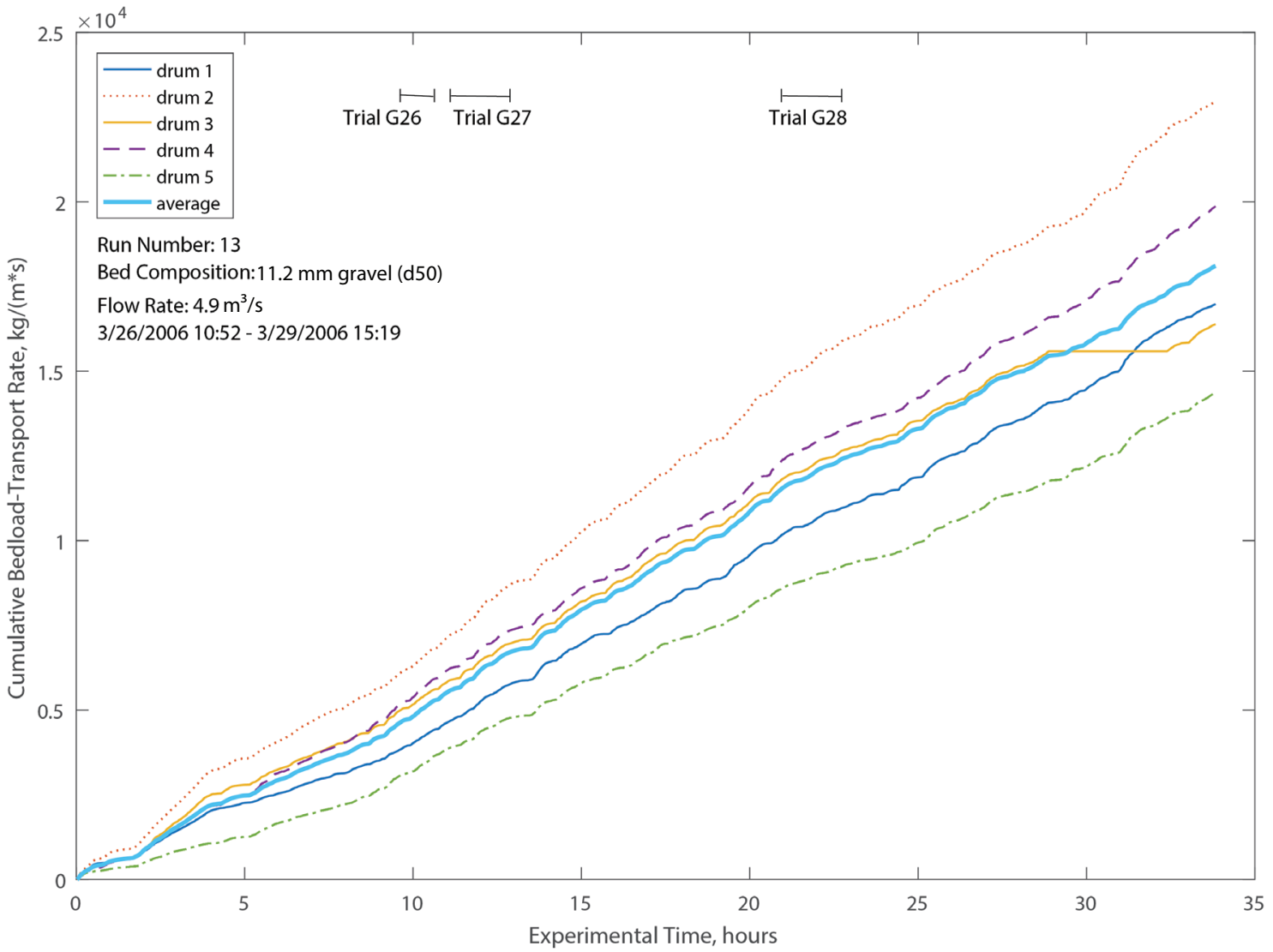

Figure 2.8. B, Plot showing the results of the StreamLab06 Run No. 13 at a steady flow of $4.9 \mathrm{~m}^{3} / \mathrm{s}$ over a gravel bed (d50=11.2 mm). Starting and ending days and times for the run are shown under the flow rate (middle left). "d50" means 50 percent of the bed composition by mass is smaller than $11.2 \mathrm{~mm}$ and 50 percent of the bed composition by mass is larger than $11.2 \mathrm{~mm}$. Trial G26: multiple samples collected from the cross-section of the flume (referred to as "cross-section"), and the bedload sampler is BLH-84. Trial G27: distance from center of sampler to left wall is $1.92 \mathrm{~m}$, and the bedload sampler is Elwha. Trial G28: distance from center of sampler to left wall is $1.92 \mathrm{~m}$, and the bedload sampler is TR-2. Abbreviations: $\mathrm{kg}$, kilograms; m, meters; mm, millimeters; $\mathrm{m}^{3}$, cubic meters; s, seconds. 

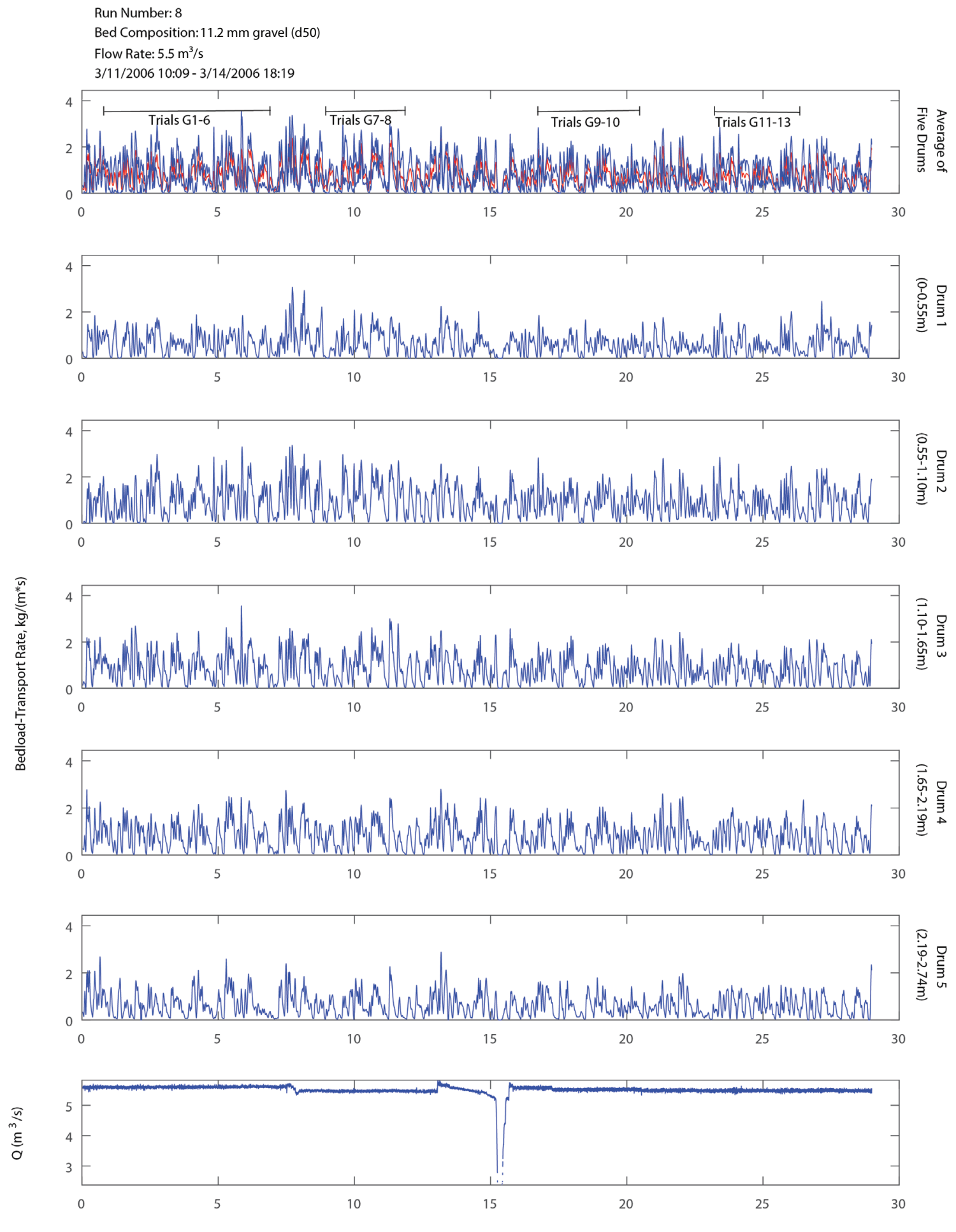

Experimental Time, hours

Figure 2.9. A, Plots showing the results of the StreamLab06 Run No. 8 at a steady flow of $5.5 \mathrm{~m}^{3} / \mathrm{s}$ over a gravel bed (d50=11.2 $\mathrm{mm}$ ). Abbreviations: kg, kilograms; m, meters; mm, millimeters; $\mathrm{m}^{3}$, cubic meters; s, seconds; 0 , discharge. "d50" means 50 percent of the bed composition by mass is smaller than $11.2 \mathrm{~mm}$ and 50 percent of the bed composition by mass is larger than $11.2 \mathrm{~mm}$. For the explanation of trials, see figure $2.9 B$. 


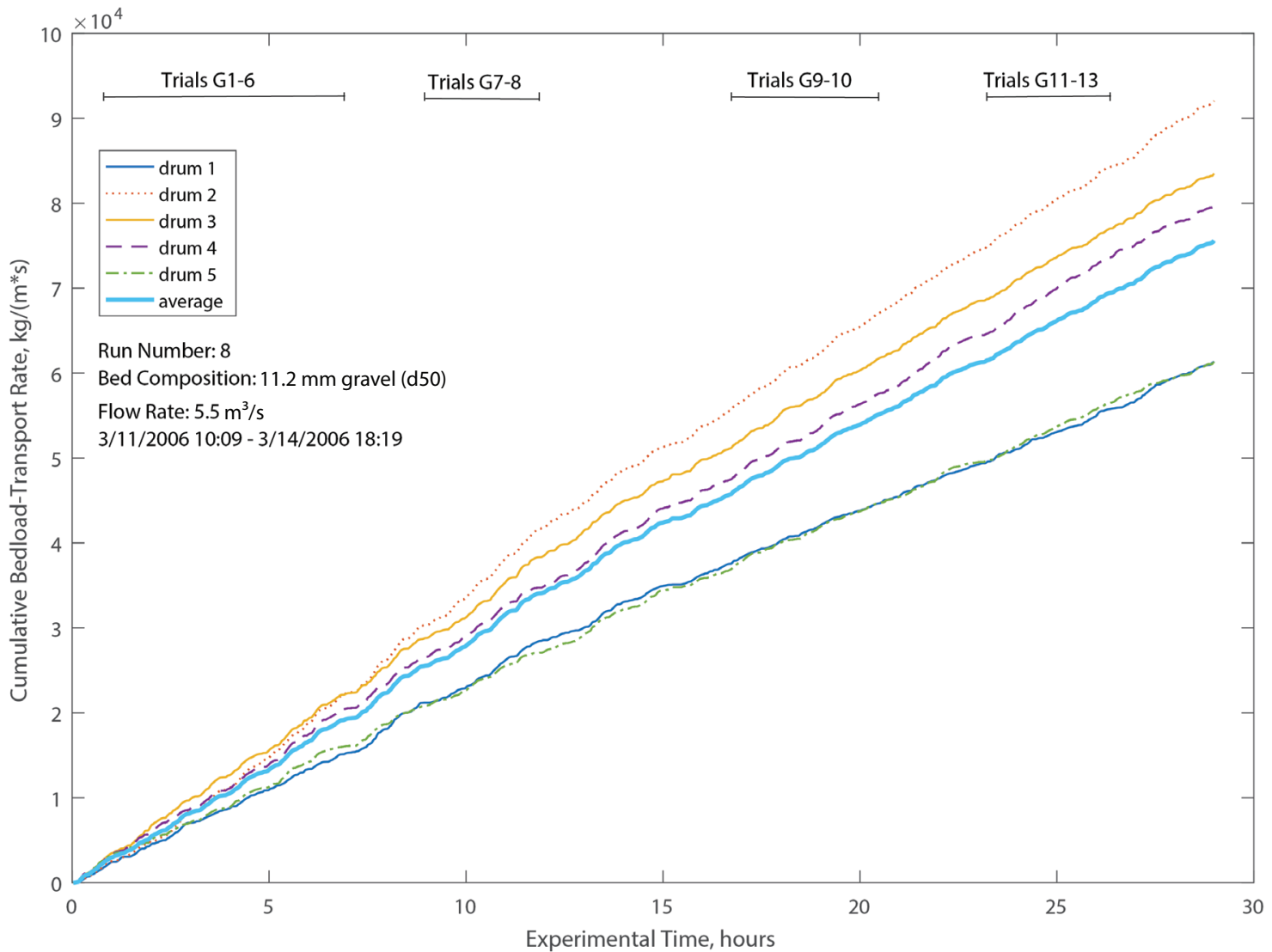

Figure 2.9. $B$, Plot showing the results of the StreamLab06 Run No. 8 at a steady flow of $5.5 \mathrm{~m}^{3} / \mathrm{s}$ over a gravel bed (d50=11.2 mm). "d50" means 50 percent of the bed composition by mass is smaller than $11.2 \mathrm{~mm}$ and 50 percent of the bed composition by mass is larger than $11.2 \mathrm{~mm}$. Trials G1-6: distance from center of sampler to left wall varies (G1) and is $0.27 \mathrm{~m}, 0.82 \mathrm{~m}, 1.37 \mathrm{~m}, 1.92 \mathrm{~m}$, and $2.47 \mathrm{~m}$ (G2-G6, respectively), and the bedload samplers are Elwha and BLH-84. Trials G7-8: distance from center of sampler to left wall is $1.92 \mathrm{~m}$ and $0.82 \mathrm{~m}$, and the bedload samplers are Elwha and BLH-84, respectively. Trials G9-10: multiple samples collected from the cross-section of the flume (referred to as "cross-section," G9) and $1.92 \mathrm{~m}(\mathrm{G} 10)$, and the bedload samplers are BLH-84 and TR-2, respectively. Trials G11-13: multiple samples collected from the cross-section of the flume ("cross-section," G11-12) and distance from center of sampler to left wall is $1.92 \mathrm{~m}(\mathrm{G} 13)$, and the bedload samplers are BLH-84 and TR-2. Abbreviations: kg, kilograms; $\mathrm{m}$, meters; mm, millimeters; $\mathrm{m}^{3}$, cubic meters; $\mathrm{s}$, seconds. 

For more information concerning the research in this report, contact Chief, Analysis and Prediction Branch

Water Resources Mission Area

U.S. Geological Survey

12201 Sunrise Valley Drive

Mail Stop 415

Reston, VA 20192

Publishing support provided by the U.S. Geological Survey Science Publishing Network, Reston and Sacramento Publishing Service Centers 


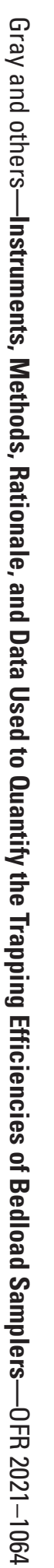

